\title{
WestVirginiaUniversity
}

THE RESEARCH REPOSITORY @ WVU

Graduate Theses, Dissertations, and Problem Reports

1999

\section{Probability analysis of slope stability}

Jennifer Lynn Peterson

West Virginia University

Follow this and additional works at: https://researchrepository.wvu.edu/etd

\section{Recommended Citation}

Peterson, Jennifer Lynn, "Probability analysis of slope stability" (1999). Graduate Theses, Dissertations, and Problem Reports. 990.

https://researchrepository.wvu.edu/etd/990

This Thesis is protected by copyright and/or related rights. It has been brought to you by the The Research Repository @ WVU with permission from the rights-holder(s). You are free to use this Thesis in any way that is permitted by the copyright and related rights legislation that applies to your use. For other uses you must obtain permission from the rights-holder(s) directly, unless additional rights are indicated by a Creative Commons license in the record and/ or on the work itself. This Thesis has been accepted for inclusion in WVU Graduate Theses, Dissertations, and Problem Reports collection by an authorized administrator of The Research Repository @ WVU. For more information, please contact researchrepository@mail.wvu.edu. 


\title{
Probability Analysis of Slope Stability
}

\section{Jennifer Lynn Peterson}

\author{
Thesis \\ Submitted to the \\ College of Engineering and Mineral Resources \\ At West Virginia University \\ In Partial Fulfillment of the Requirements for the D egree of
}

Master of Science

In

Civil and Environmental Engineering

John P. Zaniewski, Ph.D ., P.E., Committee Chair

Karl E. Barth, Ph.D.

Gerald R. Hobbs, Ph.D.

Morgantown, West Virginia

1999

Keywords: Slope Stability, Monte Carlo Simulation, Probability Analysis, and Risk Assessment 


\title{
Abstract \\ Probability Analysis of Slope Stability
}

\author{
Jennifer L. Peterson
}

Committee:

D r. John Zaniewski, CEE (Chair), Dr. Karl Barth, CEE, and Dr. Gerald Hobbs, STATS

The ability of geotechnical engineers to accurately model slope performance is compromised by a variety of factors. The net result of these considerations is that the exact behavior of slopes cannot be accurately predicted. Hence, geotechnical engineers resort to a factor of safety approach to reduce the risk of slope failure. However, the factor of safety approach cannot quantify the probability of failure, or level of risk, associated with a particular design situation.

A probabilistic approach to studying geotechnical issues offers a systematic way to treat uncertainties, especially slope stability. In terms of probability, uncertainties can be related quantitatively to the design reliability of a slope. Therefore, the development of a risk-based design procedure, which engineers can use to combine practical experience, judgement, and statistical information is beneficial for analyzing the stability of a slope for an allowable risk criterion.

The objective of this research was to develop a probabilistic model for slope stability analysis. Through Monte Carlo simulation, the distribution of each input parameter is used with traditional behavior equations to produce a probability distribution of the output of the analysis. Allowable risk criterion is then applied to the output distribution to select the slope design parameters that have an acceptable level of risk.

To demonstrate the application of the probabilistic method developed during this research, the methodology was applied to two case studies. The first case study involved the factor of safety for an infinite slope without seepage analysis. The second case study obtained the critical height for a planar failure surface and the factor of safety for a circular failure surface using the response surface analysis method combined with a Monte Carlo simulation. 


\section{Acknowledgements}

I would like to express my gratitude to my advisor Dr. John Zaniewski, for his guidance, support, and inspiration towards the completion of this research. His willingness to oversee this endeavor, time, and dedication to making me a more technical writer was greatly appreciated. Thank you to my defense committee, Dr. Karl Barth and Dr. G erald Hobbs for their constructive comments and review of this document.

A special thanks to my friends, who have given tremendous support throughout both of my engineering degrees. Finally, THANK YOU!! to my Mom and sister for all of their unconditional love, support, and friendship. 


\section{Table of Contents}

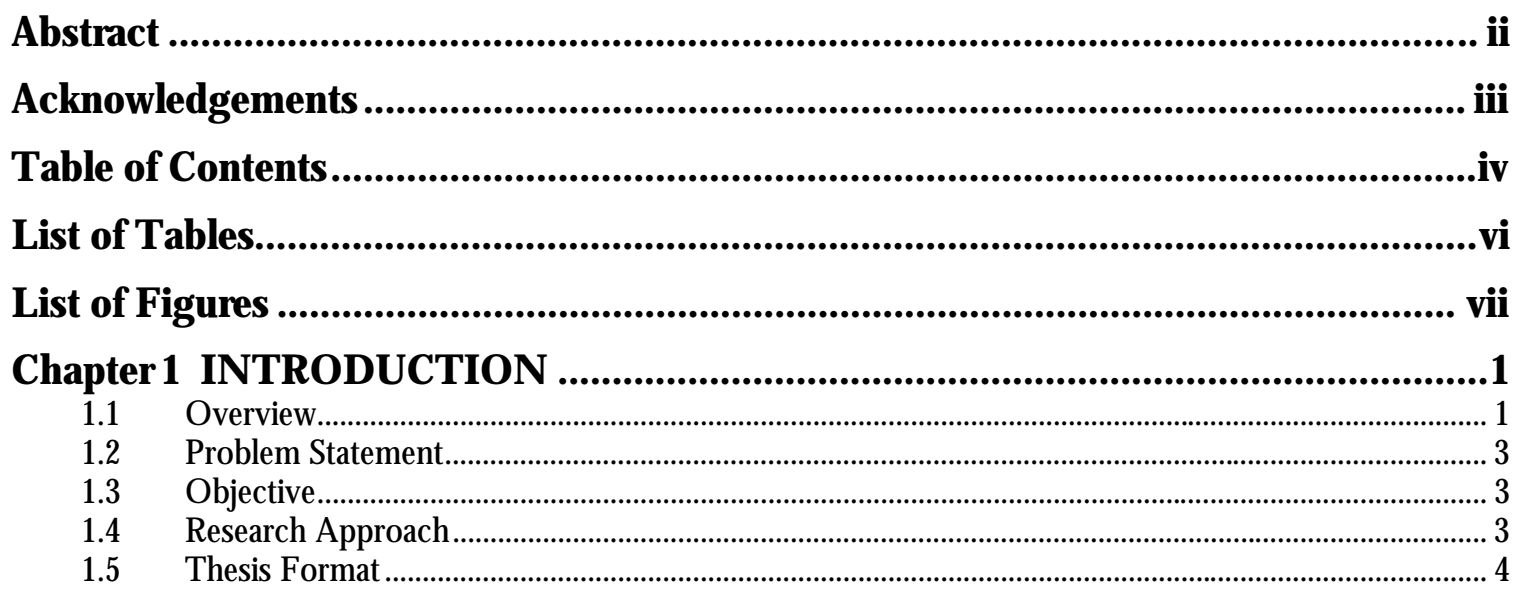

Chapter 2 LITE RATURE REVIEW ....................................................................................6

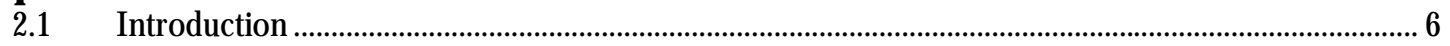

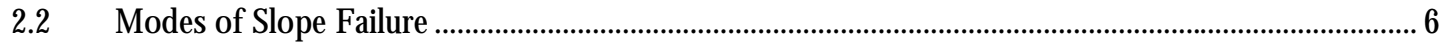

2.3 Traditional Slope Stability Analysis Methods ...................................................................................... 8

$2.4 \quad$ Probabilistic Slope Stability A nalysis Methods ....................................................................................... 14

2.4.1 Monte Carlo Simulation................................................................................................................ 15

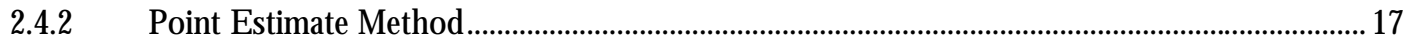

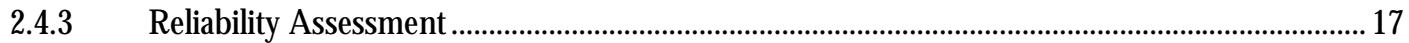

2.5 Variability of Soil Parameters........................................................................................................... 18

2.5.1 Sources of Variability in Soil Parameters ........................................................................................ 18

2.5.2 Examples of Variability in Soil Parameters ......................................................................... 18

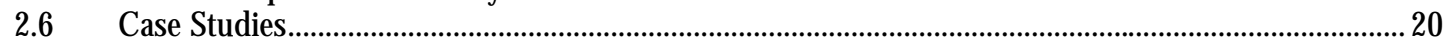

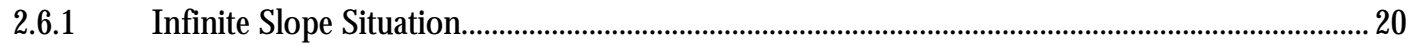

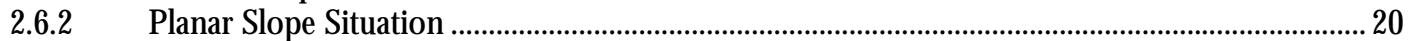

2.7 Conclusion from Literature Review................................................................................................. 21

Chapter 3 METHODOLOGY DEVELOPMENT ...............................................22

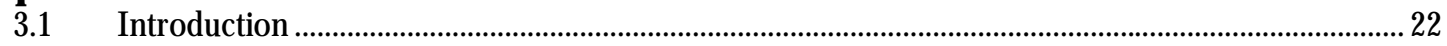

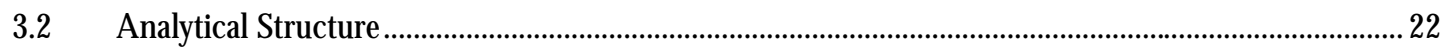

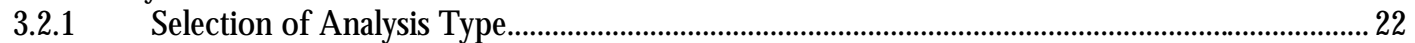

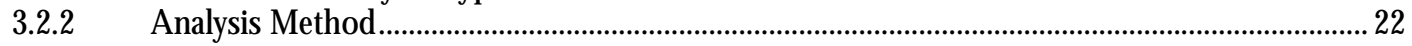

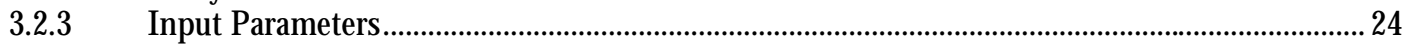

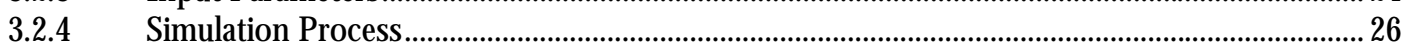

3.3 Interpretation of Monte Carlo Simulation O utput .......................................................................... 28

Chapter 4 METHODOLOGY APPLICATION AND RESULTS .................................31

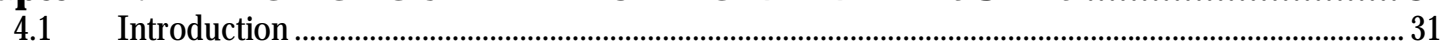

$4.2 \quad$ Infinite Slope without Seepage Analysis ............................................................................................. 31

4.3 Planar Failure Surface Analysis, Correlated Input Parameters for the Critical Height........................ 45

4.4 Planar Failure Surface A nalysis, Uncorrelated Input Parameters for the Critical Height .................. 51

4.5 Circular Failure Surface Analysis for the Factor of Safety .................................................................... 52

Chapter 5 CONCLUSIONS AND RECOMMENDATIONS...................................60

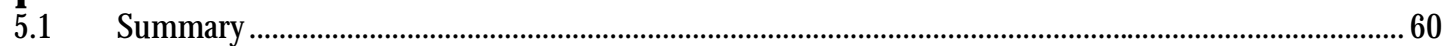

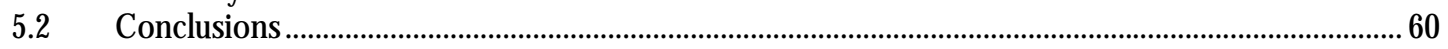

5.3 Recommendations........................................................................................................................ 62 


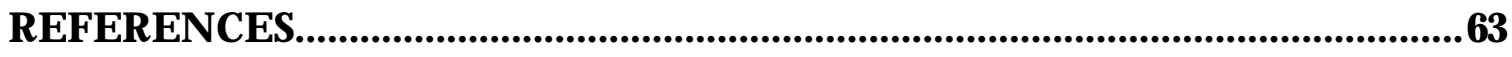

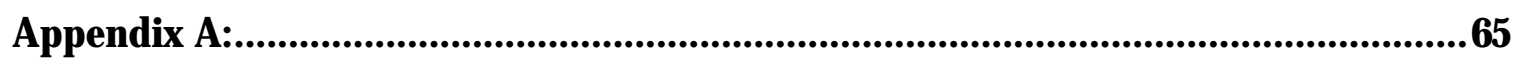

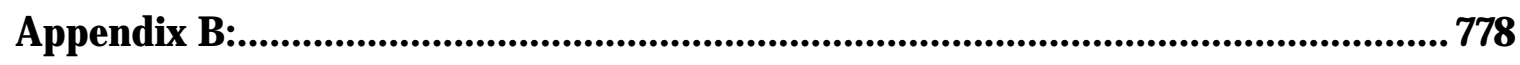

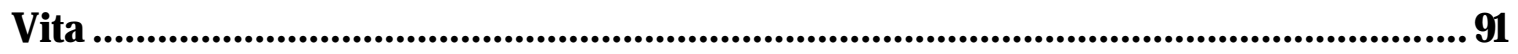




\section{List of Tables}

Table 2-1: Comparison of Elements and Classification of Geological and

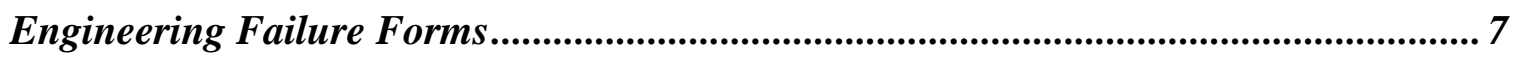

Table 2-2: Slope Stability - Probability of Failure Criteria ......................................... 17

Table 2-3: Volumetric and Gravimetric Parameters ...................................................... 19

Table 2-4: Angle of Friction Strength Parameter ..................................................... 20

Table 4-1: Input Parameters for Infinite Slope without Seepage Analysis .................. 32

Table 4-3: Summary of Sensitivity Analysis for Factor of Safety, Infinite Slope

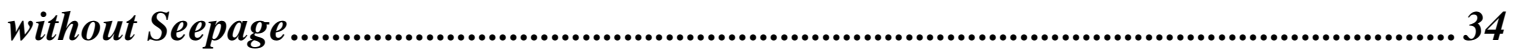

Table 4-2: Infinite Slope without Seepage, Factor of Safety Analysis........................... 35

Table 4-4: Summary of Horizontal Slope Angle Needed to Meet Probability Criteria for an Infinite Slope without Seepage ................................................................................ 44

Table 4-5: Input Parameters for Planar Slope Failure Analysis ................................ 45

Table 4-6: Planar Slope Failure Analysis for Correlated Input Parameters ............... 47

Table 4-7: Planar Slope Failure Analysis for Uncorrelated Input Parameters ........... 53

Table 4-8: Summary of Sensitivity Analysis for Critical Height, Planar Slope

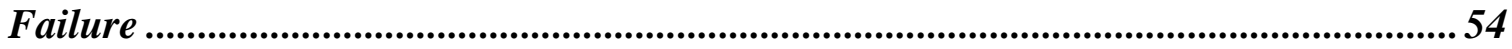

Table 4-9: PC STABL Evaluation for Response Surface Analysis............................... 54

Table 4-10: Factor of Safety, Circular Failure Surface, Response Surface

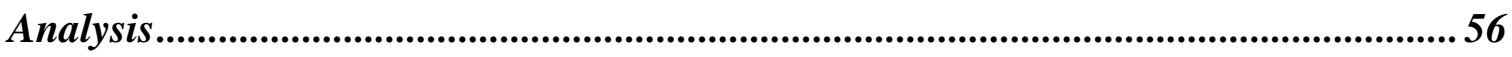




\section{List of Figures}

Figure 1.1: Average Annual Costs (Thousands of Dollars) for Constructed Highway.2

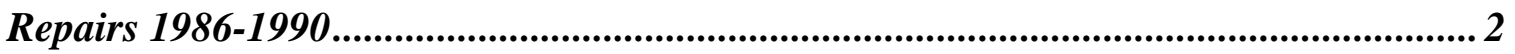

Figure 2-1: Traditional Slope Stability Analysis Methods ............................................ 9

Figure 2-2: Modes of Circular Slope Failure ......................................................... 11

Figure 2-3: Stability Number vs Slope Angle, Angle of Friction Equal to Zero.......... 12

Figure 2-4: Stability Number vs Slope Angle, Angle of Friction Greater Than Zero . 12

Figure 2-5: Bishop's Method of Slices ................................................................................. 13

Figure 2-6: Nth Slice from Bishop's Method Analysis ............................................ 13

Figure 2-7: General Monte Carlo Simulation Approach ......................................... 15

Figure 2-8: Uncertainty in Soil Properties................................................................... 19

Figure 3-1: Modeling Approach for Slope Stability Monte Carlo Simulation ............. 23

Figure 3-2: Combination of Uncorrelated Input Parameters Distribution .................. 27

Figure 3-3: Combination of Correlated Input Parameter Distribution ......................... 27

Figure 3-4: Example of Probability Distribution Function for a Monte Carlo

Simulation Analysis.

Figure 3-5: Determining the Probability of Failure for a Normal Distribution using the Results from a Monte Carlo Simulation

Figure 4-1: Example Input Variable Distribution for Infinite Slope without

Seepage

Figure 4-2: Histograms for Factor of Safety, $\beta=26.6$ degrees ..................................36

Figure 4-3: Histograms for Factor of Safety, $\beta=21.8$ degrees ..................................... 37

Figure 4-4: Histogram for Factor of Safety, $\beta=18.5$ degrees ................................... 38

Figure 4-5: Scatter Diagrams, Input Parameter vs Factor of Safety , $\beta=26.6$

degrees

Figure 4-6: Scatter Diagrams, Input Parameter vs Factor of Safety, $\beta=21.8$

degrees.

Figure 4-7: Scatter Diagrams, Input Parameter vs Factor of Safety, $\beta=18.5$

degrees

Figure 4-8: Probability Distributions Comparing the Mean Factor of Safety's to a Typical FS of 1, Indicating the Area where the Combination of Input Parameters has a Factor of Safety Less than One 
Figure 4-9: Horizontal Slope Angle vs Probability of Failure for an Infinite Slope without Seepage.................................................................................................................. 44

Figure 4-10: Histograms for Critical Height Correlated Input Parameter Analysis ... 48

Figure 4-11: Scatter Diagrams, Input Parameter vs Critical Height ........................... 49

Figure 4-12: Probability Distributions Comparing the Mean Critical Height to a Typical Slope Height of 27.5 feet, Indicating the Area where Combination of Input Parameters Creates Slope Equilibrium or Impeding Slope Failure ................................ 50

Figure 4-13: Histograms for Factor of Safety, Circular Failure Surface ...................... 57

Figure 4-14: Sensitivity Analysis for Uncorrelated Input Parameters and Factor of Safety, Circular Failure Surface .........................................................................58 


\section{Chapter 1 \\ INTRODUCTION}

\subsection{Oveniew}

A slope is a ground surface that stands at an angle to a horizontal plane. Slopes may be natural or man made. Each slope possesses unique soil characteristics and geometric features, which either will resist gravity or collapse. Slope fails cause the soil mass to slide downward and outward usually occurring slowly or suddenly without provocation. Slides usually begin from hairline tension cracks, which propagate through the soil layers (D as, 1994).

Slope failures have caused an unquantified number of causalities and economic loss throughout time. The earliest recorded slope failure occurred in 1767 B.C. Across the United States, twenty-five to fifty lives are lost each year from slope failure. Between 1971 and 1974, it was reported that approximately 600 deaths/ year worldwide were attributed to slope failure incidents. Slope movement accounts for 25-50 percent of all natural destruction worldwide (TRB Special Report 247, 1996).

Annual slope maintenance and repair of slope failures by highway agencies in the United States averaged over $\$ 100$ million from 1989 to 1990 . This is a nationwide problem as shown on Figure 1.1 (TRB Special Report 247, 1996). Between 1989 and 1990, the average annual costs in West Virginia was approximately \$1.3 million.

Geotechnical engineers are responsible for the analysis of slopes and the design of either the slope's geometry or a structure to restrain the slope. Traditional slope stability analysis uses single value estimates for each variable in the slope stability equations. The variables used for slope stability analysis are the physical characteristics of the soil and the slope geometry. The output of a traditional stability analysis is a single-value deterministic estimate of whether the slope will stand or collapse. The output can be expressed as either a 


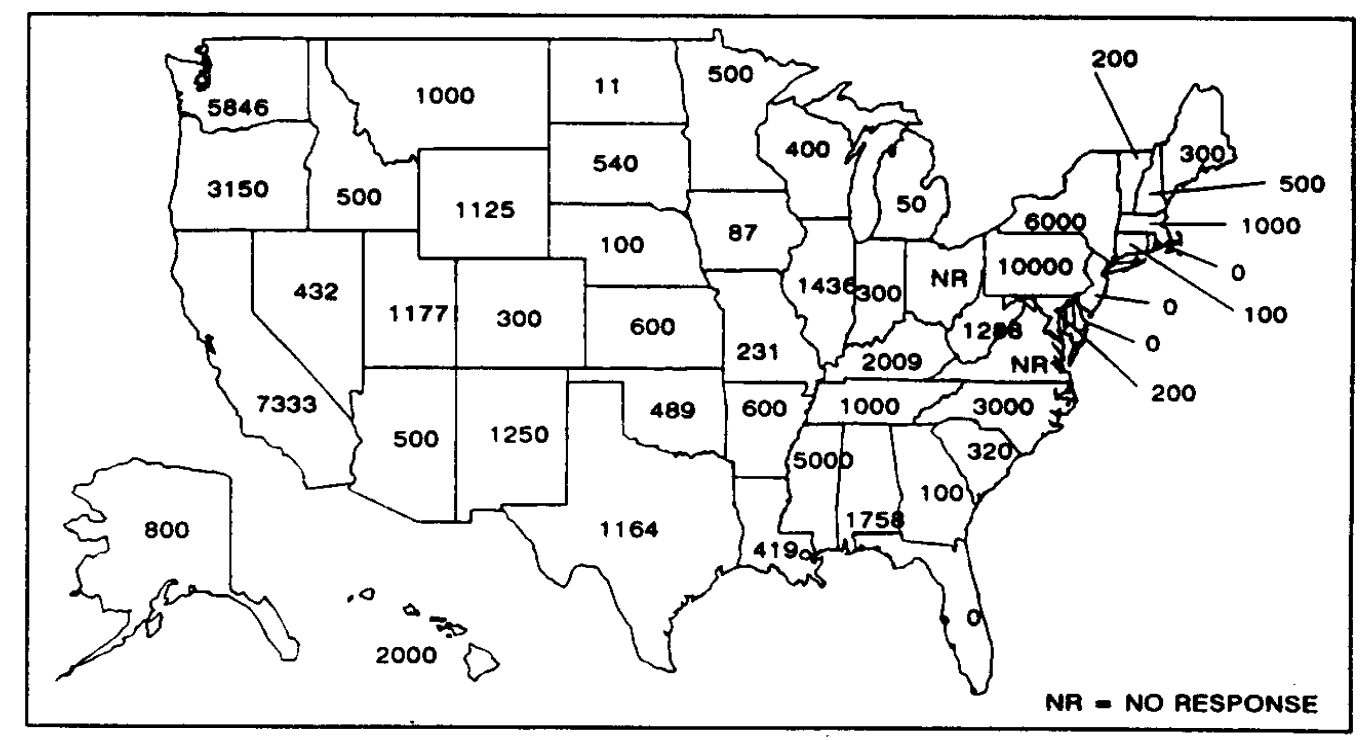

Figure 1.1: Average Annual Costs (Thousands of Dollars) for Constructed Highway Repairs 1986-1990 (Source: TRB Special Report 247, 1996)

factor of safety or critical height, which are dependent terms. The factor of safety can be analyzed for a given slope height or the critical height of the slope can be determined for a fixed level of factor of safety.

The ability of geotechnical engineers to accurately model slope performance is compromised by a variety of factors. These may be broadly classified as theoretical and practical considerations. Theoretical considerations include approximations and assumptions made for model development. Practical considerations include an inability to adequately sample and accurately test for the parameters used in the slope stability analysis. The net result of these considerations is that the exact behavior of slopes cannot be accurately predicted. Hence, geotechnical engineers resort to a factor of safety approach to reduce the risk of slope failure. However, the factor of safety approach cannot quantify the probability of failure, or level of risk, associated with a particular design situation.

A probabilistic approach to studying geotechnical issues offers a systematic way to treat uncertainties, especially slope stability. In terms of probability, uncertainties can be related quantitatively to the design reliability of a slope. The development of a risk-based design procedure, which engineers can use to combine practical experience, judgement, and statistical information is beneficial for analyzing the stability of a slope for an allowable risk 
criterion (Tang, Yucemen, \& Ang, 1976). An allowable risk criterion can establish a consistent target for the design process.

\section{$1.2 \quad$ Problem Statement}

Traditional slope stability analysis is limited by the use of single valued parameters to describe a slope's characteristics. Consequently traditional analysis methods yield single valued estimates of a slope's stability. However, the inherent variability of the characteristic's which affect slope stability dictate that slope stability is a probabilistic rather than a deterministic situation. In other words, the stability of a slope is a random process that is dependent on the distributions of the controlling parameters.

The hypothesis of this research is the analysis of slope stability can be more accurately evaluated through the use of probabilistic modeling methods. This analytical method uses information about the probability distribution of the slope's characteristics to determine the probability distribution of the output of the analysis. Knowledge of the probability distribution of the output allows the engineer to assess the probability of slope failure. Therefore, an allowable risk criterion can be used to establish a consistent target for the design process.

\subsection{Objective}

The objective of this research is to develop a probabilistic model for slope stability analysis. Through Monte Carlo simulation, the distribution of each input parameter is used with traditional behavior equations to produce a probability distribution for the output of the analysis. Allowable risk criterion is then applied to the output distribution to select the slope design parameters that have an acceptable level of risk.

\section{$1.4 \quad$ Research Approach}

A literature review was performed to document the traditional methods for slope stability analysis. This review also identified the soil characteristics and geometric parameters used in the current models. Information on the variability of the input parameters was sought to quantify their probability distributions.

A methodology for conveniently combining the traditional analytical models with the distribution of input parameters was sought. The Monte Carlo simulation method was identified as a suitable modeling method. The @ RISK software package for Microsoft Excel, was identified as a convenient method for developing a Monte Carlo simulation 
model for slope stability analysis. The output of a slope stability analysis is a probability distribution of either the factor of safety for a fixed slope height, or a probability distribution of critical height for a fixed level of factor of safety.

\subsection{Thesis Format}

The element of risk in slope stability analysis is unavoidable. A probabilistic approach offers a way to incorporate all factors that are associated with the failure of a slope. A major use of a reliability approach for geotechnical engineers is the establishment of a consistent target for design reliability. This method of dealing with uncertainties in slope stability recognizes that the design process is not exclusively dependent on one parameter, but is based on the interaction between several and their contributions to the entire system (Tang, Yucemen, \& Ang, 1976). The use of probability theory for slope stability analysis is a rational approach to an engineer's design and decision making process. Through this investigation, the output distributions were compared to established criteria which is used for designing slopes based on their critical height or factor of safety.

Chapter 2 presents a literature review. The state of the practice for slope stability analysis is summarized. Efforts of researchers to incorporate probabilistic methods into slope stability analysis are reviewed, including applications of the Monte Carlo simulation method, point estimate method, and reliability concepts. Next, data presented in the literature on the variability of soil parameters are summarized. Finally, some case studies of slope stability evaluations are presented.

Chapter 3 lays out the research methodology for this thesis. The application method is applicable for integrating data on parameter variability, conventional analytical models, response surface analysis, and Monte Carlo simulation. The methodology generates a probability distribution of slope stability. A method for using this information for the design and analysis of slopes is presented.

Chapter 4 demonstrates the application of the methods developed during this research. The analytical method was applied to the analysis of two case studies from the literature. The first case study involved the factor of safety for an infinite slope without seepage analysis. The second case study obtained the critical height for a planar failure surface and the factor of safety for a circular failure surface for Bishop's method of slices analysis using the response surface analysis method. 
Chapter 5 presents the conclusions and recommendations of the research. Included in Chapter 5 are general finding from the two cases studies which the methodology was applied to evaluate the use of a probabilistic analysis method. Further research recommendations are also discussed. 


\section{Chapter 2 \\ LITERATURE REVIEW}

\subsection{Introduction}

Due to the consequences of slope failure, the topic has received extensive treatment in the literature. Several models and analytical techniques have been developed to describe a variety of geometric and soil characteristics. The majority of literature focuses on deterministic evaluation of slope stability, however, several authors have investigated probabilistic methods of slope stability analysis.

This chapter presents a review of slope stability analysis methods, including both deterministic and probabilistic concepts. The variability within soil parameters is summarized in this review. Finally, several case studies of slope stability analysis are summarized.

\subsection{Modes of Slope Failure}

D epending on the geological conditions, slopes can fail in different modes. Table 21 presents a classification of geologic failure forms and the related elements of slope failure and engineering failure forms (Hunt, 1984). The failure forms of interest for this research are infinite slopes, planar, and circular rock and soil slides. Infinite slope models are used for cohesionless sands, stiff clays, marine shale, and residual or colluvial soils over shallow rock. Planar failure analysis is used for stiff cohesive soils, sliding blocks, and interbedded dipping rock and soil. Circular failure surface analysis is used for thick residual or colluvial soil, soft marine clay, shale, and firm cohesive soil (Hunt, 1984). 
Table 2-1: Companison of Elements and Classification of Geological and Engineening Failure Foms

(Saurce Hunt, 1984)

\begin{tabular}{|c|c|c|c|c|c|c|c|c|c|}
\hline \multirow[b]{2}{*}{ Geologic Failure Forms } & \multicolumn{6}{|c|}{ Elements of Slope Failures* } & \multicolumn{3}{|c|}{ Engineening Failure Forms ${ }^{+}$} \\
\hline & 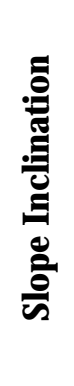 & 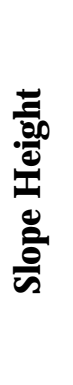 & 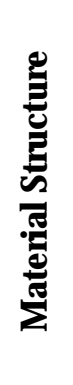 & 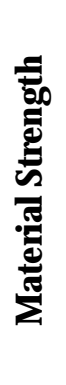 & 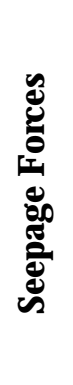 & 巻 & 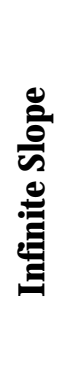 & 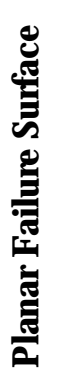 & 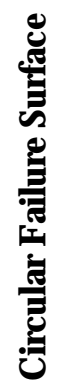 \\
\hline Falls & $\mathrm{P}$ & $\mathbf{N}$ & $\mathrm{P}$ & $\mathrm{P}$ & $\mathrm{P}$ & $\mathrm{P}$ & $\mathbf{N}$ & $\mathrm{N}$ & $\mathbf{N}$ \\
\hline Planar Slides & $\bar{P}$ & $\mathrm{~S}$ & $\mathrm{P}$ & $\mathrm{P}$ & $\bar{P}$ & $\bar{M}$ & A & A & $\bar{N}$ \\
\hline Rotational Slides (Rock) & $\bar{P}$ & $\bar{P}$ & $\mathrm{P}$ & $\bar{P}$ & $\bar{P}$ & $\bar{M}$ & $\mathbf{N}$ & $\mathrm{N}$ & $\bar{A}$ \\
\hline Rotational Slides (Soil) & $\bar{P}$ & $\mathrm{P}$ & $\mathrm{P}$ & $\bar{P}$ & $\mathrm{P}$ & $\bar{M}$ & $\mathbf{N}$ & $\mathrm{N}$ & $\bar{A}$ \\
\hline $\begin{array}{l}\text { Spreading/ Progressive } \\
\text { Failure }\end{array}$ & $\mathrm{S}$ & $\mathbf{M}$ & $\mathrm{P}$ & $\mathrm{P}$ & $\mathrm{P}$ & $\mathrm{N}$ & $\mathrm{N}$ & $\mathrm{N}$ & $\mathrm{N}$ \\
\hline Debris Slides & $\mathrm{P}$ & $\bar{M}$ & $\mathrm{P}$ & $\mathrm{P}$ & $\mathrm{P}$ & $\mathrm{N}$ & $\mathrm{S}$ & $\mathrm{S}$ & $\bar{N}$ \\
\hline Submarine Slides & $\bar{S}$ & $\mathrm{~S}$ & $\mathrm{P}$ & $\bar{P}$ & $\mathrm{P}$ & $\mathbf{N}$ & $\mathrm{N}$ & $\mathrm{N}$ & $\bar{S}$ \\
\hline
\end{tabular}

NOTE:

* P - Primary Cause, S - Secondary Cause, M - Minor Effect, N - Little/ No Effect

+A - Application, S - Some Application, P -Poor Application, N - No Application 


\subsection{Traditional Slope Stability Analysis Methods}

For the purposes of this review, traditional slope stability analysis methods are defined as those which treat slopes as deterministic situations with uniquely defined parameters. These methods are widely documented in geotechnical textbooks. The following description are based on the work of $\mathrm{D}$ as (1994). Traditional methods use principles of static equilibrium to evaluate the balance of driving and resisting forces. The factor of safety is defined as the resisting forces divided by the driving forces, or alternatively as the shear strength divided by the calculated shear stresses. A factor of safety greater than one indicates a stable slope; a value less than one indicates impending failure. For a given slope, a factor of safety of one identifies the critical height of a slope.

Figure 2-1 summarizes the types of traditional slope analysis methods, there are:

a) Infinite slope without seepage

b) Infinite slope with seepage

c) Finite slope with planar failure surface

d) Circular failure in homogeneous clays: $(\phi=0$ and $\phi>0)$

Figure 2-1 demonstrates that slope geometry is defined by two parameters, the height of the slope, $\mathrm{H}$, and the angle of the slope relative to a horizontal plane, $\beta$. The soil parameters used for slope stability analysis are:

$$
\begin{array}{lll}
\mathrm{c} & = & \text { cohesion } \\
\mathrm{C}_{\mathrm{u}} & = & \text { undrained cohesion } \\
\gamma & = & \text { unit weight } \\
\gamma_{\text {sat }} & = & \text { saturated unit weight } \\
\gamma^{\prime} & = & \text { submerged unit weight } \\
\phi & = & \text { angle of friction }
\end{array}
$$




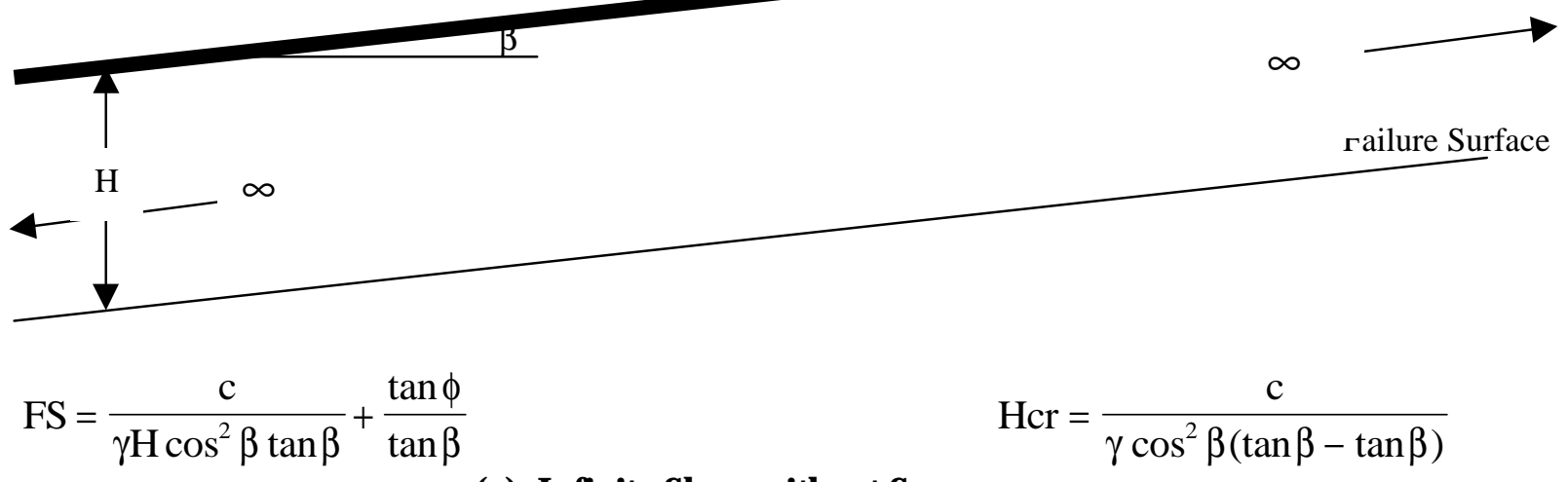

(a) Infinite Slope without Seepage

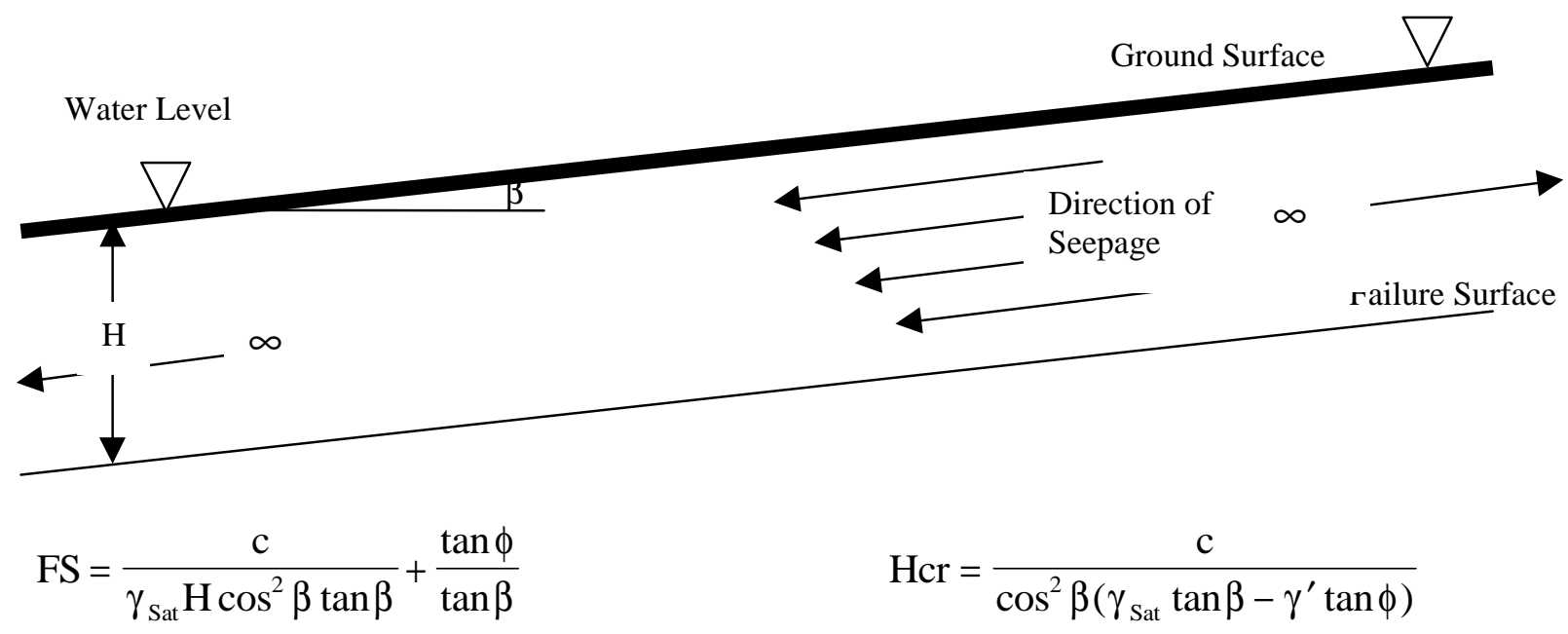

(b) Infinite Slope with seepage

Ground Surface

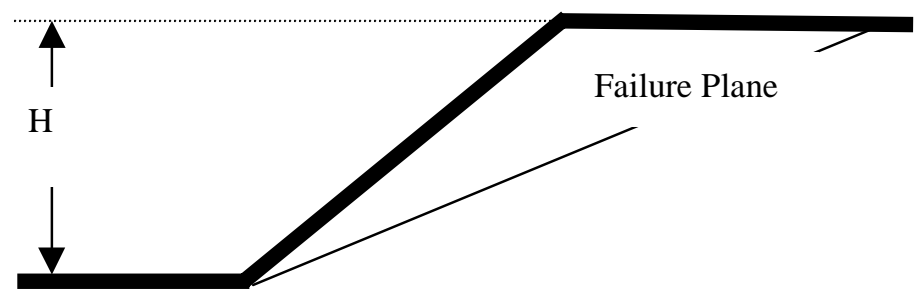
$\mathrm{FS}=\frac{4 \mathrm{c}}{\gamma \mathrm{H}}\left[\frac{\sin \beta \cos \phi}{1-\cos (\beta-\phi)}\right]$
Hcr $=\frac{4 c}{\gamma}\left[\frac{\sin \beta \cos \phi}{1-\cos (\beta-\phi)}\right]$

(c) Finite Slope with Planar Failure Surface

Figure 2-1: Traditional Slope Stability Analysis Methods (Source: Das, 1994) 
For a circular failure plane analysis, the computed factor of safety is a function of the assumed location of the center of the circle and the mode of failure as defined in Figure 2-2. The critical location produces the minimum factor of safety. The critical location are determined by trial and error. Fellenius and Taylor (D as, 1994) developed a stability number, $\mathrm{m}$, to facilitate the analysis of circular slope failures. The stability number is defined as:

$$
m=\frac{c_{d}}{\gamma H}
$$

Equation 2-1

Figures 2-3 and 2-4 give the stability number values for soils with angle of friction equal to zero and angle of friction greater than zero respectively. For an angle of friction equal to zero, e.g. clays, the stability number is a function of the slope angle, factor of safety, and mode of failure. For an angle of friction greater than zero, the stability number is a function of the slope angle and the friction angle.

The equations in Figure 2-1 assume the soil is homogeneous. This assumption is not valid for many slopes. The method of slices was developed to be able to account for the heterogeneity of soils in a stability analysis. The concept of this method is shown in Figures 2-5 and 2-6. In essence, the slope is divided into vertical slices and the equilibrium of each slice is evaluated and summed. Bishop modified the method of slices to account for the forces acting on each side of each slice. Equations 2-2 through 2-4 are used to find the factor of safety for the ordinary method of slices and the modified Bishop's method (Das, 1994).

$$
F S=\frac{\sum_{n=1}^{n=p}\left(c \Delta L_{n}+W_{n} \cos \alpha_{n} \tan \phi\right)}{\sum_{n=1}^{n=p} W_{n} \sin \alpha_{n}}
$$

Equation 2-2

$$
F S=\frac{\sum_{n=1}^{n=p}\left[\left(c b_{n}+W_{n} \tan \phi\right) \frac{1}{m_{\alpha n}}\right]}{\sum_{n=1}^{n=p} W_{n} \sin \alpha_{n}}
$$

Equation 2-3 


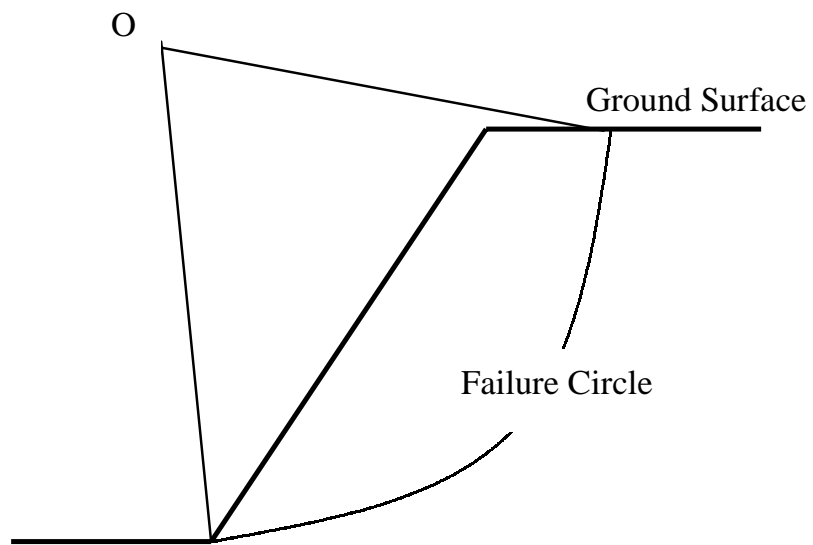

(a) Toe Circle

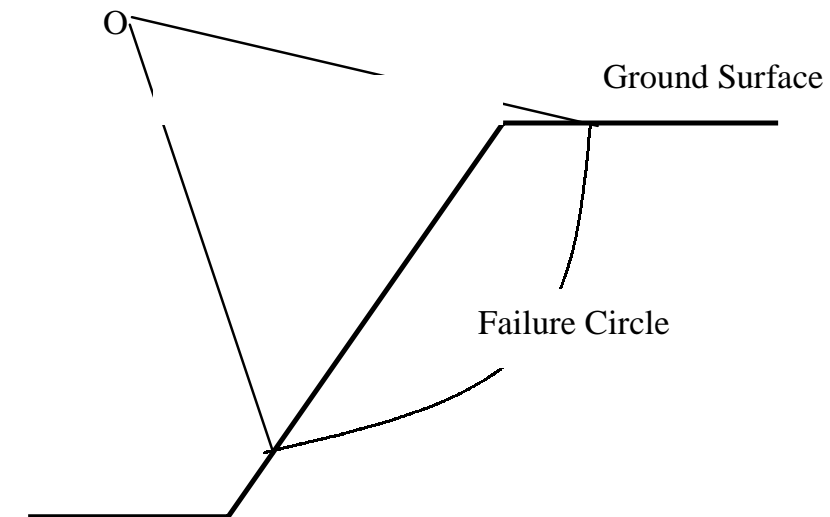

(b) Slope Circle

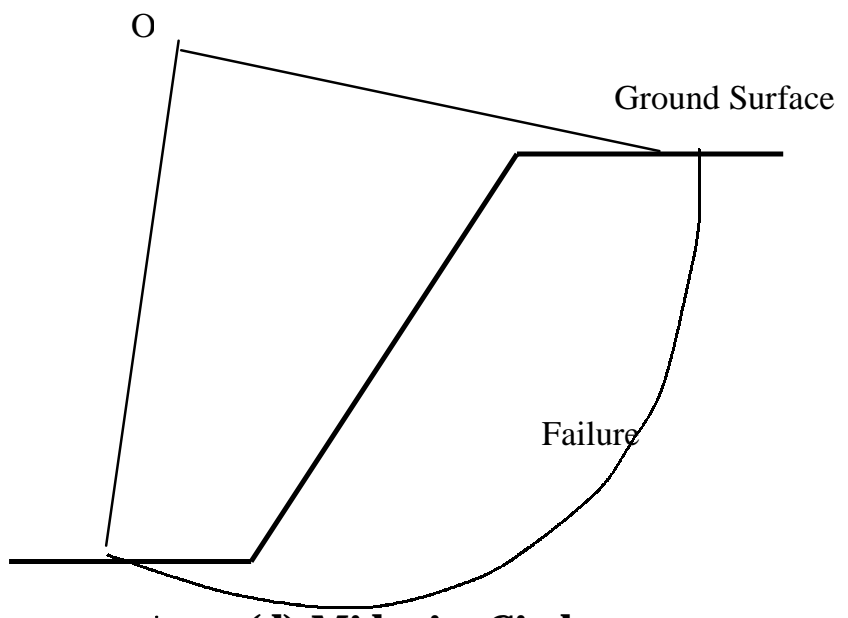

(d) Midpoint Circle

\section{Circular Slope Failures in H omogeneous Clay}

$$
\mathrm{FS}=\frac{\mathrm{c}}{\gamma \mathrm{Hm}}
$$

Hcr $=\frac{\mathrm{c}}{\gamma \mathrm{m}}$

Figure 2-2: Modes of Circular Slope Failure (Sourœ: D as, 1994) 


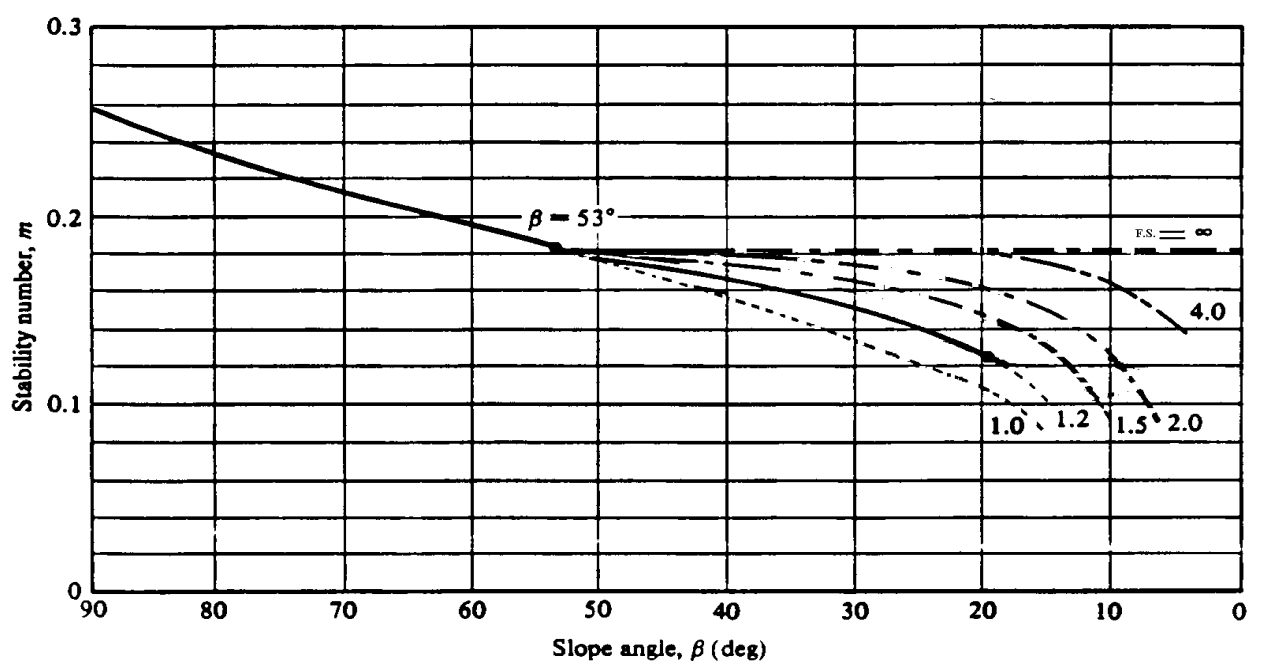

For $\beta>53^{\circ}$ All Circles are Toe Circles

For $\beta<53^{\circ} \quad$ Toe Circle

Midpoint Circle

Slope Circle

Figure 2-3: Stability N umber vs Slope Angle, Angle of Friction Equal to Zero (Sourœ: D as, 1994)

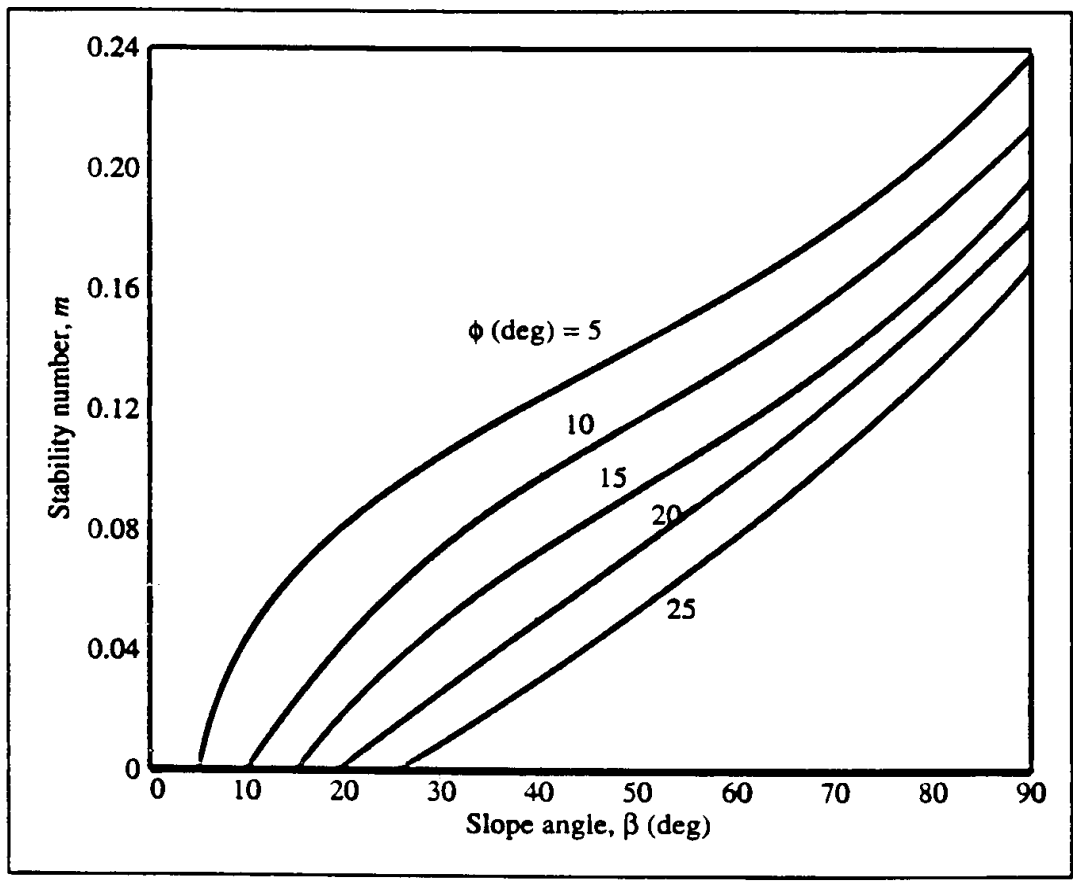

Plot of stability number with slope angie; $\phi>0$

Figure 2-4: Stability N umber vs Slope Angle, Angle of Friction Greater Than Zero(Sourœ: Das, 1994) 


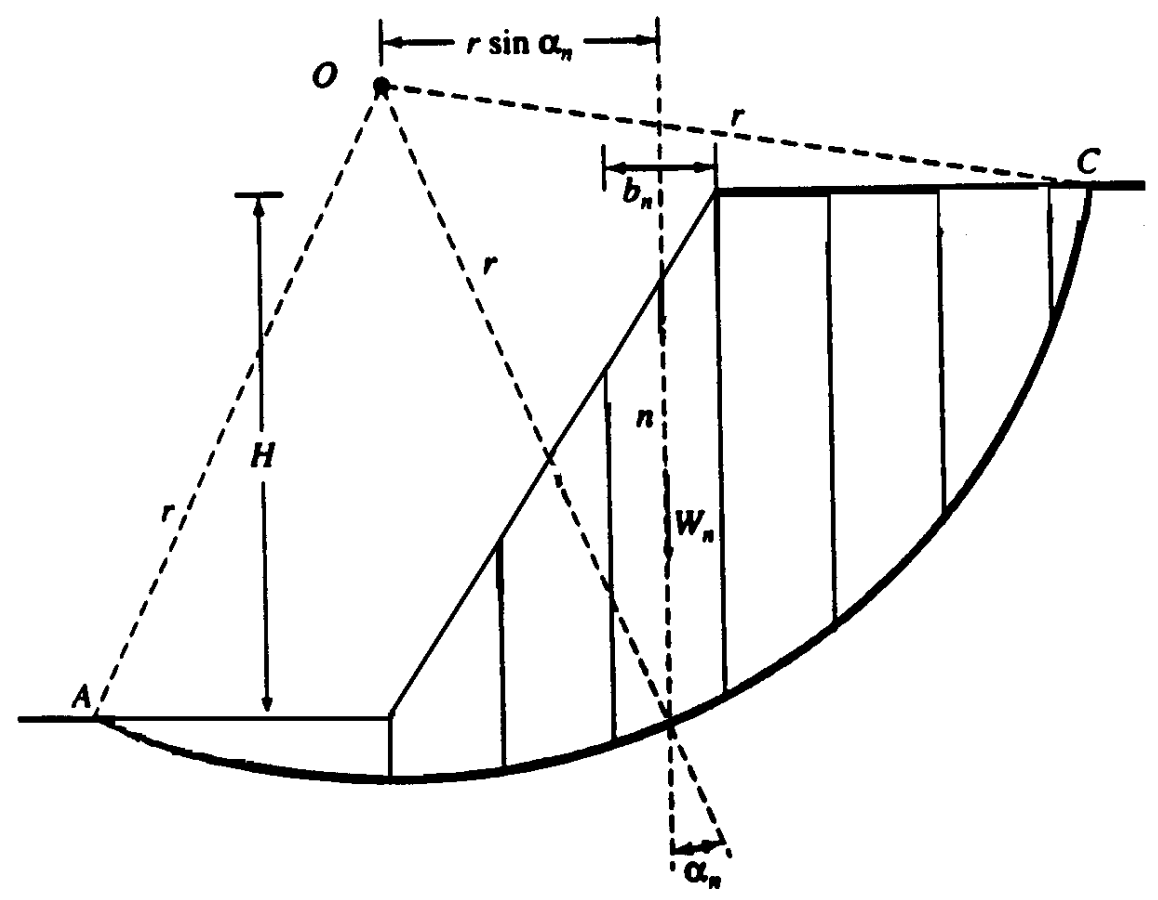

Figure 2-5: Bishop's Method of Slices (Sourœ: D as, 1994)

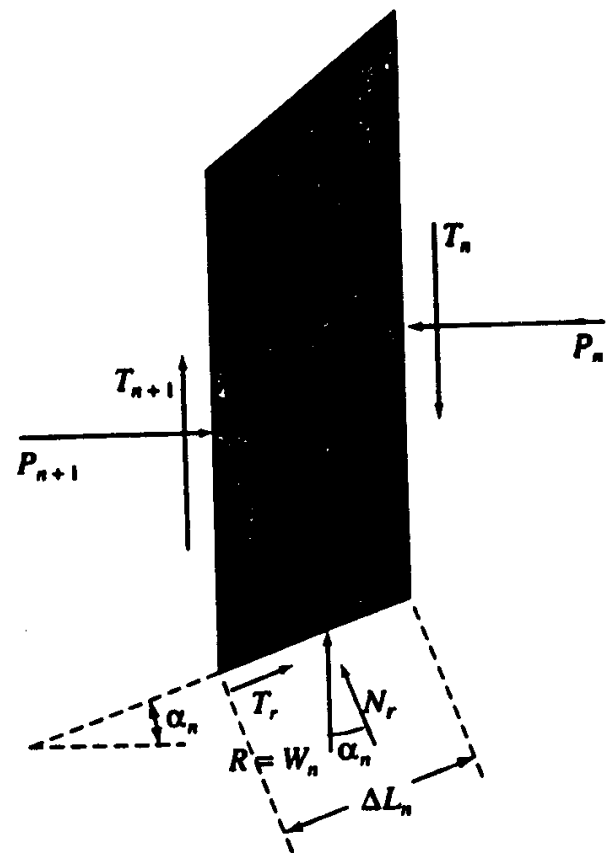

Figure 2-6: N th Slice from Bishop's Method Analysis (Source: Das, 1994) 


$$
m_{\alpha n}=\cos \alpha_{n}+\frac{\tan \phi \sin \alpha_{n}}{F S}
$$

Equation 2-4

Since the factor of safety for the Bishop's method is on both sides of the equation, a trial and error solution method is required. Several computer programs are available for solution of the Bishop method and other modifications to the method of slices. PCSTABL, developed at Purdue University, is a commonly used program for the method of slices analysis (www.ecn.purdue.edu/ STABL, Aug. 1999).

\subsection{Probabilistic Slope Stability Analysis Methods}

Arthur Casagrande, in the Terzaghi Lecture of 1964, presented the definition of calculated risk for applications within geotechnical engineering (Whitman, 1984). He emphasized that uncertainties are inherent to any project and the levels of uncertainties should be recognized. He stated that calculated risk needs to be recognized and dealt with in two steps:

- The use of imperfect knowledge, guided by judgement and experience, to estimate the probable ranges for all pertinent quantities that affect the solution of the problem.

- The decision on an appropriate level of safety, or degree of risk, taking into consideration economic factors and the magnitude of losses that would result from failure.

Uncertainties in soil properties, environmental conditions, and theoretical models are the reason for a lack of confidence in deterministic analyses (Alonso, 1976). Compared to a deterministic analysis, probabilistic analysis takes into consideration the inherent variability and uncertainties in the analysis parameters. Judgements are quantified within a probabilistic analysis by producing a distribution of outcomes rather than a single fixed value. Thus, a probabilistic analysis produces a direct estimate of the distribution of either the factor of safety or critical height associated with a design or analysis situation.

There are several probabilistic techniques that can be used to evaluate geotechnical situations. Specifically, for geotechnical analysis, researchers have conducted probabilistic evaluations using: Monte Carlo simulations, Point Estimate Method, and inconjunction with a probabilistic analysis a reliability assessment. 


\subsubsection{Monte Carlo Simulation}

The Monte Carlo method was developed in 1949 when John von Neumann and Stanislav Ulam published a paper, "The Monte Carlo Method." The Neumann and Ulam concept specifically designated the use of random sampling procedures for treating deterministic mathematical situations. The foundation of the Monte Carlo gained significance with the development of computers to automate the laborious calculations.

Figure 2-7 illustrates a general schematic for a Monte Carlo simulation (Hutchinson \& Bandalos, 1997). The first step of a Monte Carlo simulation is to identify a deterministic model where multiple input variables are used to estimate a single value outcome. Step two requires that all variables or parameters be identified. Next, the probability distribution for each independent variable is established for the simulation model, (ie normal, beta, log normal, etc). Next, a random trial process is initiated to establish a probability distribution function for the deterministic situation being modeled. During each pass, a random value from the distribution function for each parameter is selected and entered into the calculation. Numerous solutions are obtained by making multiple passes through the program to obtain a solution for each pass. The appropriate number of passes for an analysis is a function of the number of input parameters, the complexity of the modeled situation, and the desired precision of the output. The final result of a Monte Carlo simulation is a probability distribution of the output parameter.

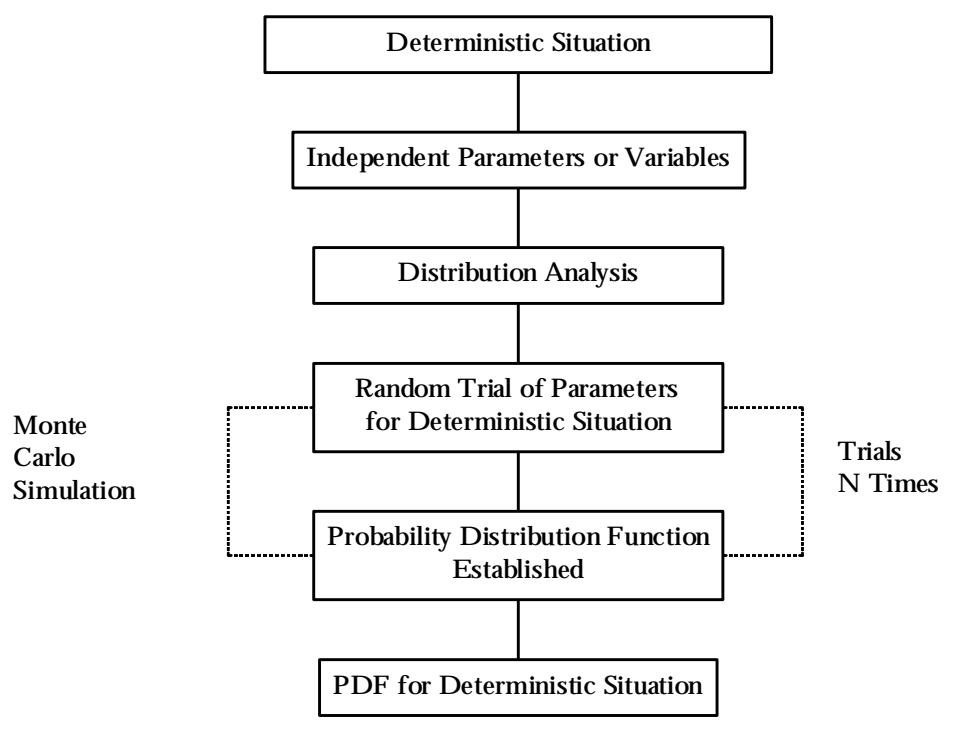

Figure 2-7: General Monte Carlo Simulation Approach

(Source: Hutchinson \& Bandalos, 1997) 
The precision of a Monte Carlo simulation output can be improved by using the Latin Hypercube Sampling (LHS) technique to sample the input distribution (Modarres, 1993). LHS sampling stratifies the input probability distributions during the simulation process. Stratification is conducted by dividing the input parameters into equal intervals when sampling the data. Samples are taken randomly from each interval to best represent the data found in each interval. Thus, LHS is a modified Monte Carlo simulation technique used during the sampling of the uncertain parameters. When using a LHS for multiple variable sampling, it is important to maintain the independence between the variables (@ RISK MANUAL, 1997). This preserves the randomness of the sampling and avoids unwanted correlation between the variables.

Previous Monte Carlo simulation applications for slope stability analysis have assumed the input parameters are independent and uncorrelated (Chowdhury, 1984). Independence of the variables within the model produce appropriate results during the simulation process (Tobutt, 1982). Commonly, normal, log-normal, and beta distributions have represented the input parameter distribution functions. The number of repetitions for each simulation model to produce adequate results varies. Based on the research conducted by Hutchinson \& Bandalos, it was found that as many as 10,000 to 100,000 iterations are required to adequately represent a deterministic solution.

Slope stability of a thinly-soiled forest area was modeled using a Monte Carlo approach to evaluate the impact for timber harvesting (Chandler, 1996). The probabilistic approach considered the effects of subsurface drainage, decay, regrowth of tree roots, variability in soil, and precipitation. The purpose of developing this model was to compare the probability of slope failures for both harvest and non harvest situations. Uncertainties of soil and vegetation characteristics were treated as random distributions.

Chandler showed through sensitivity analysis that the infinite slope method was appropriate for the area. Since the major source of errors when calculating the factor of safety is from determining the proper input factors, the infinite slope method was found to be adequate for the analysis (Chandler, 1996).

For this model, the input parameters: cohesion (c), angle of friction $(\phi)$, soil unit weight $(\gamma)$, soil saturated unit weight $\left(\gamma_{\text {sat }}\right)$, and height $(\mathrm{H})$ were treated as normally distributed, independent random variables. The use of Monte Carlo simulation to evaluate thinly-soiled forested areas provides a practical and logical methodology to analyze 
independent and dependant data needed to evaluate slope stability probability over time (Chandler, 1996).

\subsubsection{Point Estimate Method}

The Point Estimate Method (PEM) is an approximate numerical integration approach to probability modeling. Because full-scale tests are seldom conducted to model in situ conditions, one generally must rely on developed formulas and intrinsic parameters to describe the in situ situation (Harr, 1977). The evaluation of the PEM results in a single number for the sample data. This single value is a representative of the sampled population.

Thornton (1994), used the PEM to evaluate the probability of slope failures. Input parameters were assumed to be normally distributed. A model was developed to estimate the factor of safety distribution. Thomton recognized that application of this methodology requires criteria to define the acceptable level of risk.

\subsubsection{Reliability Assessment}

Chandler, Harr, Thornton, and Chowdhury have demonstrated that the output of a slope stability analysis can be defined as a distribution of either the factor of safety or critical height. Santamarina, Altschaeffl, and Chameau (1992) developed criteria for using these output distributions for assessing the consequences of slope failure with respect to:

- Loss of human life

- Economic loss

- Cost of lowering probability of failure with respect to post failure repairs

- Type and importance of service

- Existing or new construction

- Temporary or permanent duration

Through a fuzzy logic analysis of responses to a survey of geotechnical engineers,

Santamarina, Altschaeffl, and Chameau (1992) established Table 2-2. These criteria associate acceptable levels of probability of failure with various design conditions.

Table 2-2: Slope Stability - Probability of Failure Criteria

(Sourœ: Santamarina, Altschaeffl, and Chameau, 1992) 


\begin{tabular}{|l|c|}
\hline \multicolumn{1}{|c|}{ Conditions } & $\begin{array}{c}\text { Criteria for Probability of } \\
\text { Failure }\end{array}$ \\
\hline Temporary Structures with low Repair Cost & 0.1 \\
\hline Existing Large Cut on Interstate Highway & 0.01 \\
\hline Acceptable in Most Cases EXCEPT if Lives may be lost & 0.001 \\
\hline Acceptable for all Slopes & 0.0001 \\
\hline Unnecessarily Low & 0.00001 \\
\hline
\end{tabular}

\subsection{Variability of Soil Parameters}

To account for the uncertainties in slope stability, the given input parameters have been defined as random variables. For every random variable there is a mean $(\mu)$, standard deviation $(\sigma)$, variance $\left(\sigma^{2}\right)$, and probability distribution function (pdf).

\subsubsection{Sources of Variability in Soil Parameters}

Figure 2-8 demonstrates one concept of the source of variability in soil parameters (Christian, Ladd, \& Beacher, 1994). Uncertainties within soil properties arise from either scatter in the data or systematic testing and modeling discrepancies. D ata scatter emanates from the variability in the soil profile or random testing errors. Systematic discrepancies arise from bias in either the sampling process or test methods. Systematic errors are artifacts of inappropriate sampling and testing methods and should be eliminated. D ata scatter is a function of the inherent variability in the materials and test methods and must be quantified.

\subsubsection{Examples of Variability in Soil Parameters}

Table 2-3 and 2-4 present data for various soil types (Harr, 1977). For clays, the unit weight in Table 2-3 has a coefficient of variation (COV) which ranges from 1.9 to 12.3 percent depending on the plasticity of the material. Based on Table 2-4, the COV for the angle of friction for sands ranges from 7.0 to 11.0 percent. 


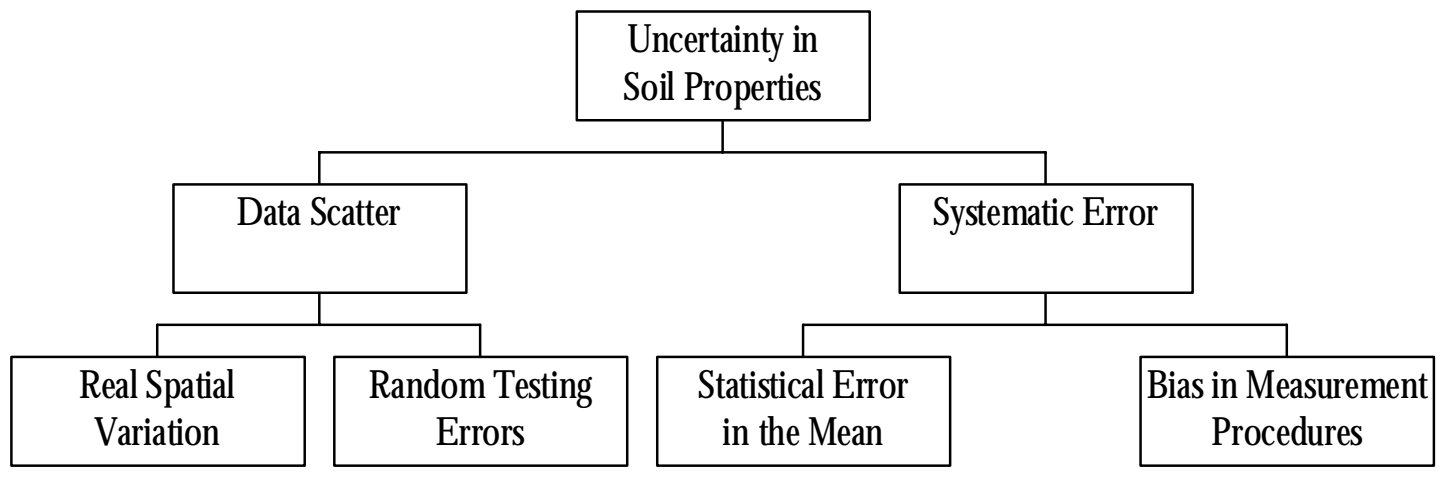

Figure 2-8: Uncertainty in Soil Properties (Sourœ: Christian, Ladd, Beacher, 1994)

Table 2-3: Volumetric and Gravimetric Parameters (Source: Harr, 1977)

\begin{tabular}{|c|c|c|c|c|c|}
\hline Material & Parameter & $\begin{array}{c}\text { Number } \\
\text { of } \\
\text { Samples }\end{array}$ & Mean & $\begin{array}{c}\text { Standard } \\
\text { Deviation }\end{array}$ & $\begin{array}{c}\text { Coefficient of } \\
\text { Variation (\%) }\end{array}$ \\
\hline Clay (High Plasticity) & Water Content & 98 & 0.206 & 0.0270 & 13.1 \\
\hline & Unit Weight & 97 & 113.300 & 2.8000 & 2.5 \\
\hline Clay (Med Plasticity) & Water Content & 99 & 0.131 & 0.0082 & 6.3 \\
\hline & Unit Weight & 99 & 115.800 & 14.2000 & 12.3 \\
\hline Clay (Low Plasticity) & Water Content & 97 & 0.138 & 0.0092 & 6.7 \\
\hline & Unit Weight & 97 & 112.500 & 2.0900 & 1.9 \\
\hline
\end{tabular}


Table 2-4: Angle of Friction Strength Parameter (Souro: Harr, 1977)

\begin{tabular}{|l|c|c|c|c|}
\hline \multicolumn{1}{|c|}{ Material } & $\begin{array}{c}\text { Number of } \\
\text { Samples }\end{array}$ & Mean & $\begin{array}{c}\text { Standard } \\
\text { Deviation }\end{array}$ & $\begin{array}{c}\text { Coefficient of } \\
\text { Variation (\%) }\end{array}$ \\
\hline Gravel & 38 & 36.22 & 2.160 & 6.0 \\
\hline Sand & 73 & 38.80 & 2.800 & 7.0 \\
\hline Sand & 136 & 36.40 & 4.050 & 11.0 \\
\hline Sand & 30 & 40.52 & 4.560 & 11.0 \\
\hline Gravelly Sand & 81 & 37.33 & 1.970 & 5.3 \\
\hline
\end{tabular}

\subsection{Case Studies}

Several authors were found to have presented probabilistic approaches for the analysis of slope stability, however, no studies were identified to be directly applicable to the modeling approach defined in this research. Two studies were selected which have results that can be used for comparison.

\subsubsection{Infinite Slope Situation}

McCook (1996) reported on failure of embankments constructed by the Soil Conservation Service (SCS) in the Black Prairie area of Texas. These embankments ranged in height from 20 to 40 feet and the slope angles ranged from 18.5 to 26.6 degrees. The embankments were constructed with a highly plastic clay; uniform soil classification of $\mathrm{CH}$. The failures occurred from 4 to 30 years following construction. Sufficient time passed between construction and failure that the slopes developed hairline cracks or slickensides. The failures occurred following heavy rain preceded by extensive dry periods. The slope failures were usually less than 4 feet deep normal to the slope. McCook argues that soil properties cannot be determined from reconstituted laboratory samples due to the effects of cracking. McCook inferred the range of the effective angle of friction and cohesion to be 9 to 18 degrees and 25 to $100 \mathrm{psf}$ respectively. McCook did not report values for the unit weight of these soils, but $\mathrm{CH}$ soils generally have unit weights in the range of 75 to $105 \mathrm{pcf}$ (G aylord, Gaylord, \& Stallmeyer, 1997).

\subsubsection{Planar Slope Situation}

Wong (1985) investigated a confined two dimensional slice of a homogeneous slope that was subjected to increasing gravitational loads until the slope became unstable and sliding of the soil mass occurred. The homogeneous slope was modeled with a constant 
horizontal slope angle of 60 degrees and unit weight of $108 \mathrm{pcf}$. The unit weight was held constant after a sensitivity analysis preformed by Wong indicated that the modeled slope was insensitive to variations from the soil's unit weight. The range for the cohesion (81 to 110 psf) and angle of friction (34.3 to 38.1 degrees) was reported by Wong to vary linearly with respect to the unit weight. In addition, the COV for the soil parameters was 2 percent. The low COV was attributed to the fact that Wong was modeling carefully selected and prepared laboratory experiment samples.

A scaled model was tested in a centrifuge. Next, a two dimensional finite element analysis method (FEM2D) was performed to correlate the findings of the centrifuged model. The finite element analysis was used to establish the four extreme conditions of the model. To establish the four extreme conditions of the slope, Wong held constant the slope height, unit weight, and the horizontal slope angle while varying the angle of friction and cohesion of the soil. From the extreme end points, a surface response regression equation was developed for predicting the intermediate points within the model. A Monte Carlo simulation was conducted using the regression equation. The input parameters were treated as independent and uncorrelated normal distributions. Based on the Monte Carlo simulation Wong obtained a mean critical height of 27.5 feet for development of the full slip form.

\subsection{Conclusion from Literature Review}

Based on the literature search it was found that, a probabilistic approach complements conventional deterministic slope stability studies. In addition, applications of statistics and probability have gained a great deal of acceptance with many design engineers, but doubts still remain over the application of the results. In conclusion, the estimation of the adequacy of a slope found by using a probabilistic analysis compared to the calculated traditional methods remains questionable. And further more, do to lingering doubts, deterministic methods will continue to be used, however probabilistic methods have begun to enter an engineer's daily practice. 


\section{Chapter 3 \\ METHODOLOGY DEVELOPMENT}

\subsection{Introduction}

This chapter presents the methodology developed for applying risk analysis methods for the analysis of slope stability. D eterministic analysis equations are used to predict either the factor of safety or critical height of slopes. These equations are structured within a Monte Carlo simulation program to perform the calculations. The output of the simulation is a probability distribution of either factor of safety or critical height. The output distribution is compared to criteria for the acceptability of risk levels for different design situations.

\subsection{Analytical Structure}

Figure 3-1 defines the approach used to apply Monte Carlo simulation for the analysis of slope stability. This was adopted from Hutchinson and Bandalos's general Monte Carlo simulation approach (1997).

\subsubsection{Selection of Analysis Type}

The analysis method developed for this research, begins with the selection of the type of analysis which will be performed, either critical height or factor of safety. This selection dictates the form of the analytical model and the subsequent output of the model.

\subsubsection{Analysis Method}

The second step is the selection of an appropriate analysis method. Criteria for the selection of the analysis method are presented in Chapter 2. The user would select from either finite slope with a planar failure surface, infinite slope, or finite slope with a circular failure surface. The analytical equations for the first two methods are deterministic and the 


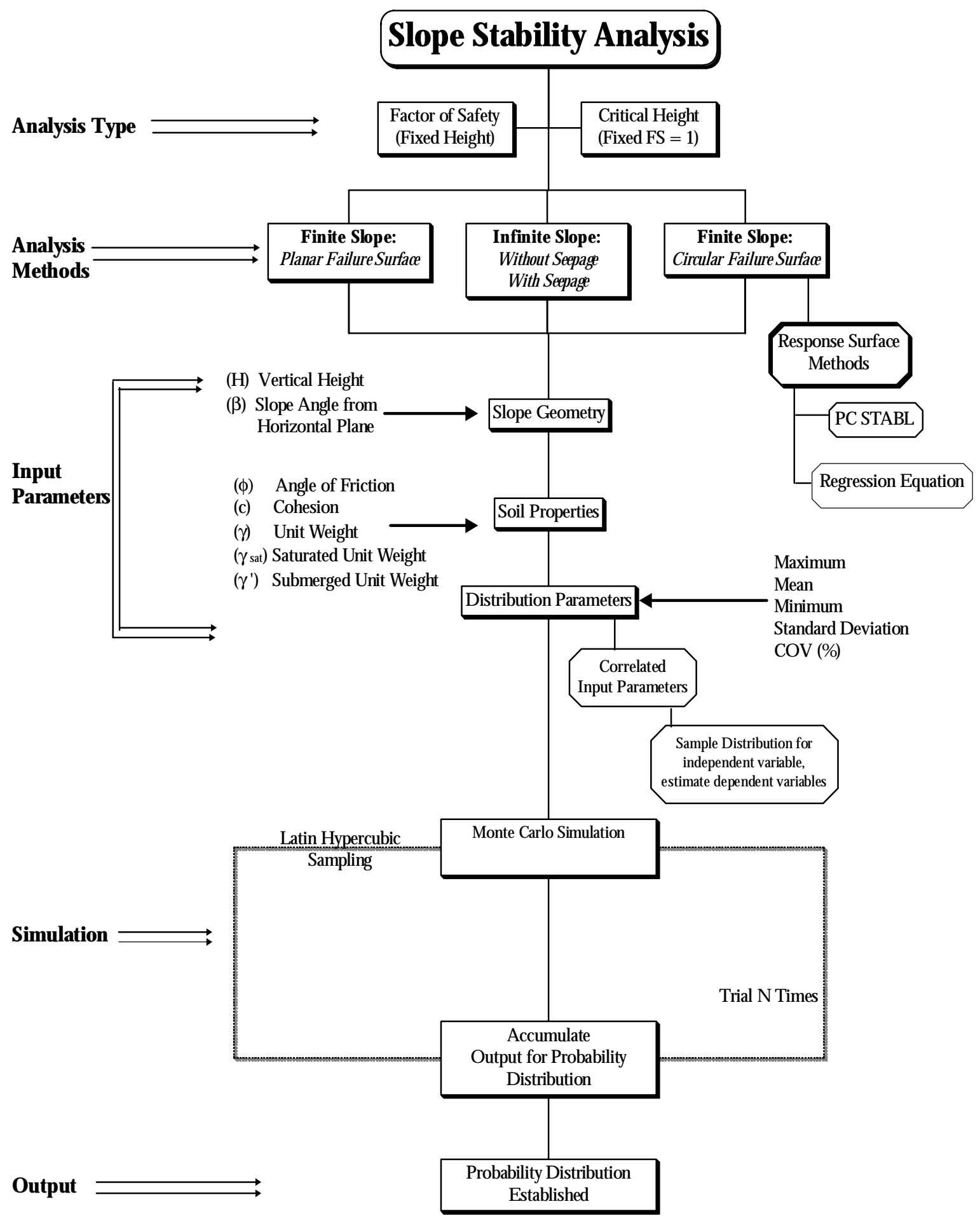

Figure 3-1: Modeling Approach for Slope Stability Monte Carlo Simulation application of a Monte Carlo simulation is straight forward. Analysis of a finite slope with a circular failure surface, Bishop's method, requires iterative solutions. 
The response surface method (Wong, 1985) was selected as a tool to overcome the incompatibilities between the Bishop's method and a Monte Carlo simulation. For a given slope and soil unit weight, four combinations of cohesion and angle of friction were selected to represent the extreme cases. PC STABL was used to determine the factor of safety for each case. This established the "response surface" of the Bishop's method for this analytical situation. A regression equation was developed from the output obtained from PC STABL. The form of the regression model was:

$$
F S=a+a_{1} c+a_{2} \phi+a_{3} c \phi
$$

Equation 3-1

Where:

$$
\begin{array}{lll}
\mathrm{FS} & = & \text { Factor of Safety } \\
\mathrm{c} & = & \text { cohesion } \\
\phi & = & \text { angle of friction } \\
\mathrm{a}_{\mathrm{n}} & = & \text { regression constant }
\end{array}
$$

The validity of the model was verified by comparing a midpoint Bishop's method analysis with the prediction from the regression equation. This regression equation was then used as a deterministic equation for use in the Monte Carlo simulation.

\subsubsection{Input Parameters}

The input parameters for a Monte Carlo simulation fall into two categories, the deterministic parameters used for a conventional analysis and the parameters which define the distribution of the input variables. For slope stability analysis the deterministic parameters are:

- Critical Height (H) or Factor of Safety (FS)

- Slope Angle from the Horizontal Plane ( $\beta$ )

- Angle of Friction $(\phi)$

- Cohesion (c)

- Unit Weight $(\gamma)$

- Saturated Unit Weight $\left(\gamma_{\text {Sat }}\right)$

- Submerged Unit Weight $\left(\gamma^{\prime}\right)$ 
For each of these parameters, Monte Carlo simulation requires definition of the descriptive statistics which define the parameters' distribution. D epending on the type of distribution, the descriptive statistics may include:

- Maximum

- Mean

- Minimum

- Standard D eviation

- Coefficient of Variation

For one of the case studies modeled, the author stated the data had a normal distribution and provided numerical values for the minimum, maximum, and the coefficient of variation. This allowed inference of the mean and standard deviation. So, the Monte Carlo simulation model of this case study treated the input parameters with the inferred values for the mean and standard deviation.

For the other case study, the author only provided the minimum and maximum values for the input parameters. Various attempts were made to use this information to infer the descriptive statistics for a normal distribution. However, when the Monte Carlo simulation was performed with these parameters, untenable results were obtained. O ne of the strengths of the @ RISK program is the ease of selecting alternative distributions. A modified beta distribution, used to describe activity duration times in Program Evaluation and Review Technique, PERT, was selected to model the input parameter distributions for this case study. The PERT distribution is defined by the minimum, maximum, and the most likely (mean) values of the data. When the most likely value is the midpoint between the minimum and maximum, the PERT distribution is symmetrical and resembles a normal distribution. Monte Carlo simulation using the PERT distribution did not produce the untenable results that were a problem with simulations using a normal distribution.

D uring the Monte Carlo simulation, the values for each of the input parameters in the analytical equations are determined by sampling from their respective distributions. However, this process assumes that the input parameter are uncorrelated, as shown in Figure 3-2. In many cases, once a soil type is identified, the soil parameters are correlated, e.g., for a specific type of clay, the cohesion and angle of friction are correlated with the unit weight. In this case, sampling from the distributions for each parameter would produce a resulting 
cumulative distribution with an excessively large variance. The correct procedure for correlated input parameters is shown in Figure 3-3. In this case, the value of one parameter is determined by sampling its distribution. The values for the other parameters are estimated from correlation equations.

\subsubsection{Simulation Process}

The Monte Carlo simulation was developed within a Microsoft Excel worksheet using the @ RISK add in program. The worksheet contained all input parameters and their specified distribution functions. For the analyses conducted within this research, the assumed probability distribution functions were substituted into the deterministic equations from Figure 2-1 for each input parameter. Both the input and output data range cells need to be specified within the worksheet before the @ RISK program is executed.

D uring the simulation process, the established model within the Excel worksheet is repetitively calculated. The statistical program, @ RISK, randomly generated the selected value from the input parameter probability distributions. The required input values are determined during the simulation based on Latin Hypercubic sampling. The number of iterations to determine the output distribution is dependent on the complexity of the model and the specified distribution. Literature presented by Hutchinson \& Bandalos (1997) indicated a range of 10,000 to 100,000 iterations are necessary during a Monte Carlo simulation to obtain precise results. The specific number of iterations for slope stability models is unknown. Therefore the auto converge monitoring feature of @ RISK was used to terminate the simulation. Auto converge monitoring allows the simulation to continue until three statistical parameters, mean, standard deviation, and average percent change in percentile values, converge to less than 1.5 percent. Convergence is monitored every 100 iterations during the simulation.

The output from the Monte Carlo simulation is a distribution of the dependent variable predicted during the analysis. For a critical height analysis, the simulation output is a distribution of critical heights derived by varying the input parameters in accordance with their defined distributions, and solving the analytical model as defined in Figure 2-1. These models were derived with the assumption that the factor of safety is equal to one. The fact that the Monte Carlo simulation produces a distribution of critical heights is reflective of the 


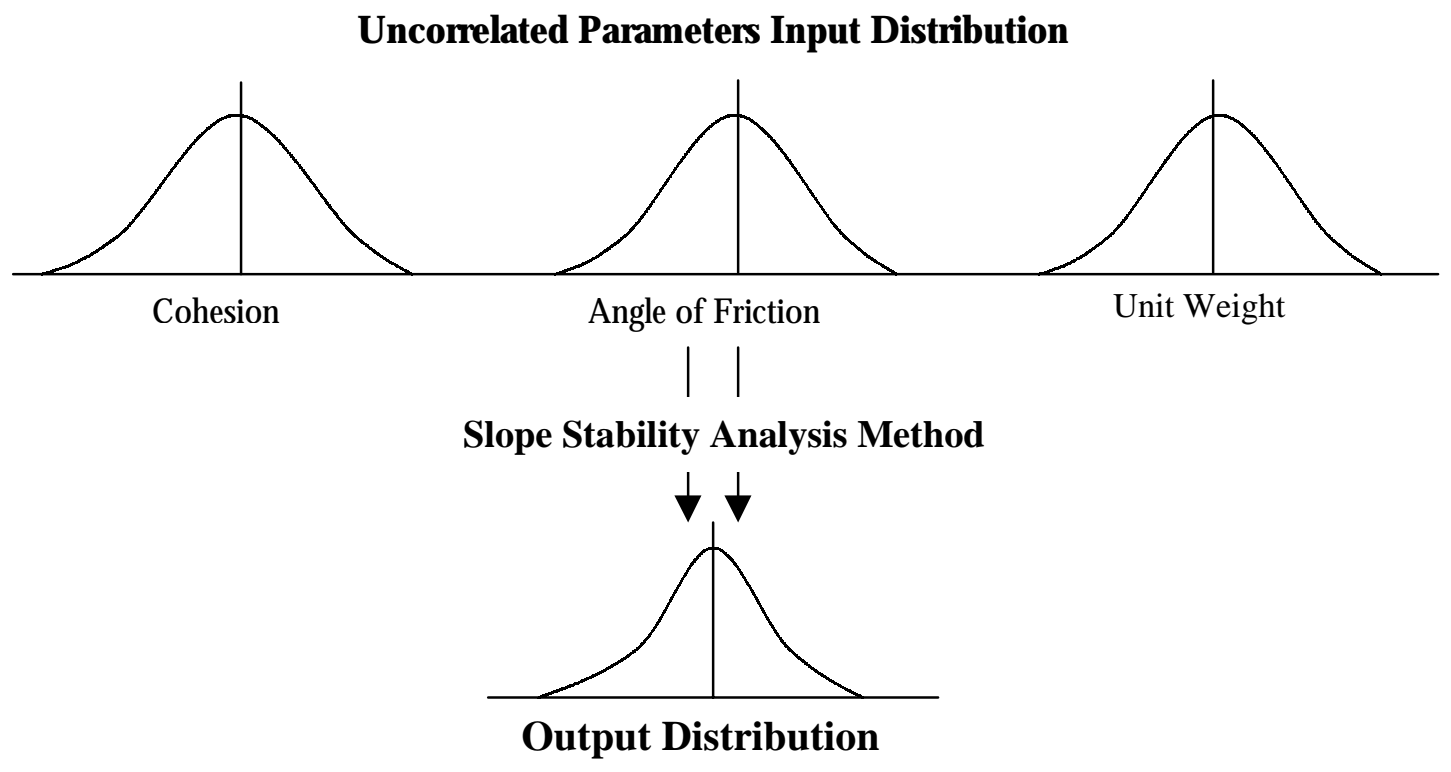

Figure 3-2: Combination of Uncomelated Input Parameters Distribution

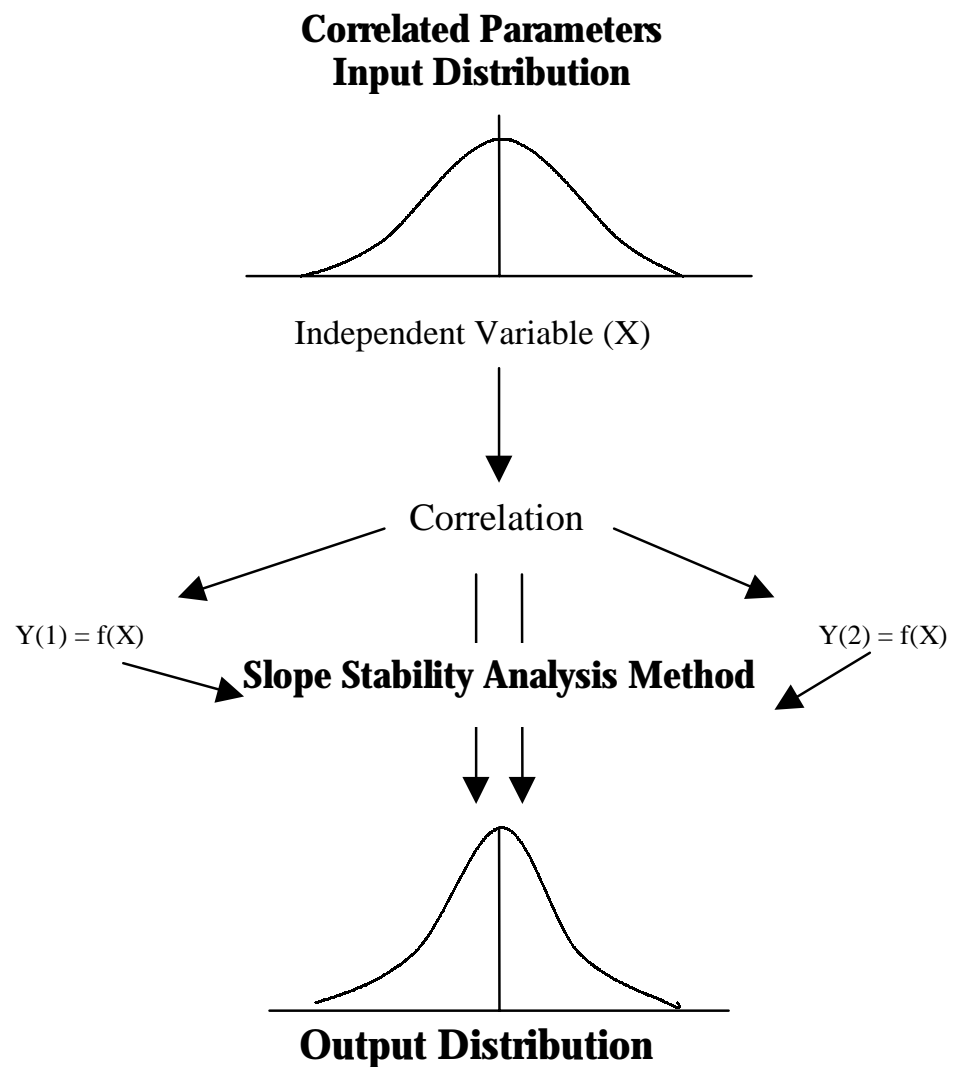

Figure 3-3: Combination of Correlated Input Parameter Distribution 
fact that a distribution rather than a single valued input defines the input parameters. The results of a traditional analysis, using a single value for each input parameter can be compared to the distribution from the Monte Carlo simulation to determine the relative level of conservatism associated with the conventional design. By analogy, this concept is equally valid for a factor of safety analysis.

\subsection{Interpretation of Monte Carlo Simulation Output}

The approach used to examine the output from the Monte Carlo simulation encompasses three features:

- Evaluation of the sensitivity of the Monte Carlo simulation output to input parameter distributions

- Evaluate Monte Carlo simulation output distribution for normality using the chisquare test, and

- Evaluation of the utility of the Monte Carlo simulation analysis for geotechnical design and analysis of slope.

The sensitivity analysis demonstrates the selective influence of the input parameters on the output of the Monte Carlo simulation. Knowledge of this information is beneficial during a geotechnical investigation; greater emphasis should be placed on the most sensitive variables. Two types of sensitivity analysis, correlation and regression, were preformed to determine the significance of the input distribution on the development of the output distribution.

The correlation analysis described the strength of the relationship between the input and output distribution. Using a linear fit between the input and output, a correlation coefficient between negative one and one was indicated. A correlation coefficient of zero indicated that the input and output distributions were independent. Whereas a correlation coefficient of one indicated the output increases when the input parameter increases and there is a perfectly dependent positive linear relationship.

Multiple regression analysis fit the input data to a planar equation which produces the output data. A normalized standard regression coefficient was determined for each input variable distribution. The standard regression coefficient associated with each input distribution ranges from negative one to one, where zero indicates no significant relationship between the input and output distributions. A standard regression coefficient of one 
indicates there is a one standard deviation change in the output distribution for a one standard deviation change in the input distributions.

The test for normality is important when using the results of the Monte Carlo simulation for developing statements regarding the probabilistic behavior of the slope being analyzed.

Finally, application of the Monte Carlo simulation permits the engineer to assess design and analysis situations using a probability of failure concepts as proposed by Santamarina, Altschaeffl, and Chameau. see Table 2-2 (1992). For example Figure 3-4 demonstrates the probability distribution for a Monte Carlo simulation analysis. The critical design height $\left(\mathrm{H}_{\mathrm{CRD}}\right)$ indicates the results that maybe obtained from a conventional analysis using "conservative" input values. The area to the left of $\mathrm{H}_{\mathrm{CRD}}$ indicates a set of input parameters which produces a lower value for the critical height $\left(\mathrm{H}_{\mathrm{CR}}\right)$ and would therefore indicate the $\mathrm{H}_{\mathrm{CRD}}$ value which is defined in terms of the combination of input parameters. Thus, this area indicates the probability of failure of a slope with a height of $\mathrm{H}_{\mathrm{CRD}}$.

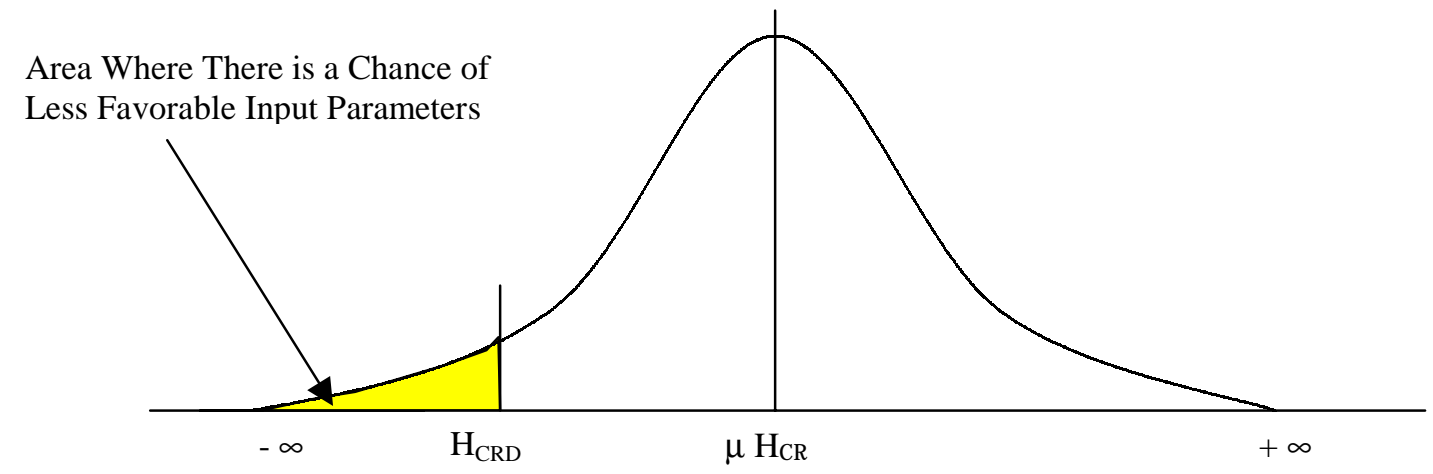

\section{Figure 3-4: Example of Probability Distribution Function for a Monte Carlo Simulation Analysis}

The area indicating the probability of slope failure is computed from the probability distribution curve for an existing slope height or the constructed design slope height which is then compared to the mean critical height determined from @ RISK. Figure 3-5 illustrates a detailed example for how to determine the probability failure from a Monte Carlo simulation for a normal distribution function. The distance (D) separating the existing height and the mean critical height can be used to find the area under the curve between the 
two heights $\left(\mathrm{A}_{\mathrm{x}-\mu}\right)$. O nce the distance between the heights is determined, the distance is divided by the standard deviation established during the @ RISK simulation. A standard normal value is determined from the relationship between the distance and the standard deviation. Therefore, the area under the curve $\left(\mathrm{A}_{\mathrm{X}-\mu}\right)$ can be found by using standard normal tables. The percent area under the probability distribution curve between the existing height and the mean critical height with a corresponding standard normal value $(\mathrm{Z})$ is then used to determine the probability of the modeled slope. $A_{X-\mu}$ therefore represents the percent by chance, that a slope failure will occur if the height of the slope is between $\mathrm{X}$ and $\mu$.

The existing or constructed design height and the negative infinite bounded area $\left(A_{1}\right)$, where the height of the slope has a less favorable combination of input variables can be obtained. The chances of obtaining the area where the combination of less favorable input parameters are chosen is determined by subtracting 50percent from the area under the curve bounded by the existing or constructed design height $\left(\mathrm{A}_{\mathrm{x}}\right.$. $)$. 50 percent represents the chance of slope failure with a height equaling the mean. The area bounded by the existing or constructed design height $\left(A_{1}\right)$ and negative infinite describes the chance, in percent, that slope failure will occur if the slope equals either the existing or constructed height of X.

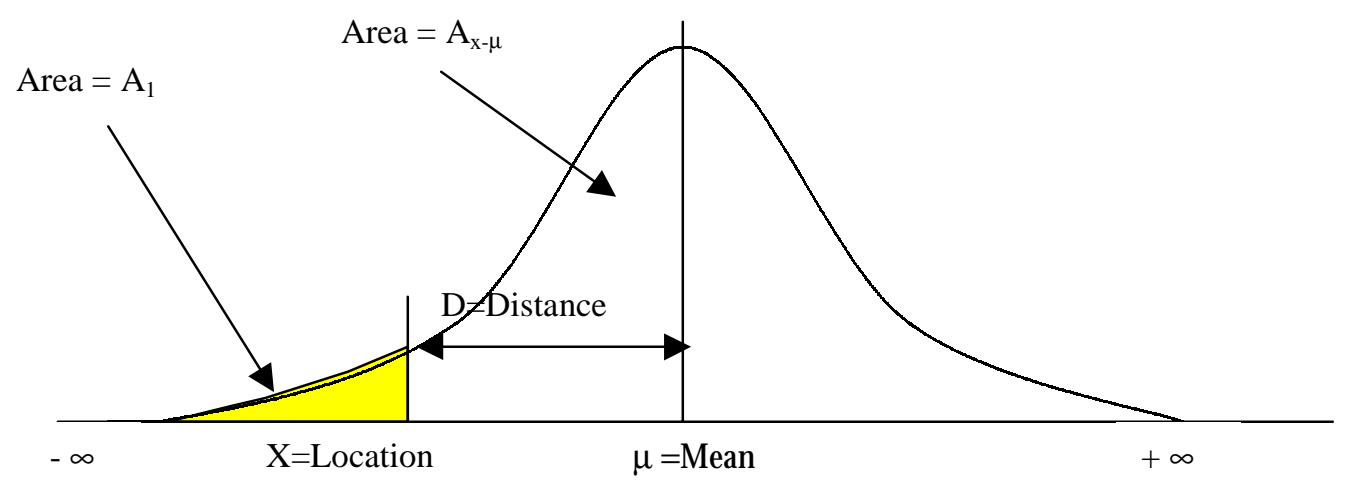

\section{Figure 3-5: Determining the Probability of Failure for a N ormal Distribution using the Results from a Monte Carlo Simulation}




\section{Chapter 4 \\ METHODOLOGY APPLICATION AND RESULTS}

\subsection{Introduction}

The methodology presented in Chapter 3 was validated using two case studies, McCook and Wong. The first case study determined the probability distribution for the factor of safety of an infinite slope without seepage. For the second case study, a finite slope with a planar failure surface was evaluated to determine the probability distribution for the critical height of a slope. The probability distribution for the critical height was evaluated using correlated and uncorrelated input parameters. Both studies were conducted to compare what the effect the relationship of the input parameters have on the output distribution. This case study was also investigated using a modified Bishop's method of slices to determine the factor of safety for a circular failure surface.

\subsection{Infinite Slope without Seepage Analysis}

The data and results from McCook's (1996) study were modeled using the methodology presented in Chapter 3. The infinite slope without seepage analysis method was used to match McCook's work. The input parameters are listed in Table 4-1. The input parameters were assumed to be uncorrelated. The distribution of factor of safety was computed assuming a constant slope height failure depth of 4 feet and the three horizontal slope angles of 18.5, 21.8, and 26.6 degrees. 
Table 4-1: Input Parameters for Infinite Slope without Seepage Analysis

\begin{tabular}{|c|c|c|c|c|c|c|}
\hline Parameter & Distribution & $\mathbf{X}$ min & $* \mathbf{X ~ m l}$ & $\mathbf{X}$ max & Units & Source \\
\hline Cohesion & PERT & 25 & 62.5 & 100 & psf & McCook \\
\hline Angle of Friciton & PERT & 9 & 13.5 & 18 & degrees & McCook \\
\hline Unit Weight & PERT & 75 & 90 & 105 & pcf & $\begin{array}{c}\text { Gaylord, Gaylord, \& } \\
\text { Stallmeyer }\end{array}$ \\
\hline
\end{tabular}

$* \mathrm{Xml}=$ Most likely Value, assumed to be the middle of the range

$\mathrm{Xmax}=$ Maximum Value

McCook did not identify the type of distribution for the soil parameters.

Chowdhury (1980), found that soil parameters can be described with a normal distribution. However, trial analysis with a normal distribution produced untenable results. D uring the simulation using a normal distribution, negative values were obtained when a normal distribution was used to describe the input parameters, specified by McCook. Thus for determining the factor of safety of the slope, the results were untenable since the factor of safety is a quantity that is greater than zero. A symmetric PERT distribution was selected since it has a similar form to the normal distribution, but is constrained by the minimum and maximum values. Figure 4-1 shows the input distributions generated by @ RISK for the input parameters shown in Table 4-1. A chi-square analysis was performed to check the input parameters for normality. For each input parameter, the hypothesis that the input distributions were normal was accepted at the 95 percent confidence level.

The analysis was performed for three horizontal slope angles corresponding to the constructed slope angles in the McCook study. Each analysis was repeated three times to evaluate the repeatability of the analysis. Table $4-2$ shows the output from the analysis. The model required from 200 to 700 iterations to converge on the criteria that the computed factor of safety changes less than 1.5 percent for the parameters: mean, standard deviation, and $95^{\text {th }}$ percentile. The convergence was checked after each 100 iterations. For each simulation, the minimum, maximum, and average values for the soil parameters were close to the values used as arguments to the PERT distribution. 


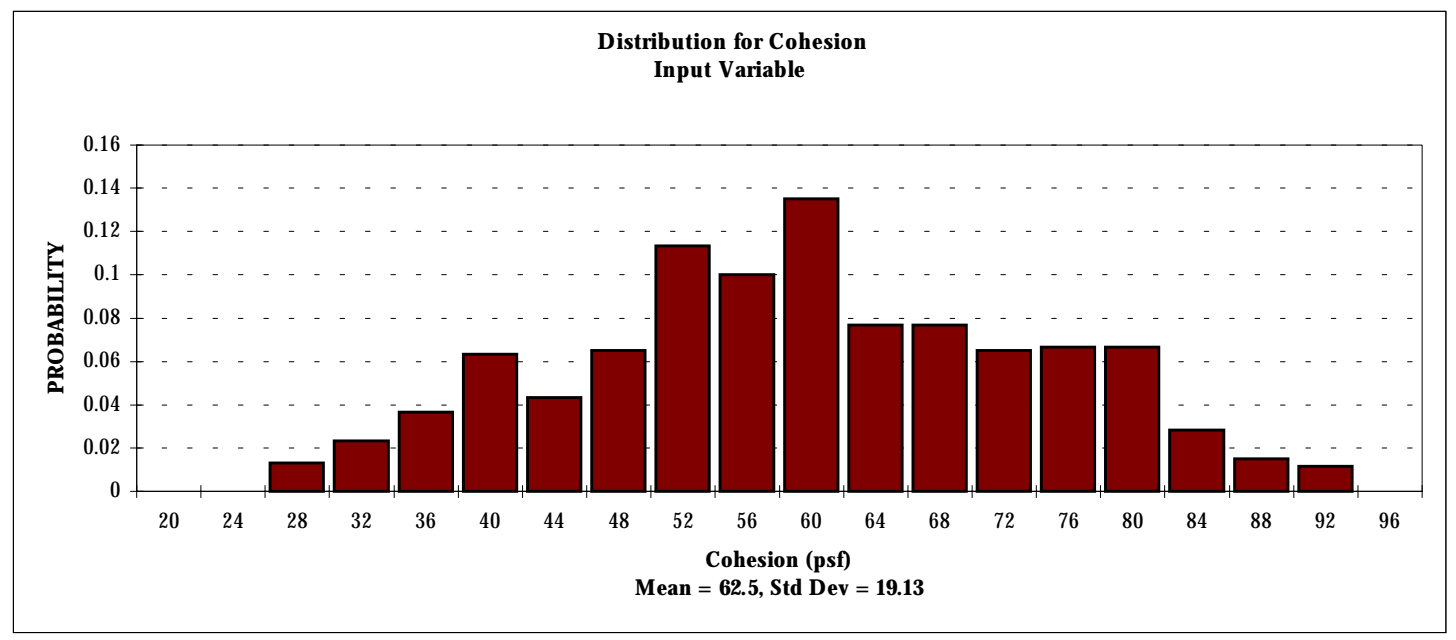

(a) Input Variable: Cohesion

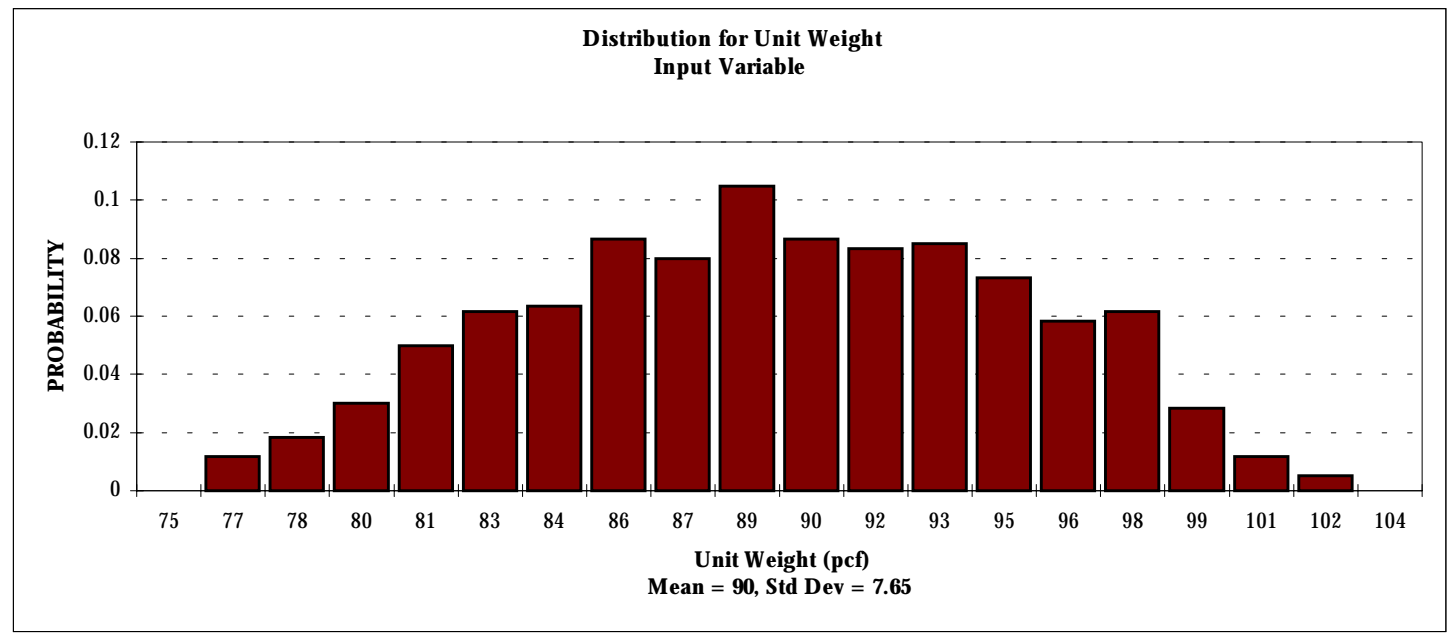

(b) Input Variable: Unit Weight

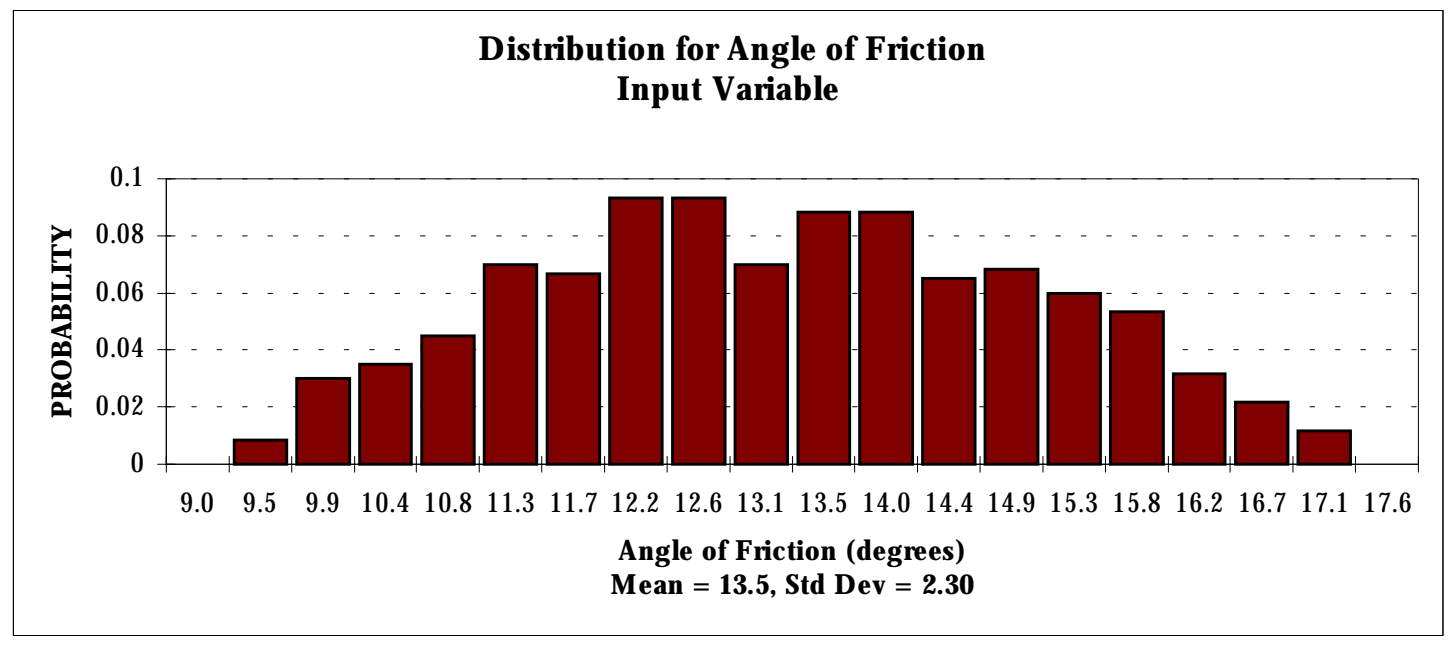

(c) Input Variable: Angle of Friction

Figure 4-1: Example Input Variable Distribution for Infinite Slope without Seepage 
The distribution of the computed factor of safety for each of the analysis run are shown in Figures 4-2 through 4-4. A chi-square test was performed to check the factor of safety distribution for normality. In each case, the hypothesis that the output distributions were normal was accepted at the 95 percent confidence level. The supporting calculations for this conclusion are presented in Appendix A. The factor of safety distribution for each replicated analysis were statistically compared, verifying there was not a sufficient variation in the distributions to statistical indicate a difference between the outputs of the replicated runs for each slope angle. The supporting calculations for this conclusion are also presented in Appendix A.

A sensitivity analysis was performed to evaluate the influence of the input parameters on the factor of safety. Both the correlation and regression methods (@ RISK, 1997) were computed and indicated similar results as shown in Table 4-3. Cohesion has the highest correlation and standard regression coefficient, followed by the angle of friction and the unit weight respectively for all three horizontal slope angles. Figures 4-5 through 4-7 shows the scatter diagrams for each input parameter versus the factor of safety.

\section{Table 4-3: Summary of Sensitivity Analysis for Factor of Safety, Infinite Slope without Seepage}

\begin{tabular}{|c|c|c|c|}
\hline $\begin{array}{c}\text { Honizontal } \\
\text { Slope Angle }\end{array}$ & Input Parameter & $\begin{array}{c}\text { Comelation } \\
\text { Coefficient }\end{array}$ & $\begin{array}{c}\text { Std Regression } \\
\text { Coefficient }\end{array}$ \\
\hline \multirow{3}{*}{26.6} & Cohesion & 0.78 & 0.77 \\
\cline { 2 - 4 } & Angle of Friction & 0.54 & 0.55 \\
\cline { 2 - 4 } & Unit Weight & -0.29 & -0.25 \\
\hline \multirow{3}{*}{21.8} & Cohesion & 0.77 & 0.78 \\
\cline { 2 - 4 } & Angle of Friction & 0.59 & 0.56 \\
\cline { 2 - 4 } & Unit Weight & -0.25 & -0.21 \\
\hline \multirow{3}{*}{18.5} & Cohesion & 0.81 & 0.77 \\
\cline { 2 - 4 } & Angle of Friction & 0.56 & 0.51 \\
\cline { 2 - 4 } & Unit Weight & -0.33 & -0.22 \\
\hline
\end{tabular}


Table 4-2 Infinite Slope without Seepage, Factor of Safety Analysis

\begin{tabular}{|c|c|c|c|c|c|c|c|c|c|c|c|c|c|}
\hline \multirow[b]{2}{*}{$\begin{array}{c}\text { Honizontal } \\
\text { Slope Angle } \\
\text { (degrees) }\end{array}$} & \multirow[b]{2}{*}{ Statistical Parameter } & \multicolumn{3}{|c|}{ Factor of Safety } & \multicolumn{3}{|c|}{ Cohesion (psf) } & \multicolumn{3}{|c|}{ Unit Weight (pcf) } & \multicolumn{3}{|c|}{ Angle of Friction (degrees) } \\
\hline & & FS(1) & FS (2) & FS(3) & c (1) & c (2) & c (3) & $\gamma(\mathbf{1})$ & $\gamma(2)$ & $\gamma(3)$ & $\phi(1)$ & $\phi(2)$ & $\phi(3)$ \\
\hline \multirow{2}{*}{26.6} & $\begin{array}{c}\text { Minimum }= \\
\text { Maximum }= \\
\text { Mean }= \\
\text { Std Deviation = } \\
\operatorname{COV}(\%)=\end{array}$ & $\begin{array}{c}0.62 \\
1.27 \\
0.92 \\
0.12 \\
12.88 \\
\end{array}$ & $\begin{array}{c}0.57 \\
1.23 \\
0.92 \\
0.12 \\
13.03 \\
\end{array}$ & \begin{tabular}{|c|}
0.62 \\
1.25 \\
0.93 \\
0.12 \\
13.24 \\
\end{tabular} & $\begin{array}{l}29.37 \\
97.55 \\
63.44 \\
13.93 \\
21.95 \\
\end{array}$ & \begin{tabular}{l|}
29.63 \\
98.66 \\
63.38 \\
14.48 \\
22.85 \\
\end{tabular} & $\begin{array}{l}32.00 \\
94.34 \\
63.43 \\
13.71 \\
21.62 \\
\end{array}$ & $\begin{array}{c}77.04 \\
104.22 \\
90.20 \\
5.56 \\
6.17 \\
\end{array}$ & $\begin{array}{c}75.97 \\
104.12 \\
90.31 \\
5.54 \\
6.14 \\
\end{array}$ & $\begin{array}{c}76.36 \\
102.26 \\
89.89 \\
6.04 \\
6.72 \\
\end{array}$ & $\begin{array}{c}9.61 \\
17.47 \\
13.60 \\
1.66 \\
12.20 \\
\end{array}$ & $\begin{array}{c}9.62 \\
17.61 \\
13.58 \\
1.70 \\
12.53 \\
\end{array}$ & $\begin{array}{c}9.55 \\
17.29 \\
13.60 \\
1.80 \\
13.21 \\
\end{array}$ \\
\hline & $\begin{array}{c}\text { Average Mean FS } \\
\text { Average FS Std Deviation } \\
\text { No. Iterations (n) }\end{array}$ & $\begin{array}{l}0.92 \\
0.12 \\
600\end{array}$ & 500 & 200 & & & & & & & & & \\
\hline \multirow{2}{*}{21.8} & $\begin{array}{c}\text { Minimum }= \\
\text { Maximum }= \\
\text { Mean }= \\
\text { Std Deviation = } \\
\text { COV }(\%)=\end{array}$ & $\begin{array}{l}0.72 \\
1.51 \\
1.10 \\
0.14 \\
13.06 \\
\end{array}$ & \begin{tabular}{l|}
0.79 \\
1.43 \\
1.10 \\
0.14 \\
12.61 \\
\end{tabular} & $\begin{array}{l}0.70 \\
1.48 \\
1.10 \\
0.14 \\
12.67 \\
\end{array}$ & $\begin{array}{l}27.53 \\
96.76 \\
61.82 \\
13.81 \\
22.35 \\
\end{array}$ & $\begin{array}{l}28.45 \\
95.18 \\
62.01 \\
14.22 \\
22.93 \\
\end{array}$ & $\begin{array}{l}29.30 \\
93.36 \\
62.01 \\
13.83 \\
22.30 \\
\end{array}$ & $\begin{array}{c}76.33 \\
103.18 \\
90.00 \\
5.41 \\
6.02 \\
\end{array}$ & $\begin{array}{c}77.22 \\
103.09 \\
90.11 \\
5.69 \\
6.32 \\
\end{array}$ & $\begin{array}{c}76.37 \\
104.29 \\
90.02 \\
5.84 \\
6.49 \\
\end{array}$ & $\begin{array}{c}9.59 \\
17.60 \\
13.50 \\
1.75 \\
12.95 \\
\end{array}$ & $\begin{array}{c}9.57 \\
17.76 \\
13.55 \\
1.63 \\
12.03 \\
\end{array}$ & $\begin{array}{c}9.48 \\
17.54 \\
13.51 \\
1.67 \\
12.35 \\
\end{array}$ \\
\hline & $\begin{array}{c}\text { Average Mean FS } \\
\text { Average FS Std Deviation } \\
\text { No. Iterations (n) } \\
\end{array}$ & $\begin{array}{l}1.10 \\
0.14 \\
500 \\
\end{array}$ & 400 & 700 & & & & & & & & & \\
\hline \multirow{2}{*}{18.5} & $\begin{array}{c}\text { Minimum }= \\
\text { Maximum = } \\
\text { Mean }= \\
\text { Std Deviation = } \\
\operatorname{COV}(\%)=\end{array}$ & $\begin{array}{r}0.84 \\
1.72 \\
1.30 \\
0.16 \\
12.38 \\
\end{array}$ & $\begin{array}{c}0.88 \\
1.77 \\
1.30 \\
0.16 \\
12.42 \\
\end{array}$ & \begin{tabular}{l|}
0.88 \\
1.82 \\
1.31 \\
0.18 \\
13.50 \\
\end{tabular} & $\begin{array}{l}26.96 \\
94.20 \\
61.86 \\
14.61 \\
23.63 \\
\end{array}$ & $\begin{array}{l}28.37 \\
96.37 \\
63.21 \\
14.16 \\
22.40 \\
\end{array}$ & $\begin{array}{l}28.15 \\
95.55 \\
63.15 \\
14.59 \\
23.10 \\
\end{array}$ & $\begin{array}{c}76.40 \\
100.98 \\
88.67 \\
5.92 \\
6.67 \\
\end{array}$ & $\begin{array}{c}77.56 \\
103.48 \\
89.81 \\
5.67 \\
6.31 \\
\end{array}$ & $\begin{array}{c}76.63 \\
103.82 \\
89.66 \\
5.98 \\
6.67 \\
\end{array}$ & $\begin{array}{c}9.41 \\
17.61 \\
13.47 \\
1.80 \\
13.33 \\
\end{array}$ & $\begin{array}{c}9.25 \\
17.40 \\
13.46 \\
1.71 \\
12.68 \\
\end{array}$ & $\begin{array}{c}9.67 \\
17.38 \\
13.59 \\
1.65 \\
12.14 \\
\end{array}$ \\
\hline & $\begin{array}{c}\text { Average Mean FS } \\
\text { Average FS Std Deviation } \\
\text { No. Iterations (n) }\end{array}$ & $\begin{array}{l}1.30 \\
0.17 \\
200\end{array}$ & 700 & 400 & & & & & & & & & \\
\hline
\end{tabular}




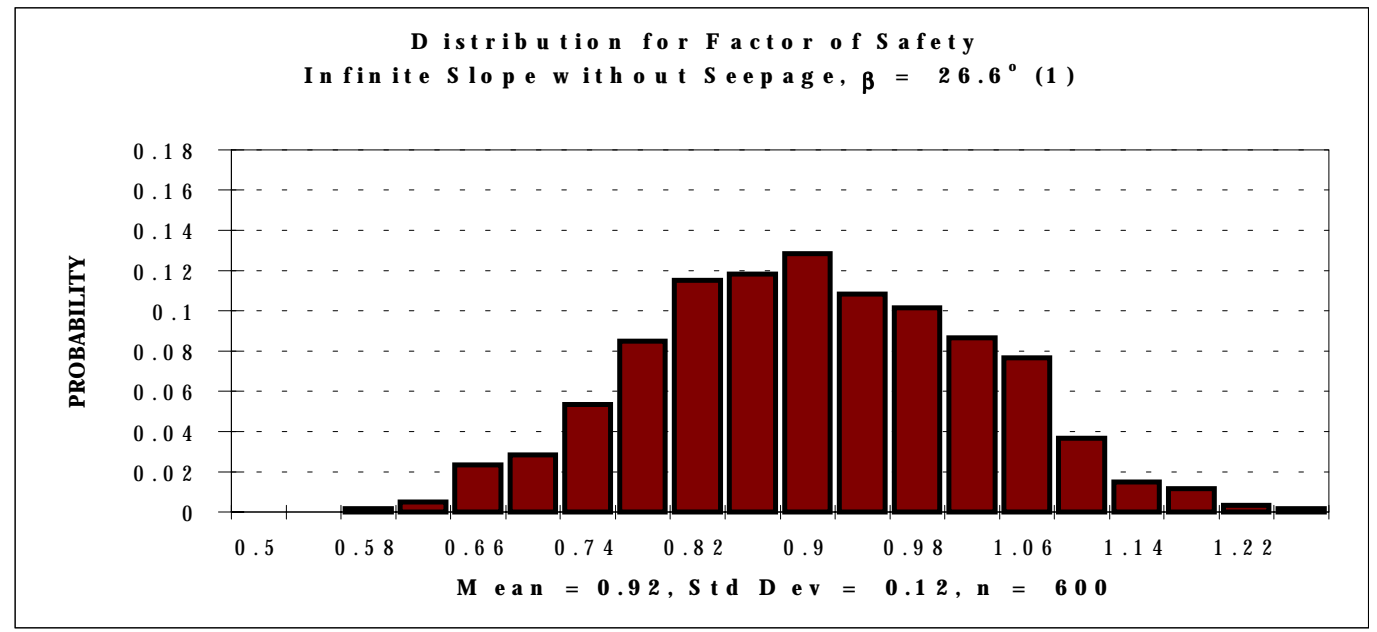

(a) Sim ulation \# 1

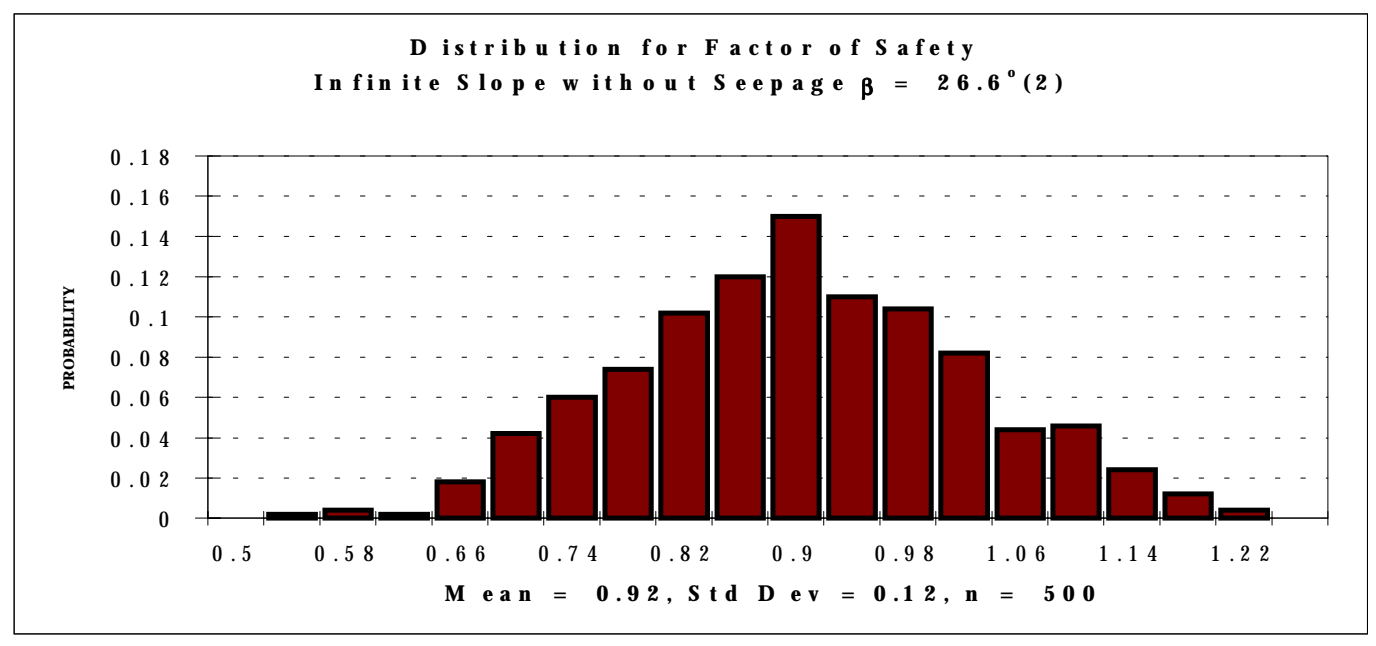

(b) S im u lation \# 2

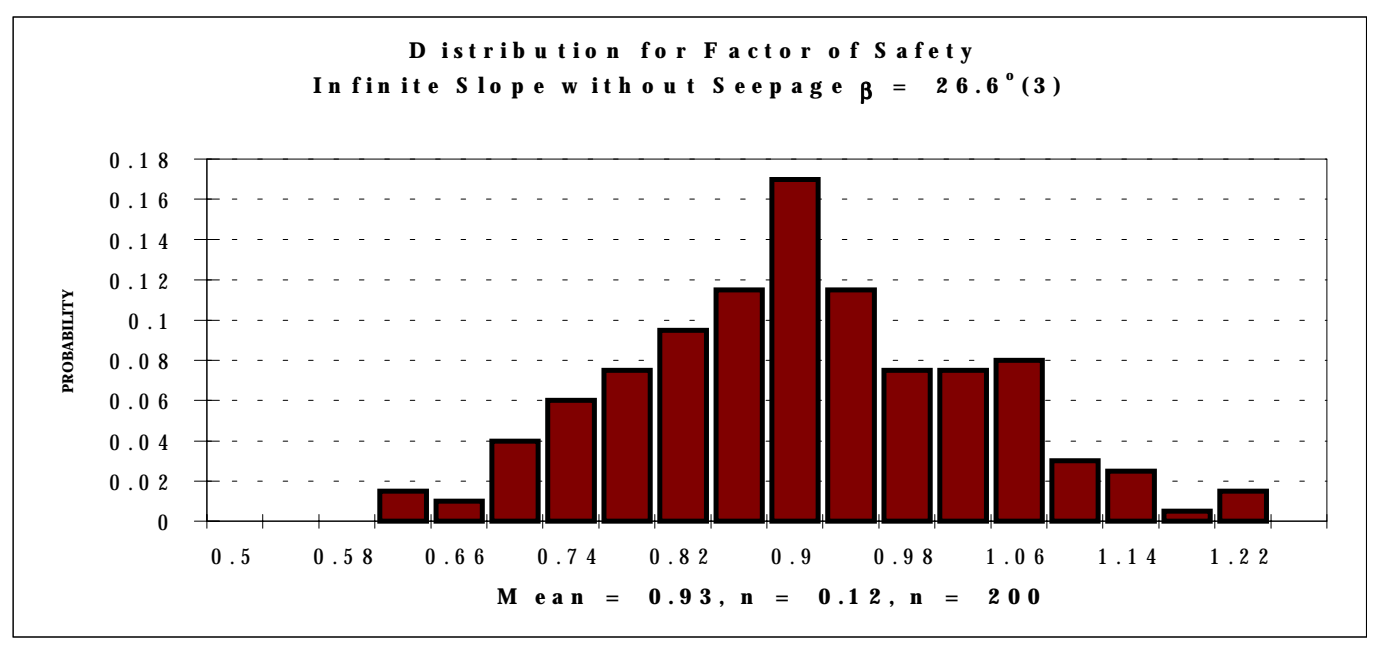

(c) Sim u lation \# 3

Figure 4-2: Histograms for Factor of Safety, $\beta=26.6$ degrees 


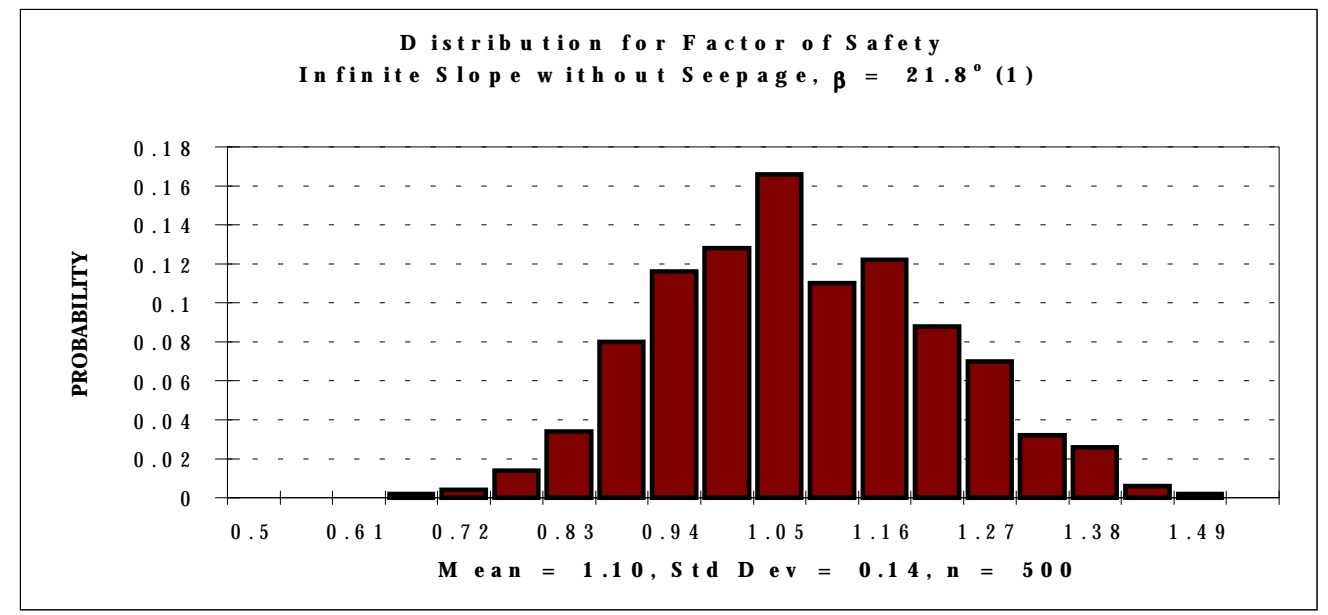

(a) Sim ulation \# 1

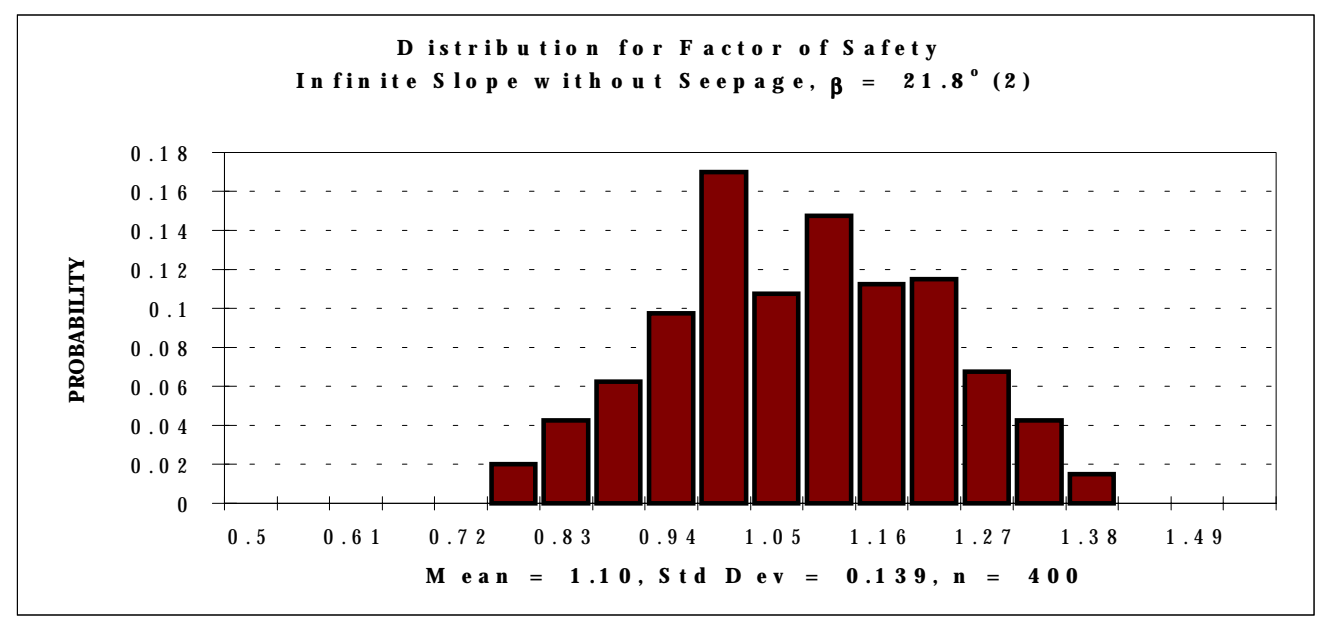

(b) S im u lation \# 2

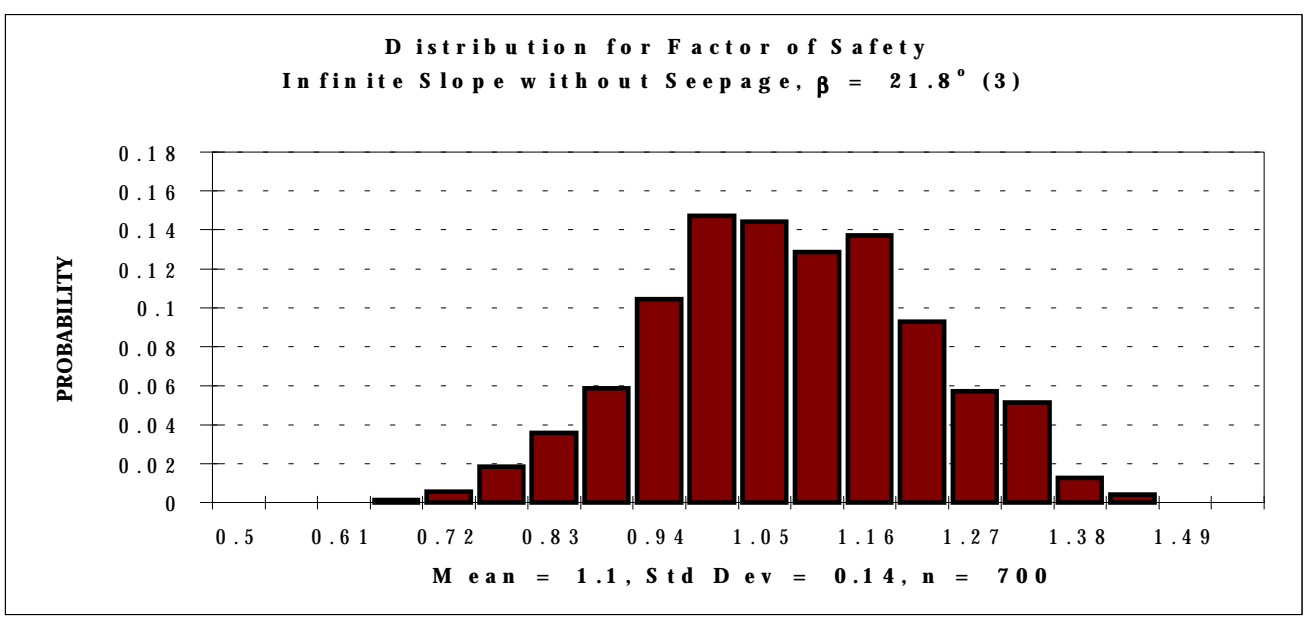

(c) S im ulation \# 3

Figure 4-3: Histograms for Factor of Safety, $\beta=21.8$ degrees 


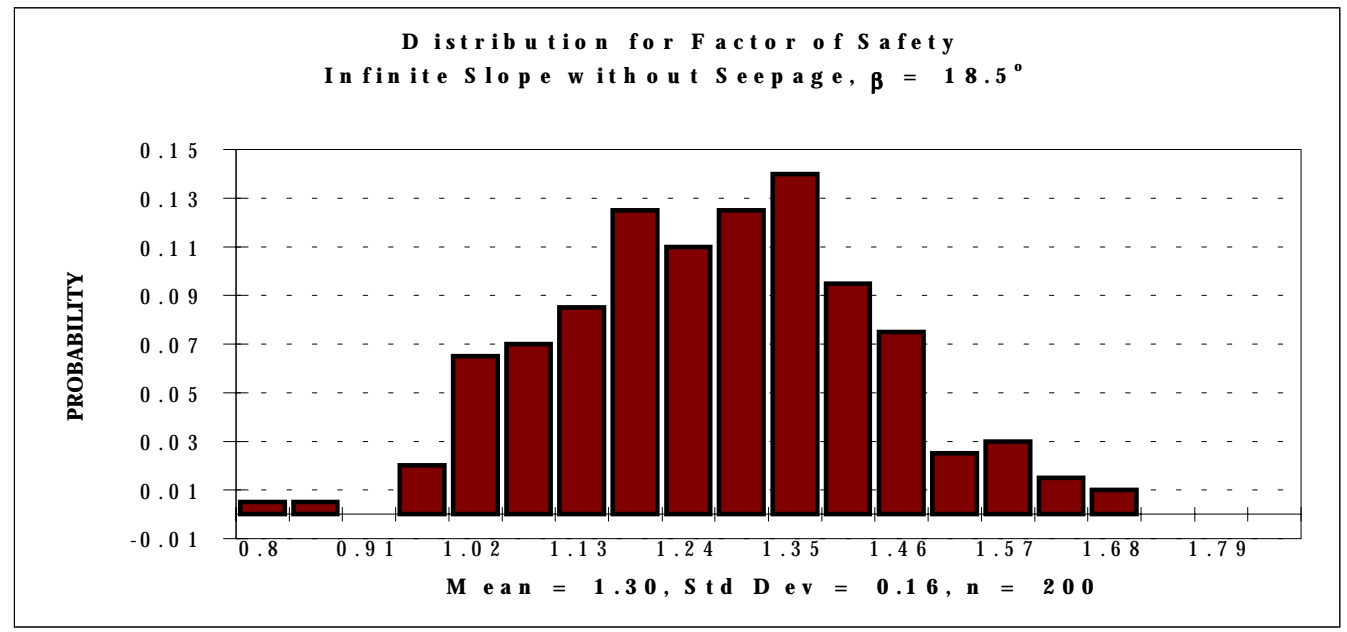

(a) S im ulation \# 1

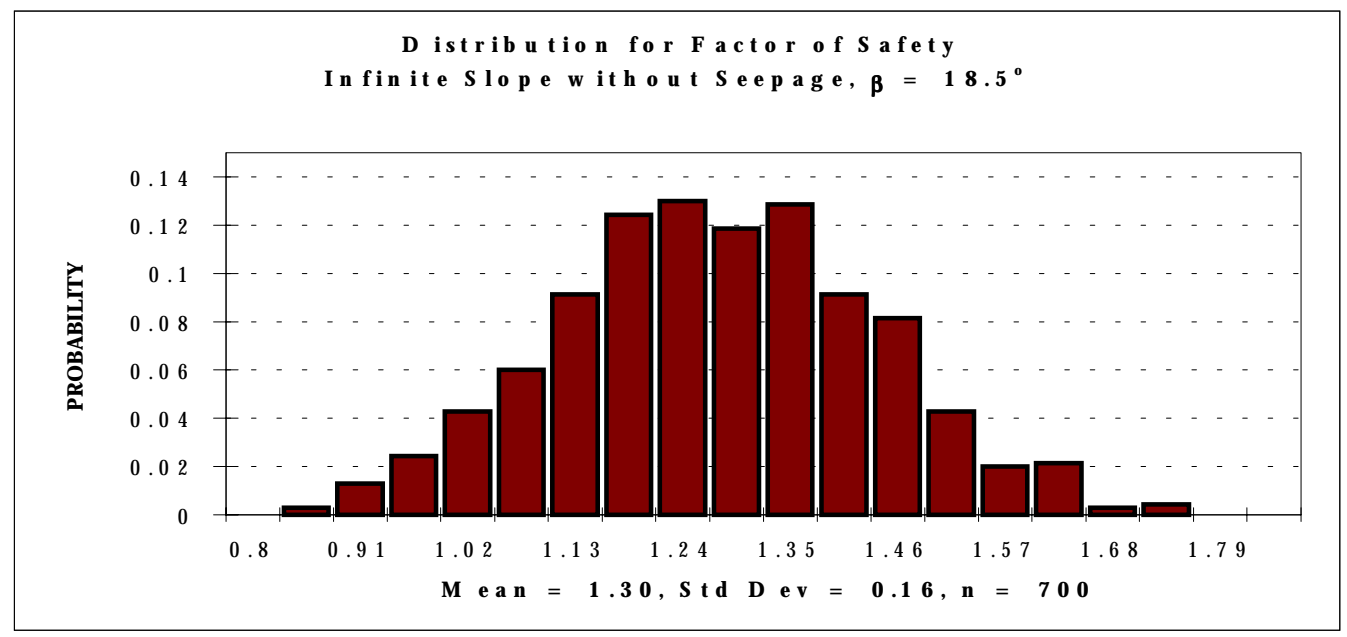

(b) S im u lation \# 2

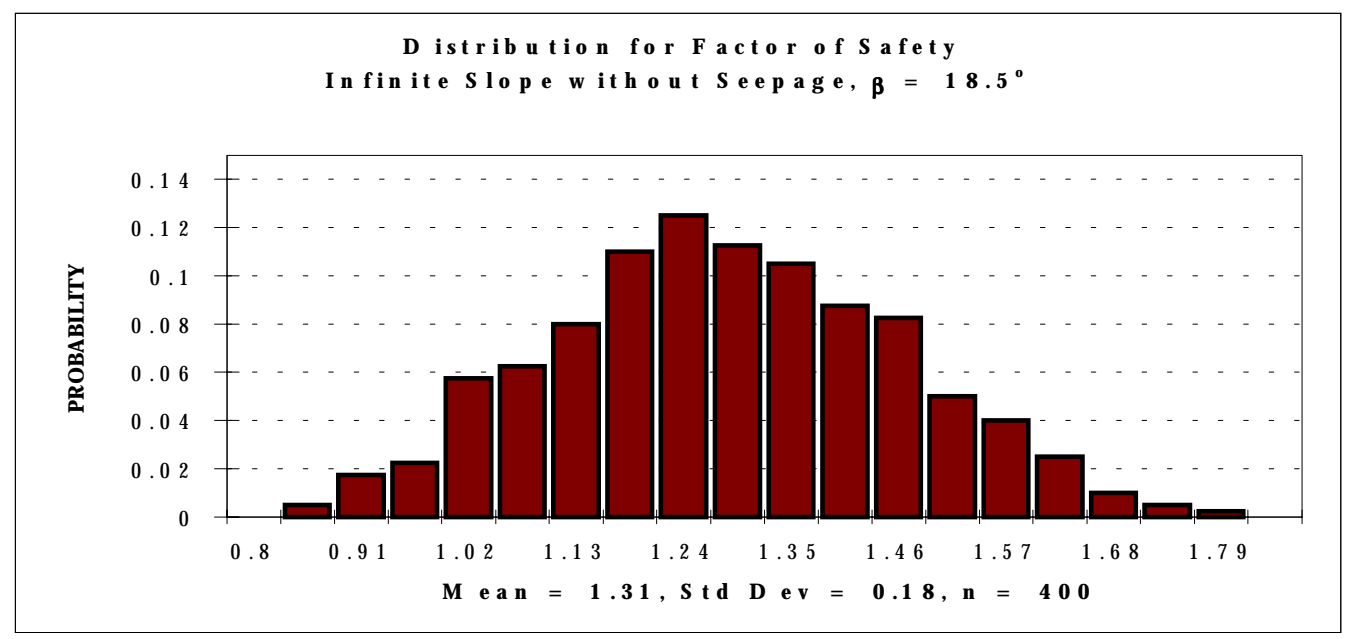

(c) S im u lation \# 3

Figure 4-4: H istogram for Factor of Safety, $\beta=18.5$ degrees 


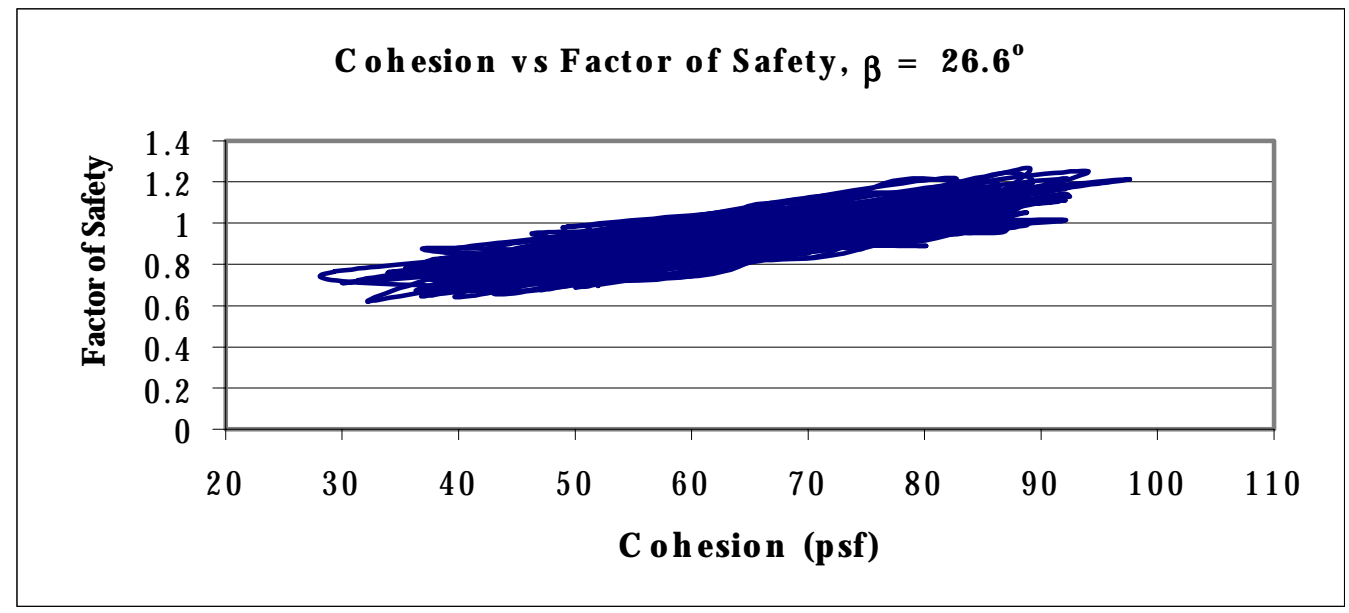

(a) Input Parameter: Cohesion

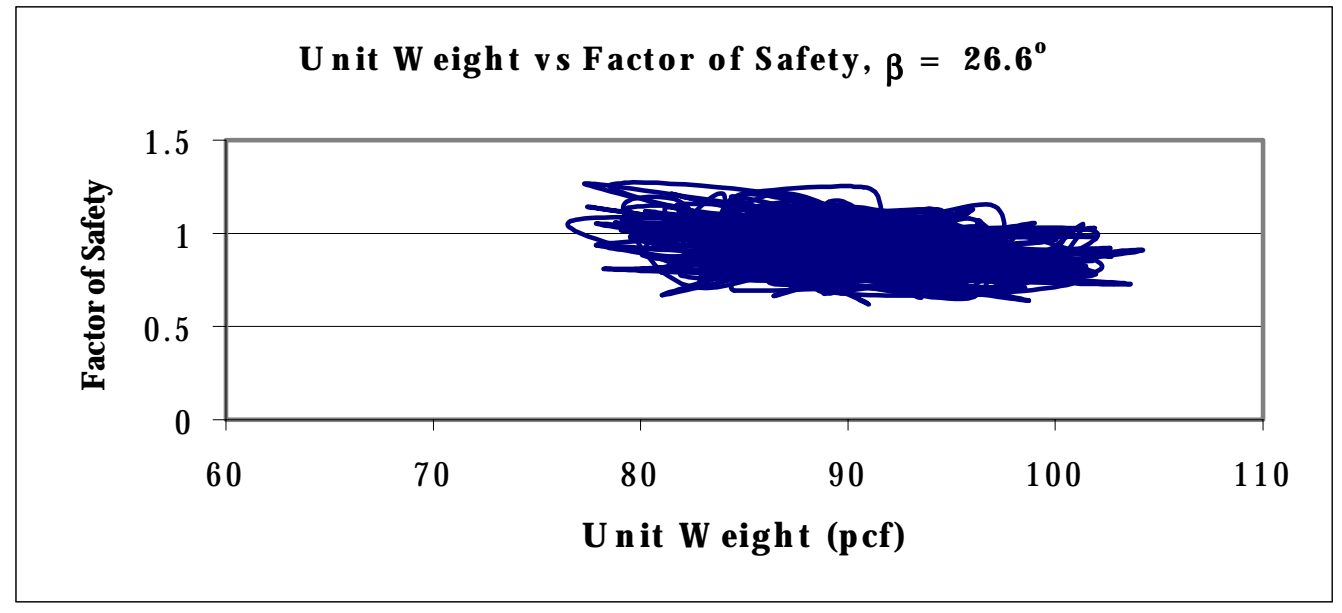

(b) Input Param eter: Unit W eight

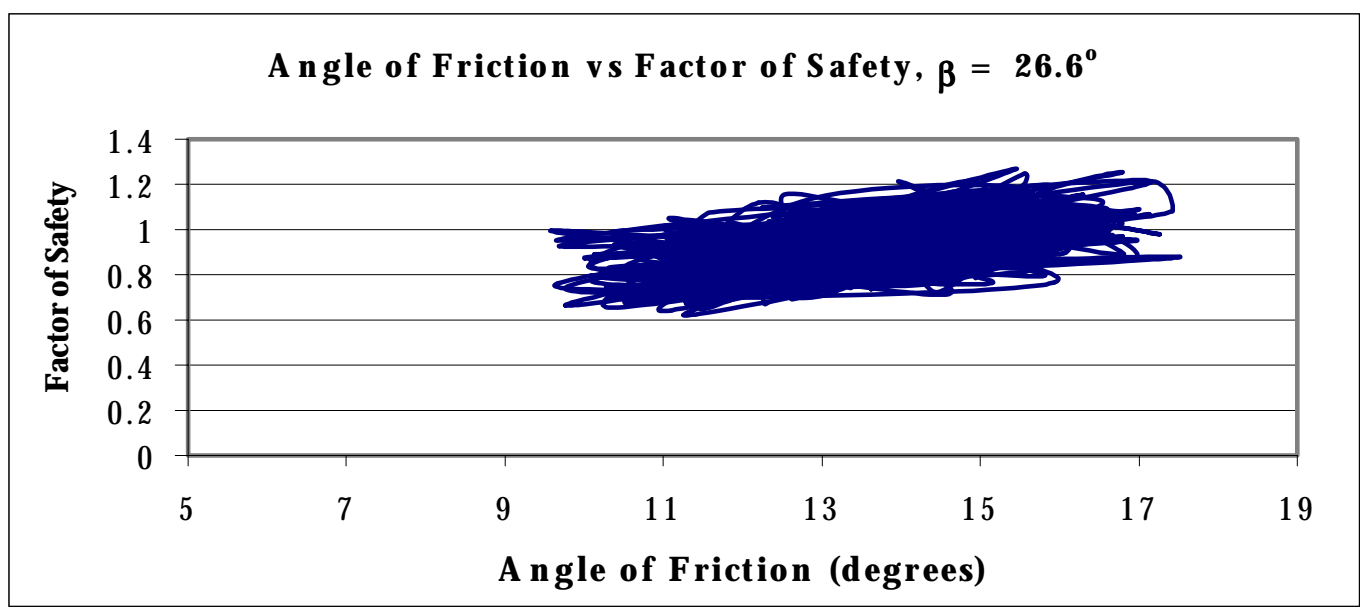

(c) Input Parameter: Angle of Friction

Figure 4-5: Scatter Diagrams, Input Parameter vs Factor of Safety , $\beta=26.6$ degrees 


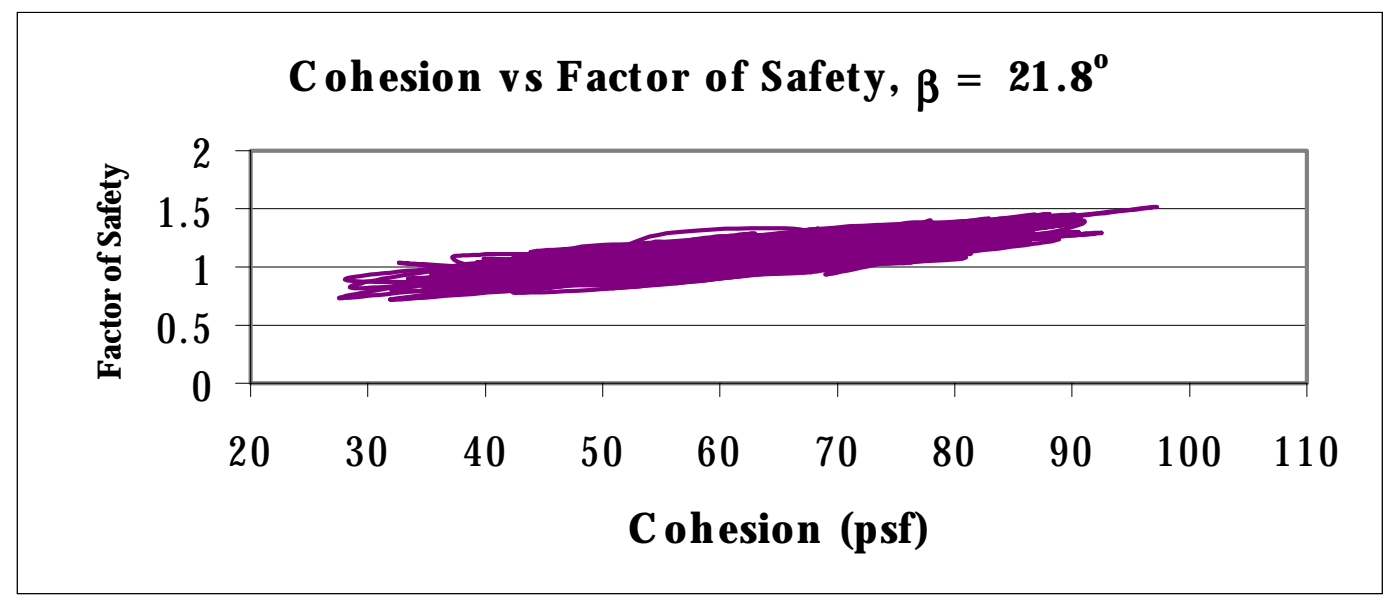

(a) Input Parameters: Cohesion

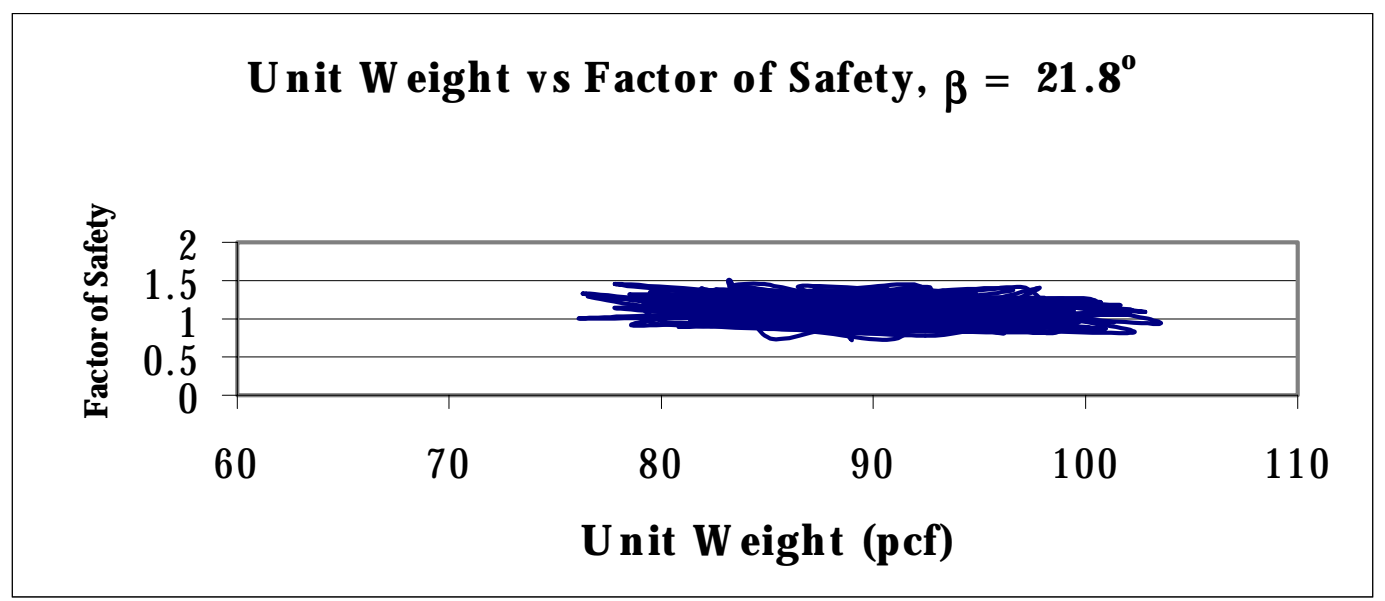

(b) Input Parameter: Unit W eight

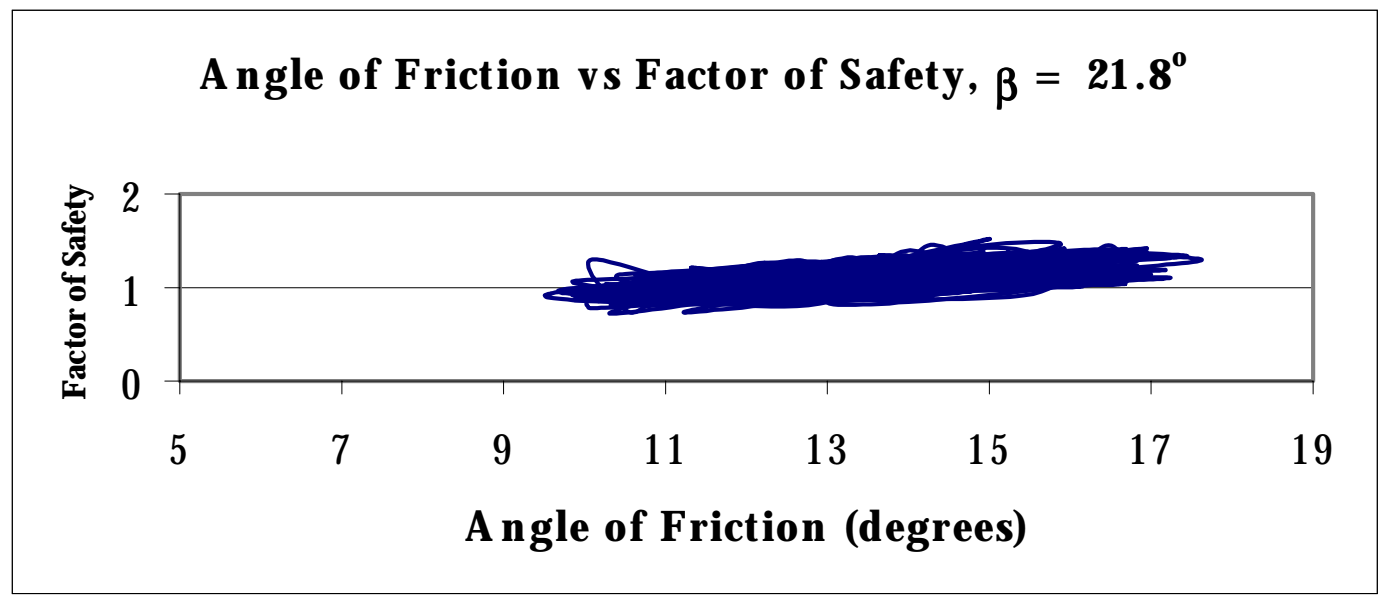

(c) Input Parameter: Angle of Friction

Figure 4-6: Scatter Diagrams, Input Parameter vs Factor of Safety, $\beta=21.8$ degrees 


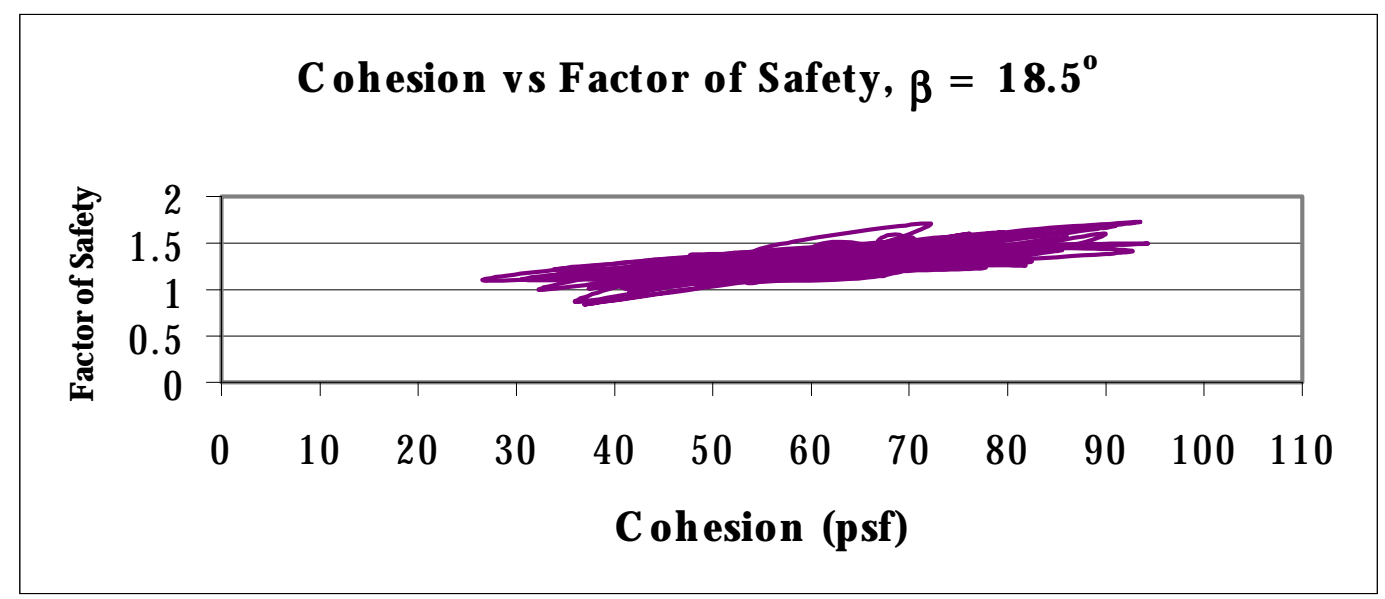

(a) Input Parameter: Cohesion

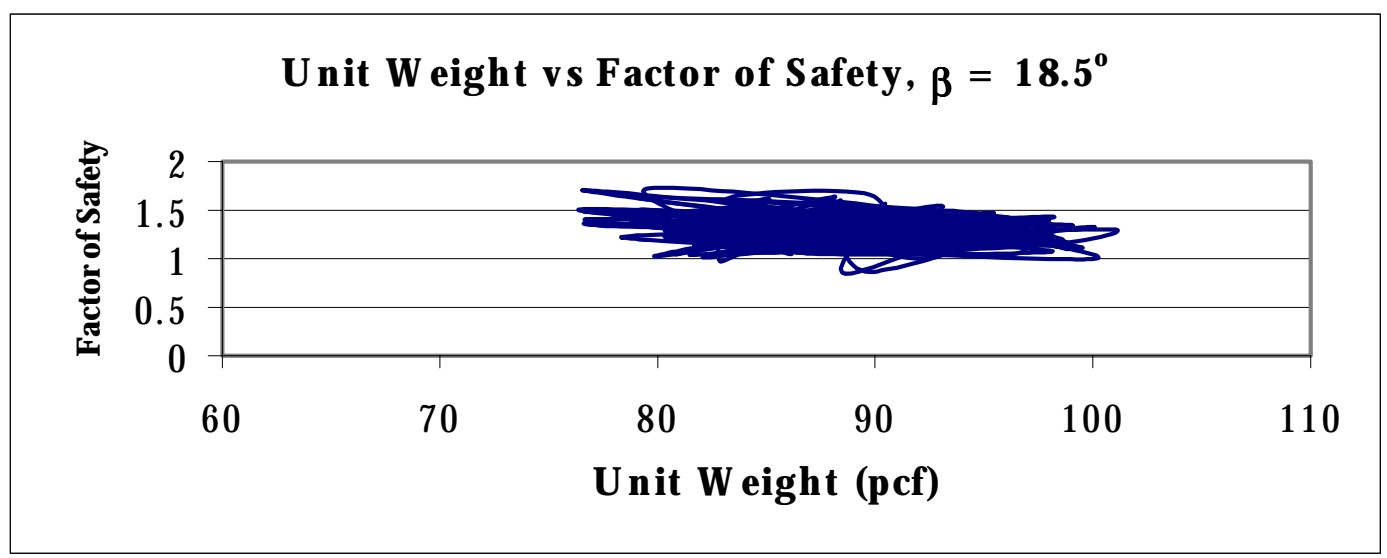

(b) Input Parameter: Unit W eight

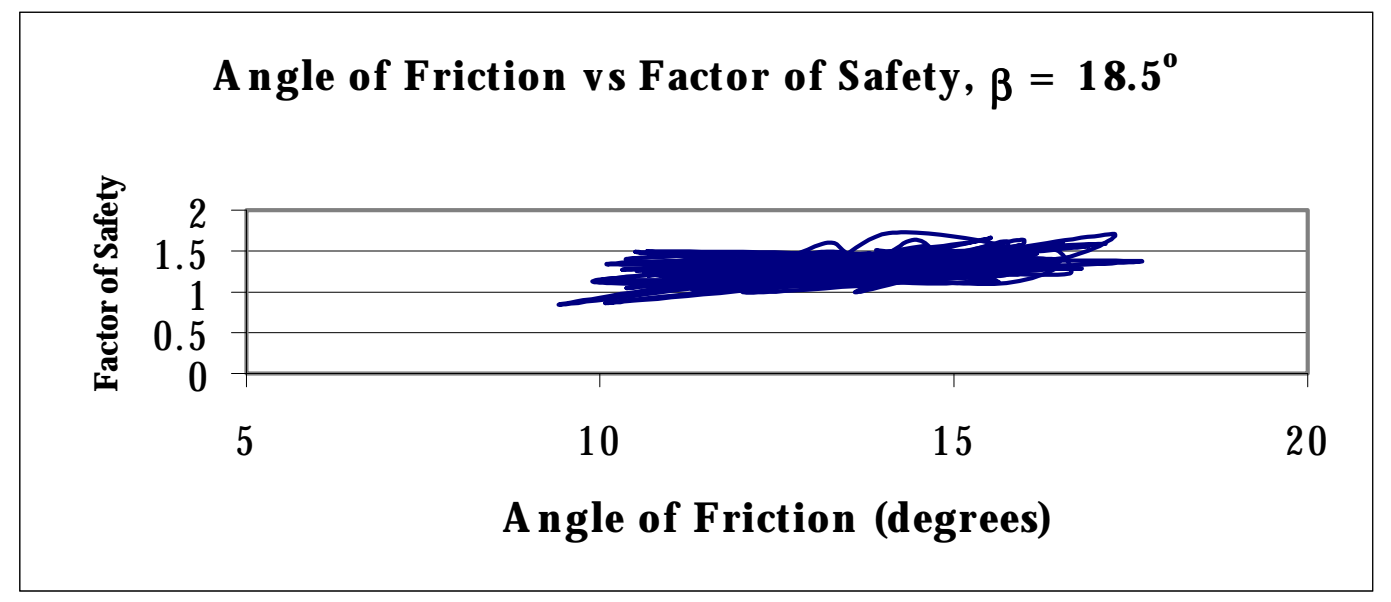

(c) Input Parameter: Angle of Friciton

Figure 4-7: Scatter Diagrams, Input Parameter vs Factor of Safety, $\beta=18.5$ degrees 
The value of the risk analysis methodology is the ability to determine the probability of a specific event occurring. By definition, a factor of safety less than one indicates a slope in an unstable condition associated with failure. Figure 4-8 shows for these slope angles analyzed, indicating a probability of failure of 75 percent, 24 percent, and 4 percent for slope angles of 26.6, 21.8, and 18.5 degrees respectively. According to the classification scheme developed by Santamarina, Altschaeffl, \& Chameau (1992), as shown in Table 2-2, only 18.5 degrees slope had a acceptable level of risk, and this would be for a temporary structure.

To demonstrate the design capabilities of the risk analysis approach, the analysis was repeated for slope angles between 10 and 18.5 degrees, and the associated probability of failure was computed as shown in Figure 4- 9. Using the Santamarina, Altschaeffl, \& Chameau, criteria the horizontal slope angle corresponding to each design condition was computed as shown in Table 4-4 (1992).

The following is a summary of the results and conclusions obtained from the factor of safety stability analysis for the infinite slope without seepage study presented by McCook.

- The output generated from @ RISK for the factor of mean safety for an infinite slope without seepage was 0.92 for a horizontal slope angle of 26.6 degrees, 1.10 for a horizontal slope angle of 21.8 degrees, and 1.30 for a horizontal slope angle of 18.5 degrees. The factor of safety was obtained for the given range of soil material parameters and a slope height of 4 feet.

- The hypothesis that the output distributions were normally distributed was accepted at the 95 percent confidence interval for the data obtained from the @ RISK simulations for all three horizontal slope angles. In addition, a hypothesis test indicated that there was no statistical difference between the factor of safety distributions for each horizontal slope angle analyzed.

- Sensitivity analysis was conducted using a correlation and a regression analysis which indicated that cohesion was the most critical input distribution followed by the angle of friction. The output distribution for all three slope angles was least significantly effected by the unit weight. 


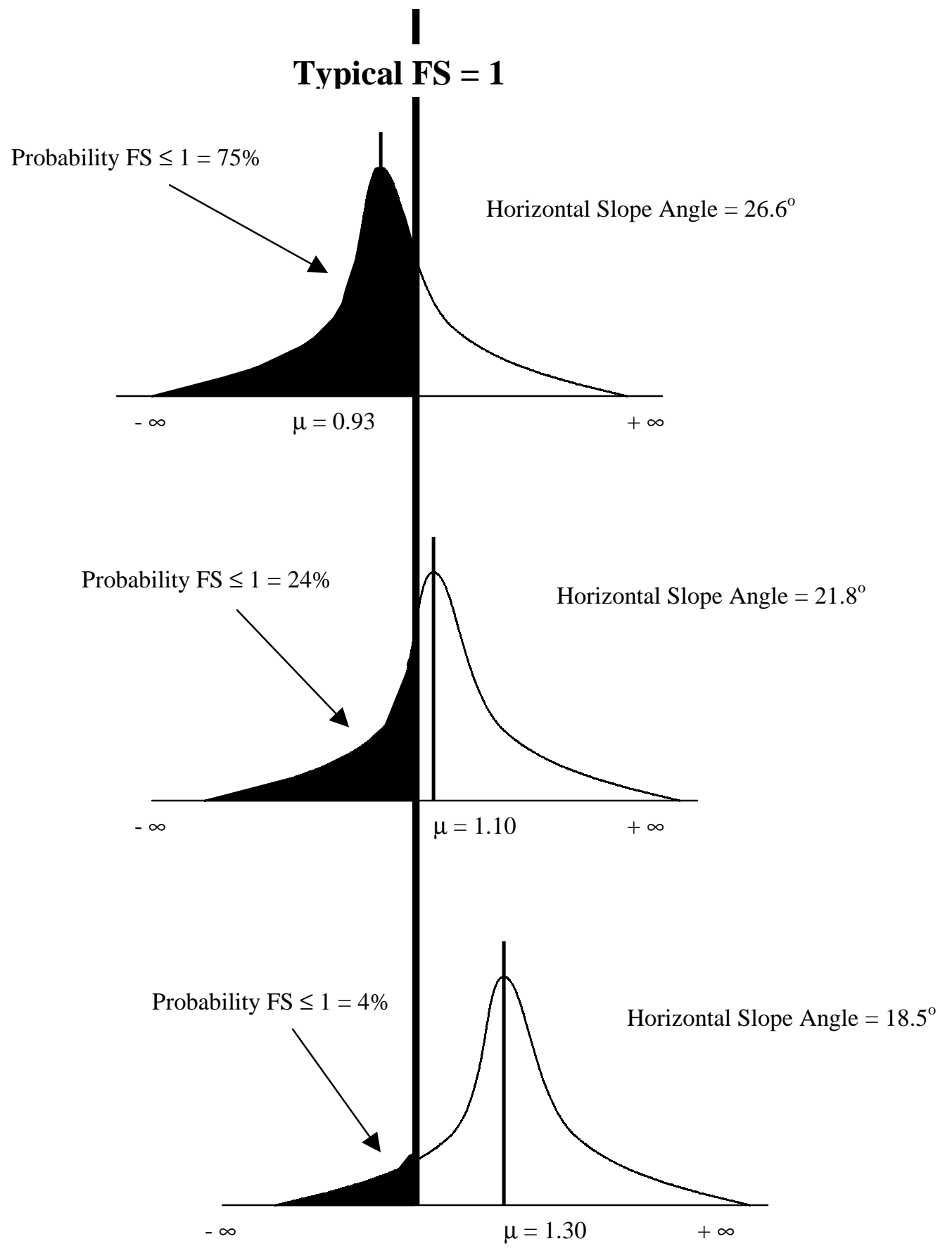

Figure 4-8: Probability Distributions Companing the Mean Factor of Safety's to a Typical FS of 1, Indicating the Area where the Combination of Input Parameters has a Factor of Safety Less than 0 ne 


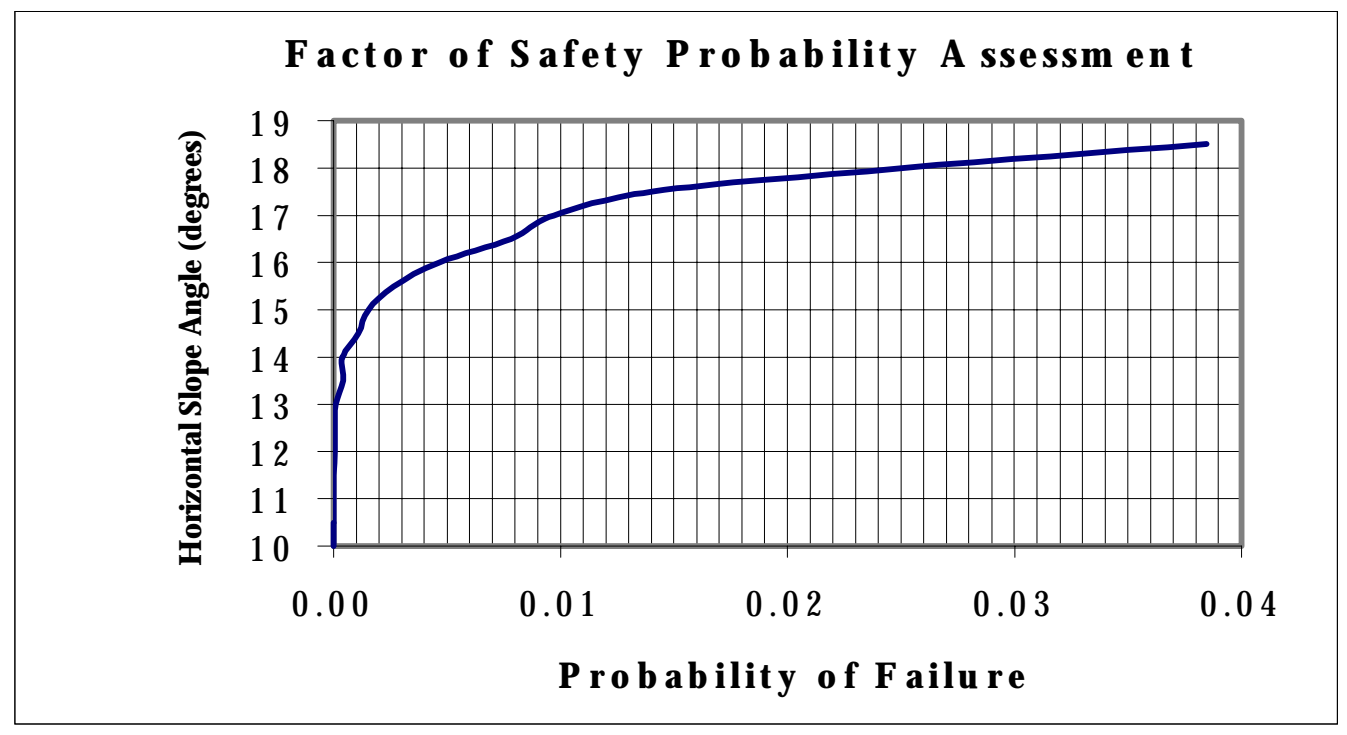

Figure 4-9: Horizontal Slope Angle vs Probability of Failure for an Infinite Slope without Seepage

Table 4-4: Summary of Horizontal Slope Angle Needed to Meet Probability Criteria for an Infinite Slope without Seepage

\begin{tabular}{|c|c|c|}
\hline Conditions & $\begin{array}{c}\text { Criteria for Probability of } \\
\text { Failure }\end{array}$ & $\begin{array}{c}\text { Horizontal Slope } \\
\text { Angle (degrees) }\end{array}$ \\
\hline Temporary Structures with low Repair Cost & 0.1 & 18.5 \\
\hline Existing Large Cut on Interstate Highway & 0.01 & 17 \\
\hline $\begin{array}{c}\text { Acceptable in Most Cases EXCEPT if Lives may } \\
\text { be lost }\end{array}$ & 0.001 & 14.5 \\
\hline Acceptable for all Slopes & 0.0001 & 13 \\
\hline Unnecessarily Low & 0.00001 & 12.5 \\
\hline
\end{tabular}

- The probability distribution for the factor of safety represents the combination of randomly selected uncorrelated input parameters for a constant horizontal slope angle and a slope height of 4 feet. The combination of input parameters where the probability that the factor of safety is less than one, slope failure, ranged from 75 percent to 4 percent for a horizontal slope angle of 26.6 and 18.5 degrees respectively. Thus, from the probability of failure analysis, the findings of McCook that the probability of failure decreases as the horizontal slope angle decreases was confirmed. 
- By reducing the horizontal slope angle from 26.6 to 18.5 degrees, while randomly selecting the soil properties for a constant slope height and horizontal slope angle, the probability of failure was reduced 70 percent when comparing to a factor of safety equal to one. The slope modeled with a horizontal slope angle of 26.6 and 21.8 degrees exceeded the maximum probability of failure indicated in Table 2-2 of 10 percent. For a horizontal slope angle of 18.5 degrees, the 10 percent probability of failure criteria for a temporary structure was met.

- A slope angle of 14.5 degrees is required to satisfy the criteria "acceptable in most cases except if lives may be lost." (Santamarina, Altschaeffl, \& Chameau, 1992)

\subsection{Planar Failure Surface Analysis, Comelated Input Parameters for the Critical Height}

The data and results from Wong's (1985) study were modeled using the methodology presented in Chapter 3. Wong used a finite element method to analyze this slope. His results indicated either a planar or circular failure surface would reasonably approximate the finite element method results for a full slip failure. Both methods were used for this case study analysis.

The data used for the Monte Carlo simulation are given in Table 4-5. Wong reported the unit weight was normally distributed with a coefficient of variation of 2 percent. Wong reported the cohesion and the angle of friction were linearly correlated with the unit weight. This correlation was modeled with the scaling relationship given in equation 4-1.

Table 4-5: Input Parameters for Planar Slope Failure Analysis

\begin{tabular}{|c|c|c|c|c|c|}
\hline \multirow{2}{*}{ Parameter } & \multicolumn{3}{|c|}{ Data from Wong } & \multicolumn{3}{c|}{$\begin{array}{c}\text { Monte Carlo } \\
\text { Simulation } \\
\text { Parameters }\end{array}$} \\
\cline { 2 - 6 } & Xmin & Xmax & COV (\%) & Mean & Std Dev \\
\hline Cohesion & 81 & 110 & 2.0 & 96 & 1.92 \\
\hline Angle of Friction & 34.3 & 38.1 & 2.0 & 36.2 & 0.72 \\
\hline Unit Weight & 106 & 110 & 2.0 & 108 & 2.16 \\
\hline
\end{tabular}




$$
D(\gamma)=D_{\text {Min }}+\left(\frac{\gamma_{\text {Max }}-\gamma_{R}}{\gamma_{\text {Max }}-\gamma_{\text {Min }}}\right)\left(D_{\text {Max }}-D_{\text {Min }}\right)
$$

Equation 4-1

Where:

$$
\begin{aligned}
& D(\gamma)=\text { Dependent Variable: Function of Unit Weight } \\
& D_{\text {Min }}=\text { Minimum D ependent Variable } \\
& D_{\text {Max }}=\text { Maximum D ependent Variable } \\
& \gamma_{\text {Min }}=\text { Minimum Independent Variable, Unit Weight } \\
& \gamma_{\text {Max }}=\quad \text { Maximum Independent Variable, Unit Weight } \\
& \gamma_{R}=\text { Random Selection of Independent Variable, Unit Weight }
\end{aligned}
$$

The analysis performed for the corresponding slope modeled by Wong for correlated input parameters was repeated three times to evaluate the repeatability of the analysis. Table 4-6 shows the output from the Monte Carlo simulation. This model required between 1200 to 800 iterations to converge on the criteria that the computed critical height changes less than 1.5 percent for the parameters: mean, standard deviation, and $95^{\text {th }}$ percentile. The convergence is checked after each 100 iterations. For each run, the minimum, maximum, and average values for the soil parameters were close to the values used as arguments to the normal distribution.

The distributions of the computed critical height are shown in Figures 4-10. A chisquare test was performed to check the critical height distribution for normality. In each case, the hypothesis that the output distributions were normal was accepted at the 95 percent confidence level. The supporting calculations for this conclusion are presented in Appendix B. The critical height distribution for each replicated analysis were statistically compared, verifying there was not a sufficient difference in the distributions to statistically indicate a difference between the outputs of the replicated simulation. The supporting calculations for this conclusion are also presented in Appendix B.

A sensitivity analysis was not preformed for the correlated model since the simulation was only dependent on one parameter, the unit weight. Figure 4-11 shows the scatter diagrams for the input parameter, unit weight versus the factor of safety. 
Table 4-6: Planar Slope Failure Analysis for Comelated Input Parameters Critical Height (ft) Unit Weight (pcf)

\begin{tabular}{|c|c|c|c|c|c|c|c|}
\hline $\begin{array}{l}\text { Horizontal Slope } \\
\text { Angle (degrees) }\end{array}$ & Statistical Parameter & $\mathbf{H}_{\mathrm{cr}}(\mathbf{1})$ & $\mathbf{H}_{\mathrm{cr}}(\mathbf{2})$ & $\mathbf{H}_{\mathrm{cr}}$ (3) & $\gamma(\mathbf{1})$ & $\gamma(2)$ & $\chi(3)$ \\
\hline
\end{tabular}

\begin{tabular}{|c|c|c|c|c|c|c|c|}
\hline \multirow{3}{*}{60} & $\begin{array}{c}\text { Minimum = } \\
\text { Maximum = } \\
\text { Mean = } \\
\text { Std Deviation = } \\
\operatorname{COV~}(\%)=\end{array}$ & $\begin{array}{r}7.80 \\
95.98 \\
30.51 \\
10.62 \\
34.81\end{array}$ & $\begin{array}{c}10.54 \\
65.05 \\
29.85 \\
9.83 \\
32.93\end{array}$ & $\begin{array}{c}6.61 \\
76.14 \\
29.78 \\
10.06 \\
33.78\end{array}$ & $\begin{array}{c}101.14 \\
115.49 \\
107.84 \\
2.18 \\
2.02\end{array}$ & $\begin{array}{c}99.95 \\
14.84 \\
108.04 \\
2.10 \\
1.95\end{array}$ & $\begin{array}{c}101.15 \\
114.98 \\
107.95 \\
2.21 \\
2.04\end{array}$ \\
\hline & $\begin{array}{c}\text { Average Mean } \mathrm{H}_{\mathrm{cr}} \\
\text { Average } \mathrm{H}_{\mathrm{cr}} \text { Std Deviation }\end{array}$ & $\begin{array}{l}30.05 \\
10.17\end{array}$ & & & & & \\
\hline & No. Iterations (n) & 1200 & 600 & 800 & & & \\
\hline
\end{tabular}




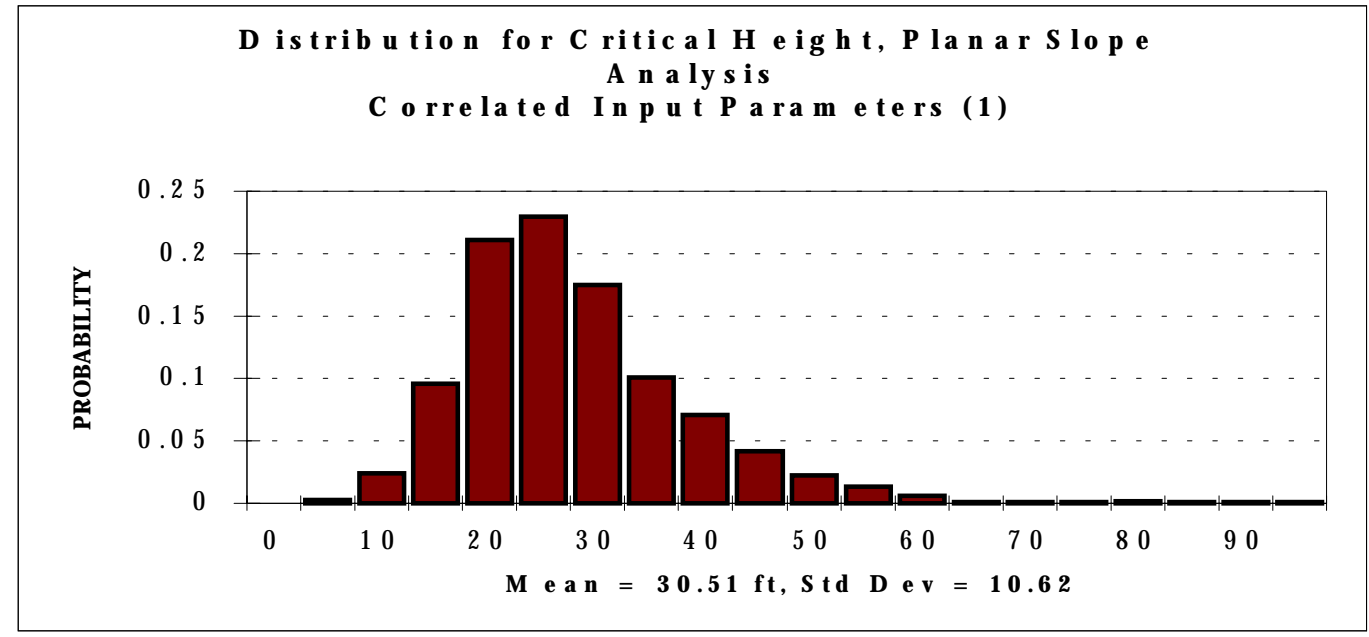

(a) Sim ulation \# 1

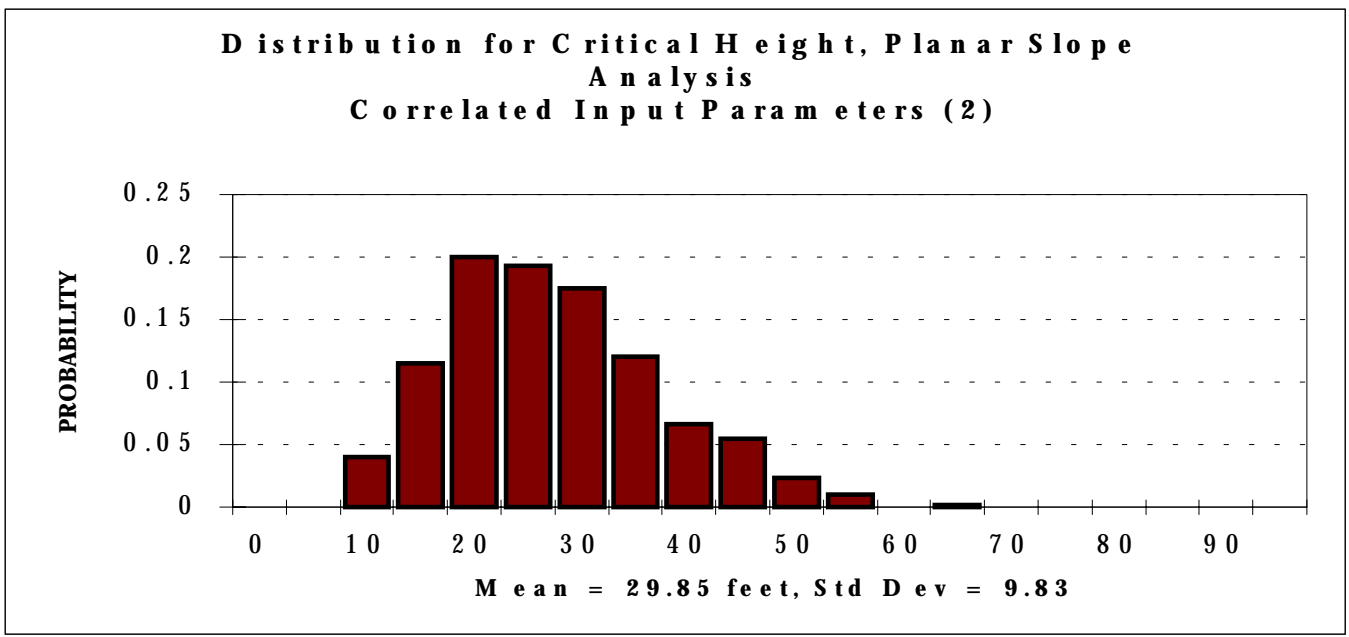

(b) S im ulation \#2

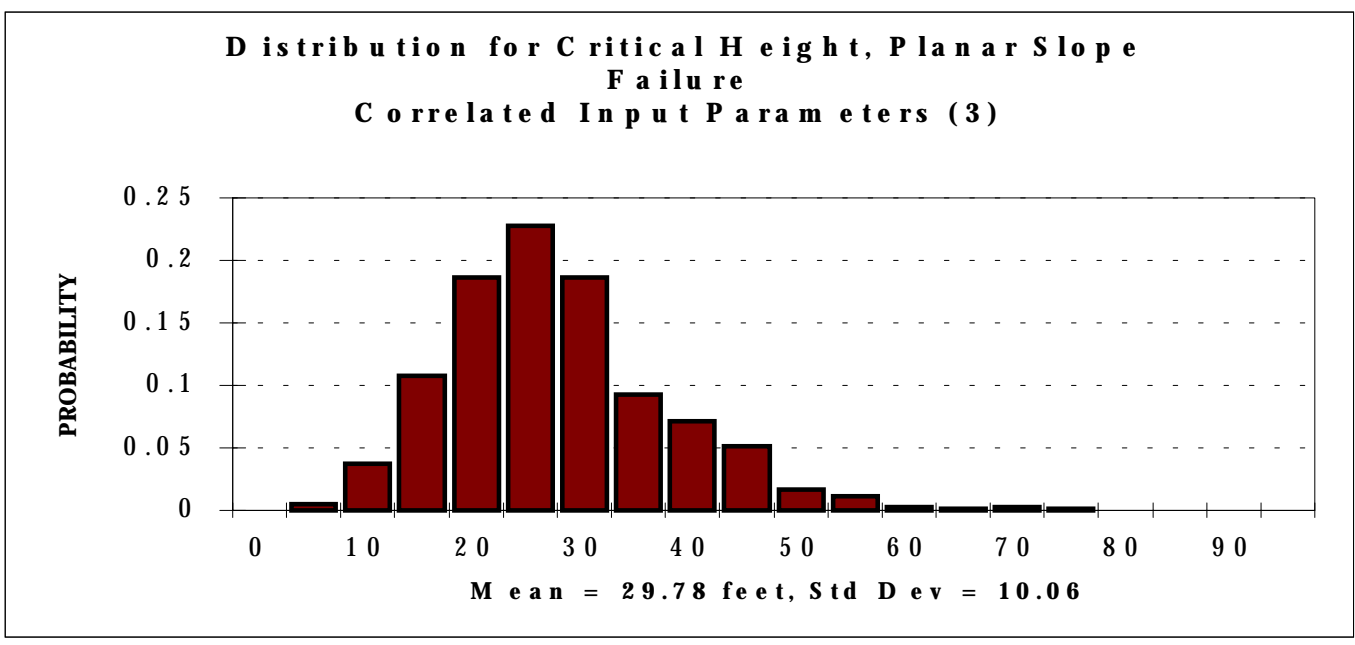

(c) Sim ulation \# 3

Figure 4-10: H istograms for Critical H eight Correlated Input Parameter Analysis 


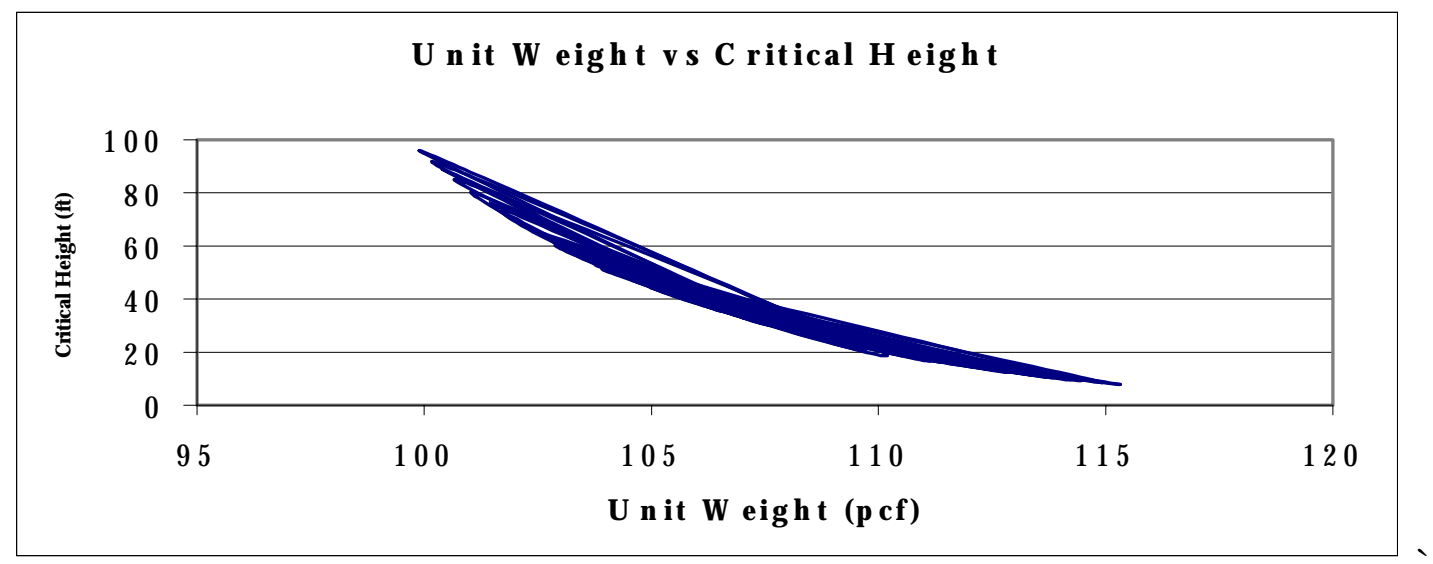

\section{Figure 4-11: Scatter Diagrams, Input Parameter vs Critical Height}

The value of the risk analysis methodology is the ability to determine the probability of a specific event occurring. By definition, the critical height is for a factor of safety equal to one and when a slope is at equilibrium or impending failure. Figure 4-12 shows for correlated input parameters, a probability of failure equal to 40 percent when compared to the failure depth indicated by Wong of 27.5 feet. The 40 percent failure expectation is due to the large standard deviation produced by the Monte Carlo simulation analysis. The standard deviation is large due to the fact that only one parameter, the unit weight, was randomly selected during the analysis. The coefficient of variation of this parameter was approximately 35 percent. Hence, the variability estimated from the Monte Carlo simulation indicates that for a finite slope with a planar failure surface, 40 percent of the time the slope will fail.

The following is a summary of the results and conclusions obtained from the stability analysis of a slope with a planar failure surface for critical height using correlated input parameters.

- The output generated from @ RISK for the critical height of a slope 30.05 feet for correlated input parameters. These critical heights were obtained for the given range of soil material properties that had a COV of 2 percent.

The following is a summary of the results and conclusions obtained from the stability analysis of a slope with a planar failure surface for critical height using uncorrelated input parameters. 


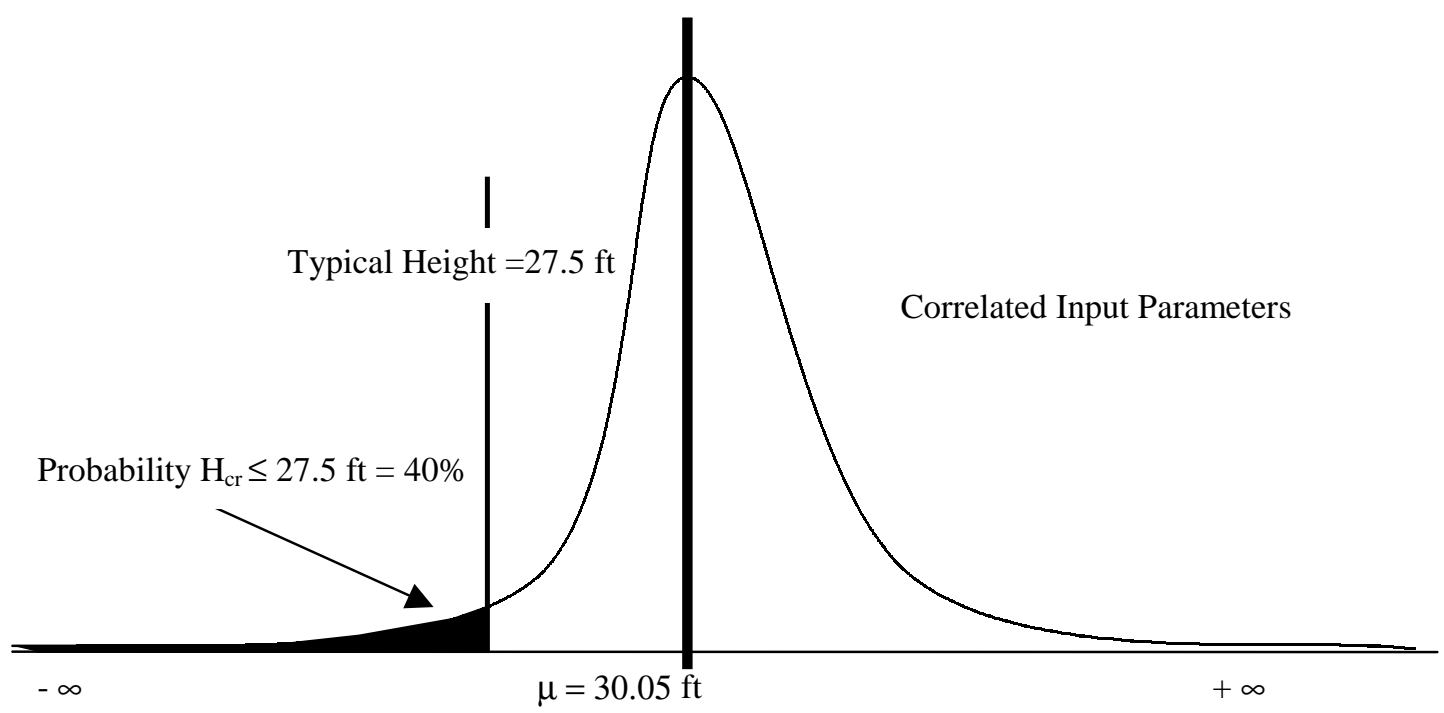

Figure 4-12: Probability Distributions Comparing the Mean Critical Height to a Typical Slope Height of 27.5 feet, Indicating the Area where Combination of Input Parameters Creates Slope Equilibrium or Impeding Slope Failure

- The output generated from @ RISK for the critical height of a slope was 27.14 feet for uncorrelated input parameters. These critical heights were obtained for the given range of soil material properties that had a COV of 2 percent.

- The hypothesis that the output distributions were normally distributed was accepted at the 95 percent confidence interval for the data obtained from the @ RISK simulations for both the uncorrelated input parameters. In addition, a hypothesis test indicated that the critical height distribution for both analyses indicated that there was no statistical difference between the critical height distribution for each analysis.

- The hypothesis that the output distributions were normally distributed was accepted at the 95 percent confidence interval for the data obtained from the @ RISK simulations for both the uncorrelated and correlated input parameters. In addition, a hypothesis test indicated that the critical height distribution for both analyses indicated that there was no statistical difference between the critical height distribution for each analysis.

- The probability distribution for the critical height represents the combination of correlated input parameters for a factor of safety equal to one. The combination of input parameters where slope is in a state of equilibrium or impending slope failure using a typical depth equal to or less than 27.5 feet equaled 40 percent for correlated input 
parameters. Thus from the probability of failure analysis, the maximum acceptable limit for the criteria of failure of 10 percent for a temporary structure was exceeded.

\subsection{Planar Failure Surface Analysis, Uncomelated Input Parameters for the Critical Height}

The previous analysis produced a high standard deviation due primarily to the constraints on the randomization caused by the correlation between the input variables. While the approach used in the previous analysis is correct, the constraints on randomization appears to produce results that are obtainable, but have a resulting high standard deviation and COV. To investigate how the restriction on randomization affected the results, the analysis was repeated under the assumption that the input parameters are uncorrelated. The data in Table 4-5 were used for this analysis.

The results of the analysis are given in Table 4-7. The mean critical height for the uncorrelated analysis was 29.15 feet as compared to 30 feet for the correlated analysis. The standard deviation for the uncorrelated analysis was 1.93 which is five times smaller than the standard deviation of 10.17 for the correlated analysis.

This analysis contradicts the argument that an uncorrelated analysis produces large standard deviations and variances while correlated Monte Carlo analysis produces less variation. The reported results for the uncorrelated analysis indicated a standard deviation of 1.93. This is a direct result of defining the input parameters with a normal distribution. D uring the Monte Carlo simulation and the sampling process, data was sampled outside of the given range of data, thus causing the output to be manipulated. In addition the input data range which was reported by Wong does not account for 95 percent of the sampled data. Instead the data which was reported by Wong actually accounts for over 100 percent of the data range!

The sensitivity analysis demonstrated similar results to the correlated analysis as shown in Table 4-8.

- The sensitivity analysis conducted using a correlation and regression analysis indicated that the angle of friction was the most critical input distribution when analyzing the slope for a planar failure surface. The output distribution was least significantly effected by the unit weight. 


\subsection{Circular Failure Surface Analysis for the Factor of Safety}

The results from Wong's (1985) study indicated a circular failure surface should be considered. The modified Bishop's method of slices is the preferred method for analyzing circular failure surfaces. Since the method requires an iterative solution method, it is not compatible with Monte Carlo simulation. Thus, the response surface method, as described in Chapter 3 was used to develop a predictive equation that can be used in the Monte Carlo simulation. The response surface method was evaluated using PC STABL to obtain the factor of safety for four extreme input parameter cases based on the established range of data. For this analysis, the following input parameters were held constant, the horizontal slope angle $=60$ degrees, unit weight $=108 \mathrm{pcf}$, and the slope height of 27.5 feet as defined 
Table 47: Planar Slope Failure Analysis for Unoonelated Input Parameters

\begin{tabular}{|c|c|c|c|c|c|c|c|c|c|c|c|c|c|}
\hline & & \multicolumn{3}{|c|}{ Crilical Height (fit) } & \multicolumn{3}{|c|}{ Cohesion(ps) } & \multicolumn{3}{|c|}{ Unit WEight (pd) } & \multicolumn{3}{|c|}{ AngleofFridion (degrees) } \\
\hline $\begin{array}{l}\text { Hoivontal Slope } \\
\text { Angle(dagrees) }\end{array}$ & Statistical Parameter & $\mathbf{H}_{\mathbf{r}}(\mathbf{D})$ & $\mathbf{H}_{\mathbf{r}}(\mathbf{2})$ & $\mathbf{H}_{\mathbf{r}}(\mathbf{3})$ & $\mathbf{C}(\mathbf{D})$ & c(2) & C(3) & $\gamma(\mathbb{D})$ & $\gamma(2)$ & $\gamma(3)$ & $\phi(1)$ & $\phi(2)$ & $\phi(3)$ \\
\hline \multirow{8}{*}{60} & Mrimm= & 2371 & 2387 & 2278 & 89.56 & 89.29 & 8875 & 10091 & 101.74 & 101.43 & 3360 & 3402 & 3420 \\
\hline & Meximm = & 3521 & 3544 & 3557 & 101.44 & 100.56 & 101.20 & 11543 & 11347 & 11629 & 3858 & 3845 & 3842 \\
\hline & $\operatorname{Men}=$ & 29.22 & 29.10 & 29.12 & 9528 & 9536 & 9527 & 107.99 & 10808 & 107.84 & 3625 & 3620 & 3619 \\
\hline & StdDeviation = & 1.95 & 1.99 & 1.86 & 1.91 & 1.98 & 1.99 & 223 & 213 & 223 & 0.71 & 0.74 & 0.68 \\
\hline & $\operatorname{COV}(\%)=$ & 668 & 683 & 638 & 200 & 208 & 208 & 206 & 1.97 & 207 & 1.96 & 206 & 187 \\
\hline & AverageMeanH $H_{r}$ & 29.15 & & & & & & & & & & & \\
\hline & Average $H_{r} S t d D e v i d i o n$ & 1.98 & & & & & & & & & & & \\
\hline & No. Iterations (n) & 600 & 500 & 600 & & & & & & & & & \\
\hline
\end{tabular}


Table 4-8: Summary of Sensitivity Analysis for Critical Height, Planar Slope Failure

\begin{tabular}{|c|c|c|}
\hline Input Parameter & $\begin{array}{c}\text { Comelation } \\
\text { Coefficient }\end{array}$ & Std Regression Coefficient \\
\hline Cohesion & 0.30 & 0.33 \\
\hline Angle of Friction & 0.86 & 0.87 \\
\hline Unit Weight & -0.29 & -0.32 \\
\hline
\end{tabular}

Table 4-9: PC ST ABL Evaluation for Response Surface Analysis

\begin{tabular}{|c|c|c|c|}
\hline Input Parameter Combination & Cohesion (psf) & $\begin{array}{c}\text { Angle of Friction } \\
\text { (degrees) }\end{array}$ & $\begin{array}{c}\text { Factor of } \\
\text { Safety }\end{array}$ \\
\hline Most Favorable $(+,+)$ & 110 & 38.1 & 1.01 \\
\hline Least Favorable $(-,-)$ & 80.64 & 34.3 & 0.851 \\
\hline Most and Least Favorable $(+,-)$ & 110 & 34.3 & 0.928 \\
\hline Least and Most Favorable $(-,+)$ & 80.64 & 38.1 & 0.941 \\
\hline Midpoint & 96 & 36.2 & 0.938 \\
\hline
\end{tabular}

by Wong. The input parameters and the resulting factor of safety from the PC STABL evaluation are summarized in Table 4-9.

Next, to develop the deterministic relationship which represented the response surface for a circular surface, a regression analysis was preformed. The following deterministic equation was established to represent Bishop's method for the factor of safety.

$$
F S=-0.37119+0.005082 c+0.02947 \phi-0.000072 c \phi
$$

Equation 4-2

Where:

$$
\begin{array}{lll}
\text { FS } & = & \text { Factor of Safety } \\
\mathrm{C} & = & \text { Cohesion } \\
\phi & = & \text { Angle of Friction }
\end{array}
$$

A midpoint analysis was used to verify the developed regression equation for the response surface. Based on the results of the regression equation, using the midpoint input parameters, the factor of safety equaled 0.933 which is approximately equal to the factor of safety determined from the PC STABL evaluation of 0.938 . Therefore, the regression equation represents a deterministic relationship for a circular slope failure and can be used for the Monte Carlo simulation. 
The distribution for the factor of safety for a circular slope failure was computed using random input parameters for the angle of friction and cohesion to mimic the study conducted by Wong. The analysis was repeated three times to evaluate the repeatability of the analysis. Table 4-10 shows the output from the analysis. The model required between 200 and 600 iterations to converge on the criteria that the computed factor of safety changes less than 1.5 percent for the parameters: mean, standard deviation, and $95^{\text {th }}$ percentile. The convergence was checked after each 100 iterations.

The distribution of the computed factor of safety for each of the analyses run are shown in Figure 4-13. A chi-square test was performed to check the factor of safety distribution for normality. In each case, the hypothesis that the output distributions were normal was accepted at the 95 percent confidence level. The supporting calculations for this conclusion are presented in Appendix B. The factor of safety distribution for each replicated analysis were statistically compared, verifying there was not enough difference in the distributions to statistically indicate a difference between the outputs of the replicated runs for each slope angle. The supporting calculations for this conclusion are also presented in Appendix

Both the correlation and regression sensitivity analyses indicated the angle of friction was the most significant input parameter, followed by cohesion. Figure 4-14 indicates the correlation and regression analysis generated by @ RISK for the modeled slopes.

The Monte Carlo simulation using the response surface method computed the mean factor of safety as 0.93 and the standard deviation as 0.02 for the input parameters. These statistical parameters indicate the factor of safety is equal to or less than one for 99.0 percent of the combinations of input parameters. Clearly any risk consideration of this slope would identify this as an unacceptable situation. Potential explanations for these results include:

1) Wong used a different analysis method. Difference between the Wong's modeling method and the method developed during this research could account for some of the discrepancy.

2) The coefficient of variation in the data reported by Wong was only two percent. Consequently the COV for the Monte Carlo simulation was only two percent. This extremely low amount of variation means that even a slight difference between a selected value and the mean will develop a large area under the normal distribution curve. 
Table 4-10 Factor of Safety, Circular Failure Sunface, Response Sunface Analysis

\begin{tabular}{|c|c|c|c|c|c|c|c|c|c|c|}
\hline \multirow[b]{2}{*}{$\begin{array}{l}\text { Honizontal Slope } \\
\text { Angile (degrees) }\end{array}$} & \multirow[b]{2}{*}{ Statistical Parameter } & \multicolumn{3}{|c|}{ Factor of Safety } & \multicolumn{3}{|c|}{ Cohesion (psf) } & \multicolumn{3}{|c|}{ Angle of Friction (degrees) } \\
\hline & & FS (1) & FS (2) & FS (3) & C (1) & c (2) & c (3) & $\phi(\mathbf{D})$ & $\phi$ (2) & $\phi(3)$ \\
\hline 60 & $\begin{array}{c}\text { Minimum }= \\
\text { Maximum }= \\
\text { Mean }= \\
\text { Std Deviation = } \\
\text { COV }(\%)=\end{array}$ & $\begin{array}{l}0.88 \\
0.99 \\
0.93 \\
0.02 \\
1.79\end{array}$ & $\begin{array}{l}0.88 \\
0.98 \\
0.93 \\
0.02 \\
1.83\end{array}$ & $\begin{array}{l}0.90 \\
0.98 \\
0.93 \\
0.02 \\
1.78\end{array}$ & $\begin{array}{c}88.88 \\
101.31 \\
95.95 \\
1.82 \\
1.90\end{array}$ & $\begin{array}{c}90.25 \\
101.06 \\
96.05 \\
1.92 \\
2.00\end{array}$ & $\begin{array}{c}91.03 \\
100.20 \\
95.82 \\
1.91 \\
1.99\end{array}$ & $\begin{array}{c}34.09 \\
38.69 \\
36.25 \\
0.71 \\
1.95\end{array}$ & $\begin{array}{c}34.11 \\
38.41 \\
36.21 \\
0.75 \\
2.07\end{array}$ & $\begin{array}{r}34.67 \\
38.09 \\
36.21 \\
0.70 \\
1.95\end{array}$ \\
\hline
\end{tabular}

$\begin{array}{cc}\begin{array}{cc}\text { Avrage Mean FS } \\ \text { Average FS Std } \\ \text { Deviation }\end{array} & 0.93 \\ & 0.02\end{array}$

No. Iterations (n)

600

400

200 


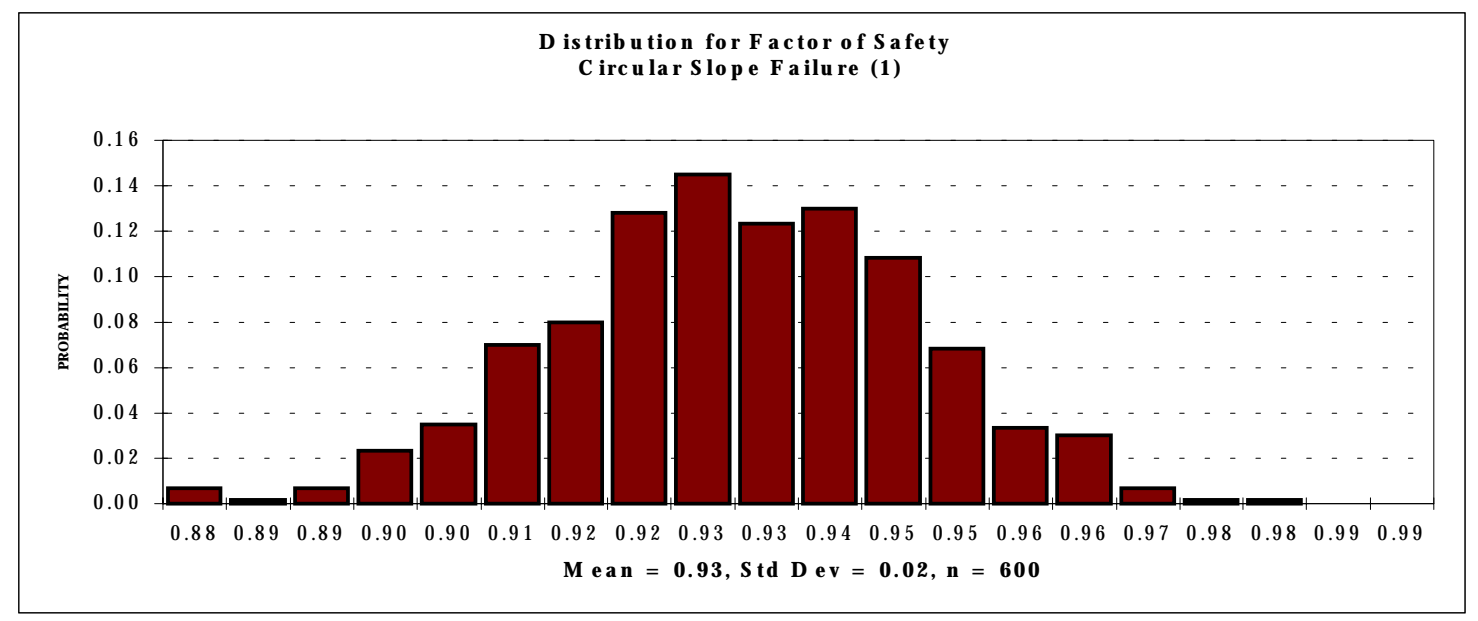

(a) Simulation \# 1

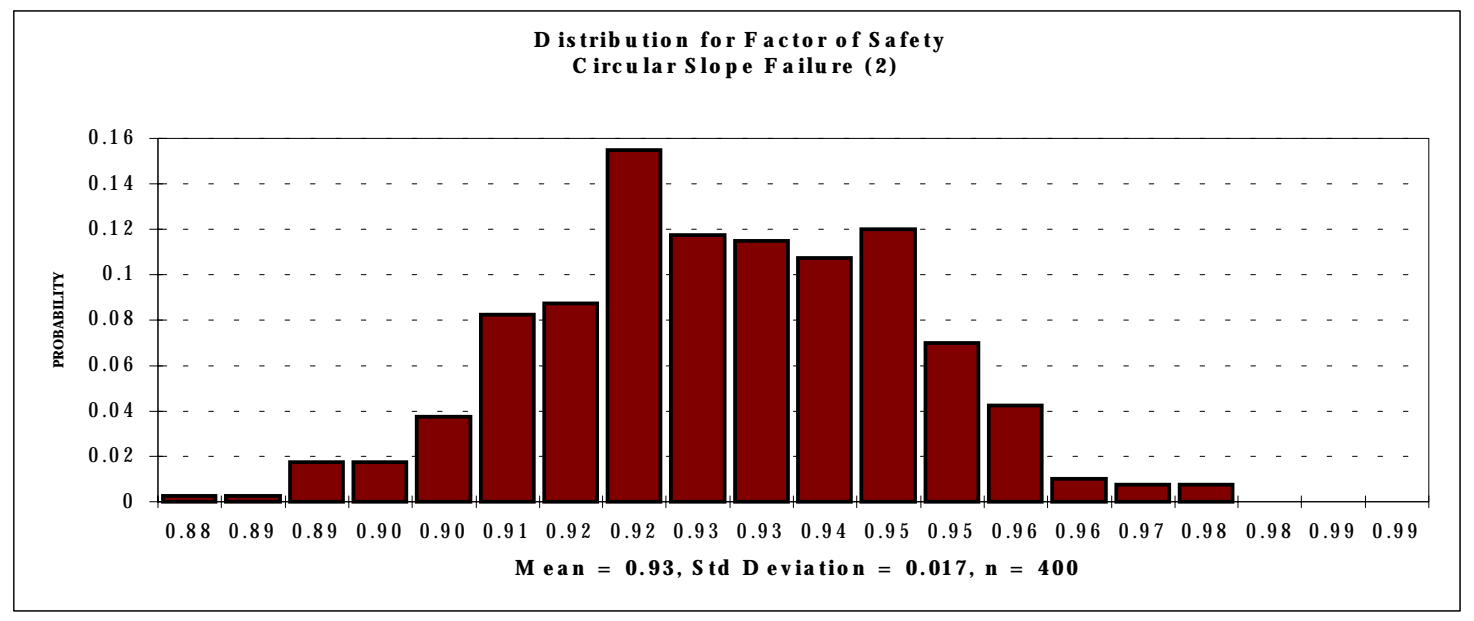

(b) Simulation \#2

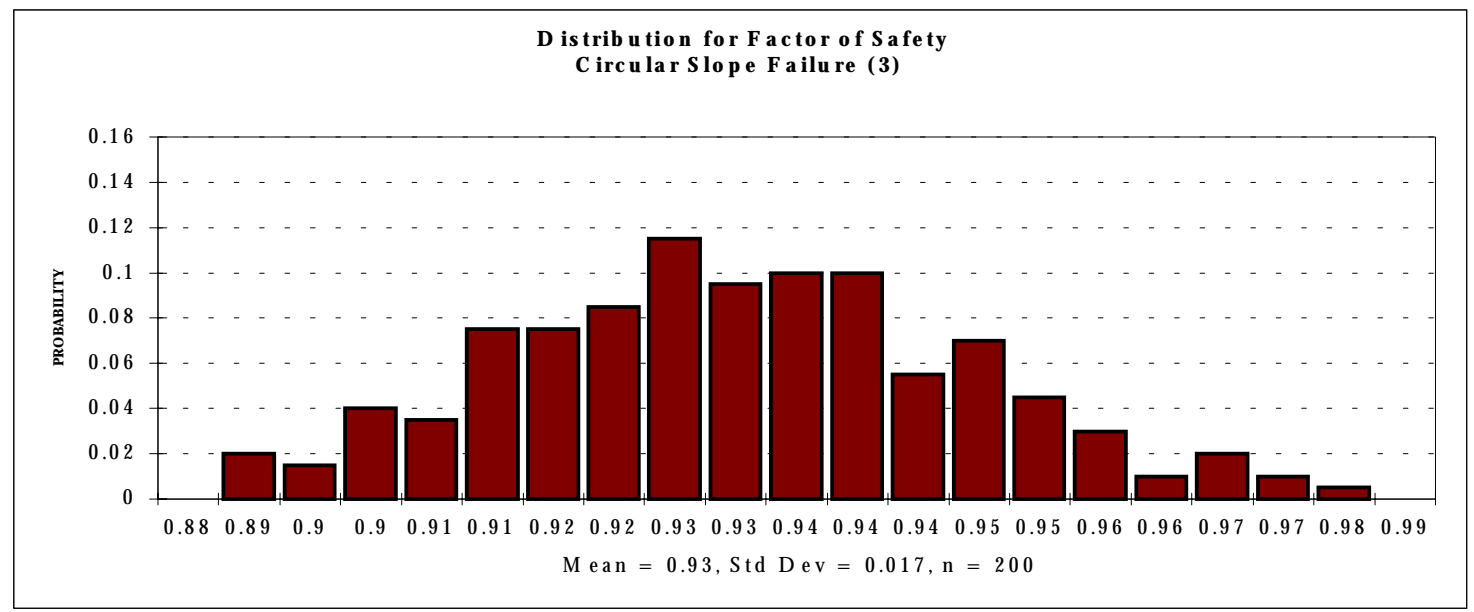

(c) Sim ulation \# 3

Figure 4-13: Histograms for Factor of Safety, Circular Failure Surface 


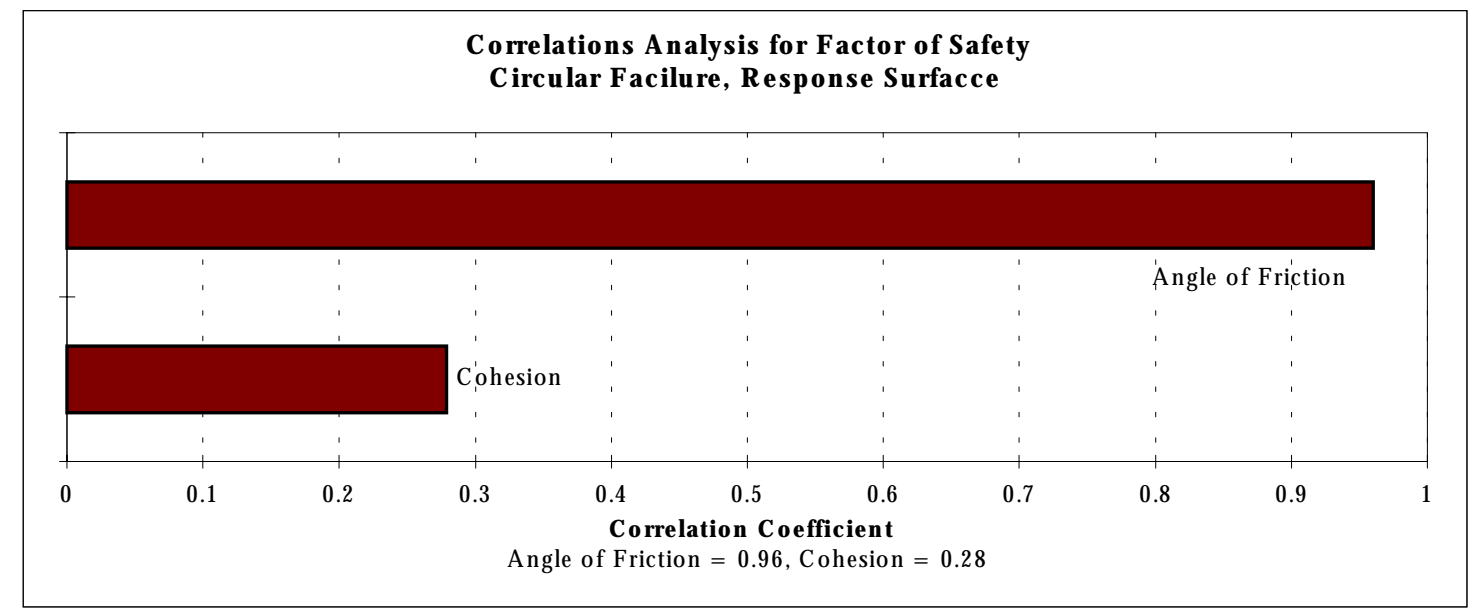

(a) Correlation Sensitivity Analysis

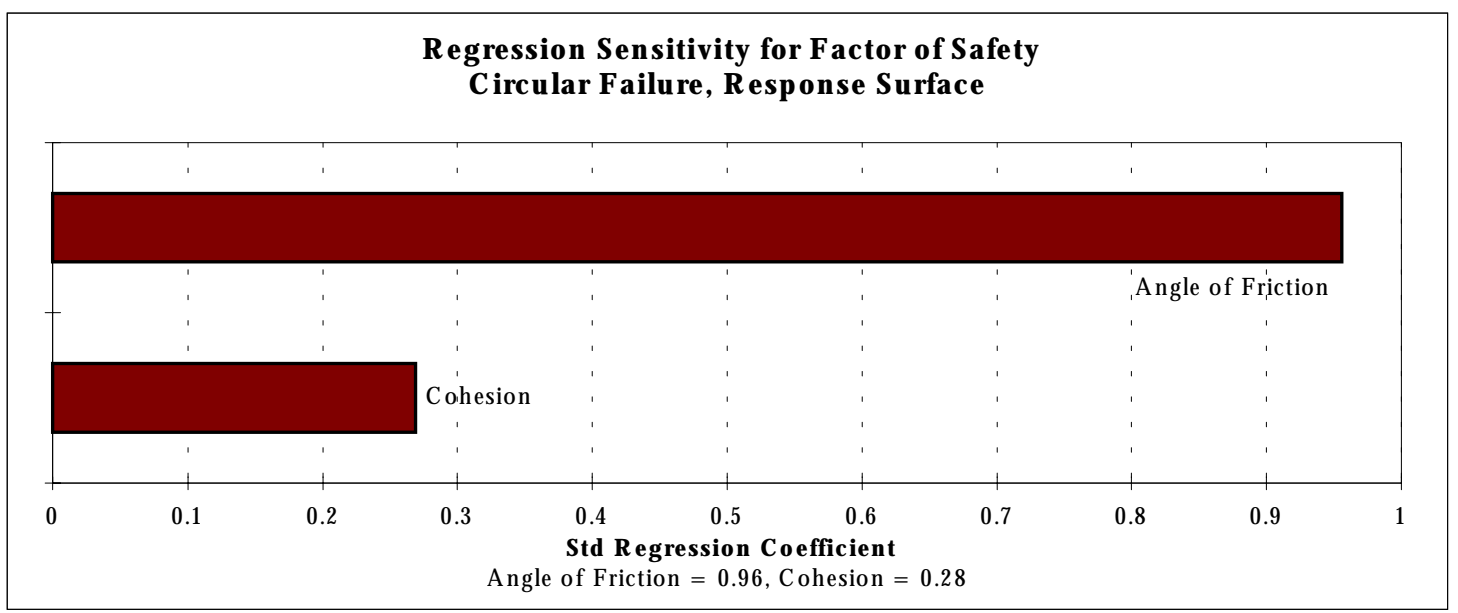

(b) Regression Sensitivity Analysis

Figure 4-14: Sensitivity Analysis for Uncorrelated Input Parameters and Factor of Safety, Circular Failure Surface 
The following is a summary of the results and conclusions obtained from the stability analysis of a slope with a circular failure surface for factor of safety using a response surface analysis in conjunction with a Monte Carlo simulation for uncorrelated input parameters.

- The hypothesis that the output distributions were normally distributed was accepted at the 95 percent confidence interval for the data obtained from the @ RISK simulations for the uncorrelated input parameters. In addition, a hypothesis test indicated that the factor of safety distributions for the analysis indicated that there was no statistical difference between the factor of safety distribution for each analysis.

- The sensitivity analysis conducted using a correlation and regression analysis indicated that the angle of friction was the most critical input distribution when analyzing the slope for a circular failure surface followed by cohesion. The sensitivity analysis confirms the expected significance of each input parameter.

- The probability distribution for the factor of safety represents the combination of randomly uncorrelated input parameters for a circular slope failure analysis.

- From the probability distribution function analysis, for a factor of safety equal to or less than one, 99.0 percent of the time a slope with randomly selected uncorrelated input parameters will fail.

- The mean factor of safety from this analysis was 0.93 . This was expected as the midpoint factor of safety from the Modified Bishop's Method of slices was 0.938 and the model used in the Monte Carlo simulation was a simple linear regression equation with one interactive term. Thus, the Monte Carlo simulation appears to behave to expectations. If results of this analysis are to be challenged, the primary source for concern would be with the results obtained from the modified Bishop's Method of slices. Thus, the objectives for this portion of the research were accomplished. Validation of the modified Bishop's Method of slices is not concern or an objective of this research. 


\section{Chapter 5 \\ CONCLUSIONS AND RECOMMENDATIONS}

\subsection{Summary}

Research has shown that slope stability is a probabilistic situation. Inherent variability in soil parameters and simplifying assumptions in modeling equations constrains the ability of engineers to analyze and design slopes when using a deterministic analysis to adequately determine the associated level of risk. Consequently engineers resort to a factor of safety approach for evaluating slopes. However, the risk associated with this approach cannot be quantified. This has lead to the use of probabilistic models for slope stability analysis and resulting risk based criteria for slope stability design and analysis.

The research presented herein developed a risk based slope analysis method using Monte Carlo simulation. D eterministic models for slope analysis were implemented into the @ RISK program. In addition, the response surface methodology was developed to interface the modified Bishop's method of slices, with the Monte Carlo simulation. Thus, the complete range of traditional slope analysis methods were incorporated in this study.

To demonstrate the capabilities of this methodology, two case studies were evaluated with the Monte Carlo simulation method. O ne used an infinite slope without seepage and the other used both planar and circular analysis methods.

\subsection{Conclusions}

Based on the results obtained from the two studies modeled, the use of a Monte Carlo simulation to determine the probability of slope failure appears to be an acceptable analysis method. The analysis technique can determine the distribution for either the factor of safety or the critical height of a slope. In addition, any slope failure geometry can be examined using a Monte Carlo simulation.

Infinite slope failures, planar slope failures, and circular slope failures in homogeneous clays are modeled with deterministic equations which may be used directly in the Monte Carlo simulation. Other circular slope failures are analyzed with the modified 
Bishop's method of slices. This method requires an iterative solution process which is incompatible with a Monte Carlo simulation. This obstacle was resolved by using the response surface method. This method produces a regression model developed from the prediction modified Bishop's method for a given slope. The regression model is then used in the Monte Carlo simulation. The marriage of the response surface method with the Monte Carlo simulation extends the probabilistic analysis to all slope types.

It is generally accepted that soil parameters have a normal distribution. However, when the Monte Carlo simulation was performed for an infinite slope case, untenable results were obtained due to sampling from the tails of the distribution. To resolve this conflict, the input data were assumed to have a PERT distribution. Simulations using the PERT distribution produced reasonable results. Further, a chi-square test of the input parameters generated with the PERT distribution indicated no significant difference from a normal distribution. It was concluded from this analysis that the PERT distribution may better describe soil parameters than the normal distribution, particularly when the range of the data is constrained by physical limitations.

From the sensitivity analysis preformed for each case study, the unit weight of the soil was found to be the least significant input parameter for determining the stability of a slope for either a factor of safety or critical height analysis. Cohesion and the angle of friction were found to be the most significant input parameters for the slopes modeled. Therefore, determining the exact unit weight distribution of soil for a probabilistic analysis is less critical than cohesion and the angle of friction.

One restriction of Monte Carlo simulations is the input parameters should be uncorrelated. The author of one case study reported that cohesion and the angle of friction were linearly correlated with unit weight. To examine the effect of incorrectly modeling correlated inputs under a false assumption, the Monte Carlo simulation was performed using both the correlated and uncorrelated assumptions. The output parameter was critical height. Assuming the parameters were uncorrelated increased the computed mean by 10 percent. However, the standard deviation was six times larger under the uncorrelated assumption. This analysis highlights the need to correctly examine input parameters for correlation prior to performing a Monte Carlo simulation analysis.

The design of any civil engineering structure involves risk. This is especially true for slopes where native material and environmental conditions have a strong influence on 
performance. Traditionally this risk is minimized through the use of factors of safety and conservative input parameters. However, the level of risk associated with this approach cannot be quantified. If the analysis and design are not conservative enough, an excessive number of slopes will fail. On the other hand, there are negative economic consequences associated with design and analysis methods which are too conservative. The risk based criteria developed by Santamarina, Altschaeffl, and Chameau (1992), presents an approach to deciding on an acceptable level of risk based on the consequences of failure. The Monte Carlo simulation developed in this research provides a methodology for estimating the distribution of outcomes for estimating the distribution of outcomes so the associated risk can be determined.

\subsection{Recommendations}

This research demonstrated the feasibility of probabilistic slope analysis. However, before this research is implemented into practice several issues need further development and refinement.

- Data collection of soil input parameters needs to be amplified to obtain sufficient information to quantify the distribution of soil parameters and slope geometry.

- The analysis of data must include an evaluation of the correlation between variables using statistical methods.

- @ RISK has the capability of analyzing partially correlated data. This feature should be further evaluated.

- The approach was validated using two case studies. The number of case studies should be expanded to improve confidence in the method.

- The probability of failure criteria was drawn from a single research project. The recommendations for this project should be further validated to produce universally acceptable criteria.

Finally, probability analysis methods are somewhat foreign to many practicing engineers. Implementation of a risk based procedure for the design and analysis of sloes will require further education regarding the benefits of probabilistic methods relative to deterministic methods. 


\section{REFERENCES}

@ RISK M anual. (1997). Newfield, NY: Palisade Corporation.

Alonso, E. (1976). Risk Analysis of Slopes and its Application to Slopes in Canadian Sensitive Clays. G eotechnique, 26, 453-472.

Brizendine, A. (1997). Risk Analysis of Levees. (D octoral Dissertation, West Virginia University, 1997).

Chandler, D . (1996). Monte Carlo Simulation to Evaluate Slope Stability. U ncertainity in the $\mathrm{G}$ eologic $\mathrm{E}$ nvironment, 474-493.

Christian, J., Ladd, C., \& Baecher, G. (1994). Reliability Applied to Slope Stability Analysis. Journal of $\mathrm{G}$ eotechnical E ngineering, 120, 2180-2207.

Chowdhury, R. (1984). Recent D evelopments in Landslide Studies: Probabilistic Methods State-of-the-Art-Report - Session VII (a). IV International Symposium on $\mathrm{L}$ andslides, 209-228.

Das, B. (1994). Principles of G eotechnical E ngineering. Boston: PWS Publishing Company.

Gaylord, E., Gaylord, C., \& Stallmeyer, J., (1997). Structural E ngineering H andbook. New York: McGraw-Hill Book Company.

Harr, M., (1977). M echanics of Partiaulate M edia. New York: McG raw-Hill Book Company.

Hunt, R., (1984). G eotechnical E ngineering Investigation M anual. New Y ork: McG raw-Hill Book Company.

Hutchinson, S. \& Bandalos, D. (1997). A Guide to Monte Carlo Simulation Research for Applied Researchers. Journal of V ocational E ducation Research, 22, 233-245.

Li, K., \& Lumb, P. (1987). Probabilistic D esign of Slopes. Canadian G eotechnical Journal, 24, 520-535.

McCook, D., (1996). Surficial Stability of Compacted Clay: Case Study. Journal of $\mathrm{G}$ eotechnical E ngineering, 112, 246-247.

Mendenhall, W., Beaver, R., \& Beaver, B. (1999). Introduction to Probability and Statistics. New York: Duxbury Press. 
Modarres, M. (1993). W hat E very E nginer Should Know A bout Reliability and Risk A nalysis. New Y ork: Marcel D ekker, Inc.

Santamarina, J., Altschaeffl, A., \& Chameau, J. (1992). Reliability of Slopes:

Incorporating Q ualitative Information. T ransportation Research Reord 1343, $1-5$.

Steger, J., (1971). Readings in Statistics F or the Behavioral Scientist. New Y ork: Holt, Rinehart and Winston, Inc.

Tang, W. , Y ucemen, M., \& Ang, A. (1976). Probability-Based Short Term D esign of Soil Slopes. Canadian G eotechnical Journal, 13, 201-215.

Thornton, S., (1994). Probability Calculation for Slope Stability. C omputer M ethods and A dvanoes in $\mathrm{G}$ eomechanics. 2505-2509.

Tobutt, D . (1982). Monte Carlo Simulation Methods for Slope Stability. C omputers \& G eosciences, 8, 199-208.

Transportation Research Board (TRB) Special Report 247 - L andslides: Investigation and Mitigation. (1996). Washington D .C.: National Academy Press.

Whitman, R. (1984). Evaluating Calculated Risk in G eotechnical Engineering. Journal of $\mathrm{G}$ eotechnical E ngineering, 110, 145-185.

Wong, F. (1985). Slope Reliability and Response Surface Method. Journal of G eotechnical E ngineering, 111, 32-53.

www.ecn.purdue.edu/STABL (August, 1999) 


\section{Appendix A:}

(McCook, 1996) 
Simulation 1 and Simulation 2 for 26.6 Factor of Safety

\begin{tabular}{|c|c|c|c|c|c|}
\hline mean $x 1$ & mean $\mathbf{x} 2$ & std $x 1$ & std $x 2$ & & n1 \\
\hline 0.92 & 0.92 & 0.12 & 0.12 & & 600 \\
\hline $\mathrm{m} \times 1-\mathrm{m} \times$ & & std $1 / n 1$ & std $2 / \mathrm{n} 2$ & & \\
\hline 0 & & 0.0002 & 0.00024 & 0.00044 & \\
\hline
\end{tabular}

$$
\begin{array}{cc} 
& \text { Right } \\
+ \text { or - } & 0.041113
\end{array}
$$

\begin{tabular}{|lll|}
\hline-0.041113 & 0 & 0.0411133 \\
\hline
\end{tabular}

Do Not Reject Hypothesis

Simulation 2 and Simulation 3 for 26.6 Factor of Safety

$\begin{array}{ccccc}\text { mean x2 } & \text { mean x3 } & \text { std x2 } & \text { std x3 } & \\ 0.92 & 0.93 & 0.12 & 0.12 & \\ & & & & \\ \mathbf{m ~ x 2 - m ~ x 3 ~} & & \text { std 2/n2 } & \text { std 3/n3 } & \\ -0.01 & & 0.00024 & 0.0006 & 0.00084\end{array}$

Simulation 1 and Simulation 3 for 26.6 Factor of Safety

$\begin{array}{ccccc}\text { mean x1 } & \text { mean x3 } & \text { std x1 } & \text { std x3 } & \\ 0.92 & 0.92 & 0.12 & 0.12 & \\ & & & & \\ \text { m x1-m x3 } & & \text { std 1/n1 } & \text { std 3/n3 } & \\ 0 & & 0.0002 & 0.0006 & 0.0008\end{array}$

$\begin{array}{cc}\mathbf{n 2} & \mathbf{n 3} \\ 500 & 200\end{array}$

$\begin{array}{cc}\mathbf{n 1} & \mathbf{n 3} \\ 600 & 200\end{array}$

$$
\text { Right }
$$

\begin{tabular}{|lll|}
-0.066806 & -0.01 & 0.0468062 \\
\hline
\end{tabular}

Do Not Reject Hypothesis

$$
\text { +or - } \quad 0.055437
$$

\begin{tabular}{lll}
-0.055437 & 0 & 0.0554372 \\
\hline
\end{tabular} Do Not Reject Hypothesis 
Table A-2: Chi Square Test for Evaluating Fit of N ormal Curve

Infinite Slope without Seepage, $\beta=26.6^{\circ}$ (1)

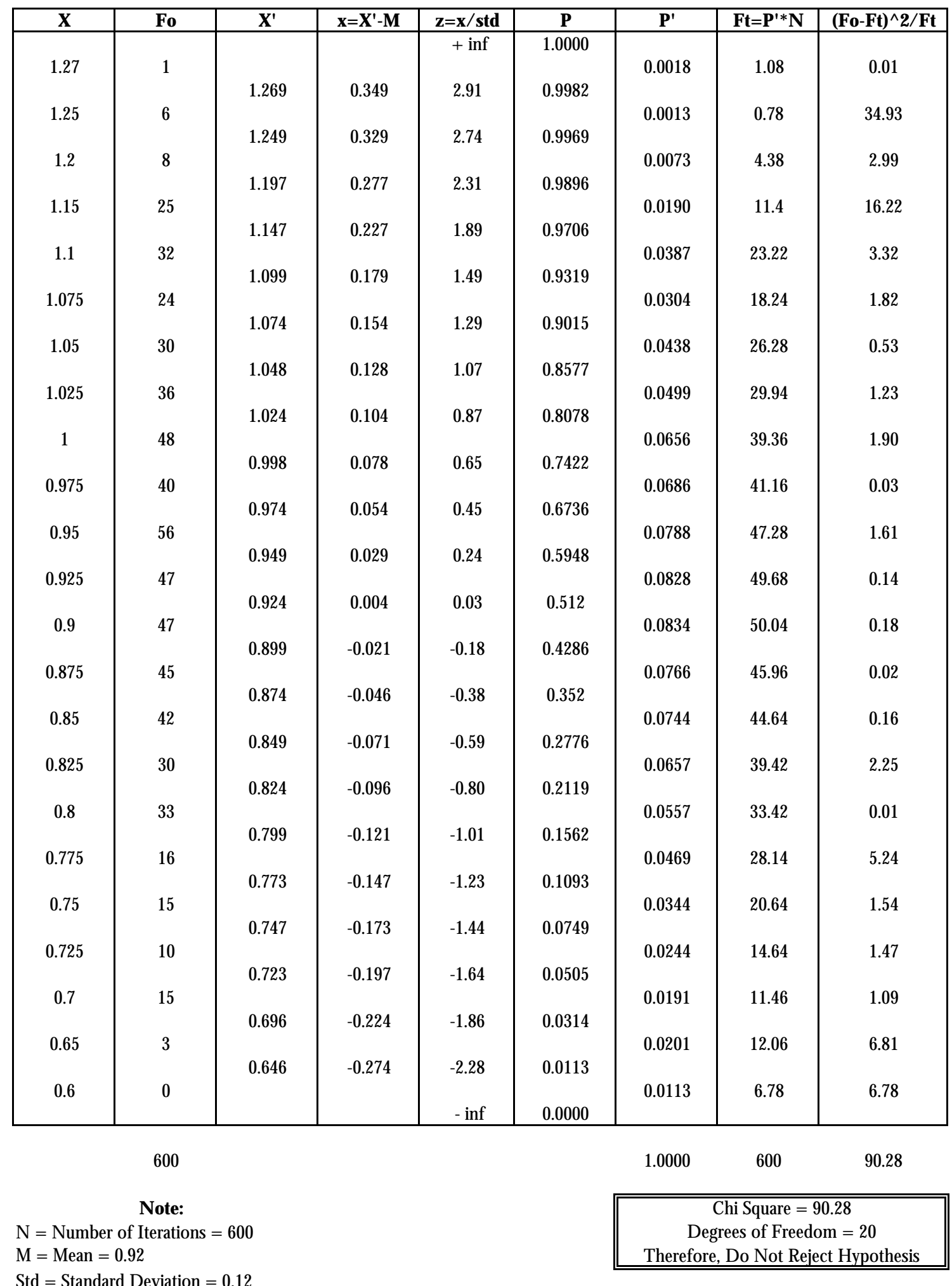

Std $=$ Standard D eviation $=0.12$

D egrees of Freedom $=23-3=20$ 
Table A-3: Chi Square Test for Evaluating Fit of N ormal Curve

Infinite Slope without Seepage, $\beta=26.6^{\circ}$ (2)

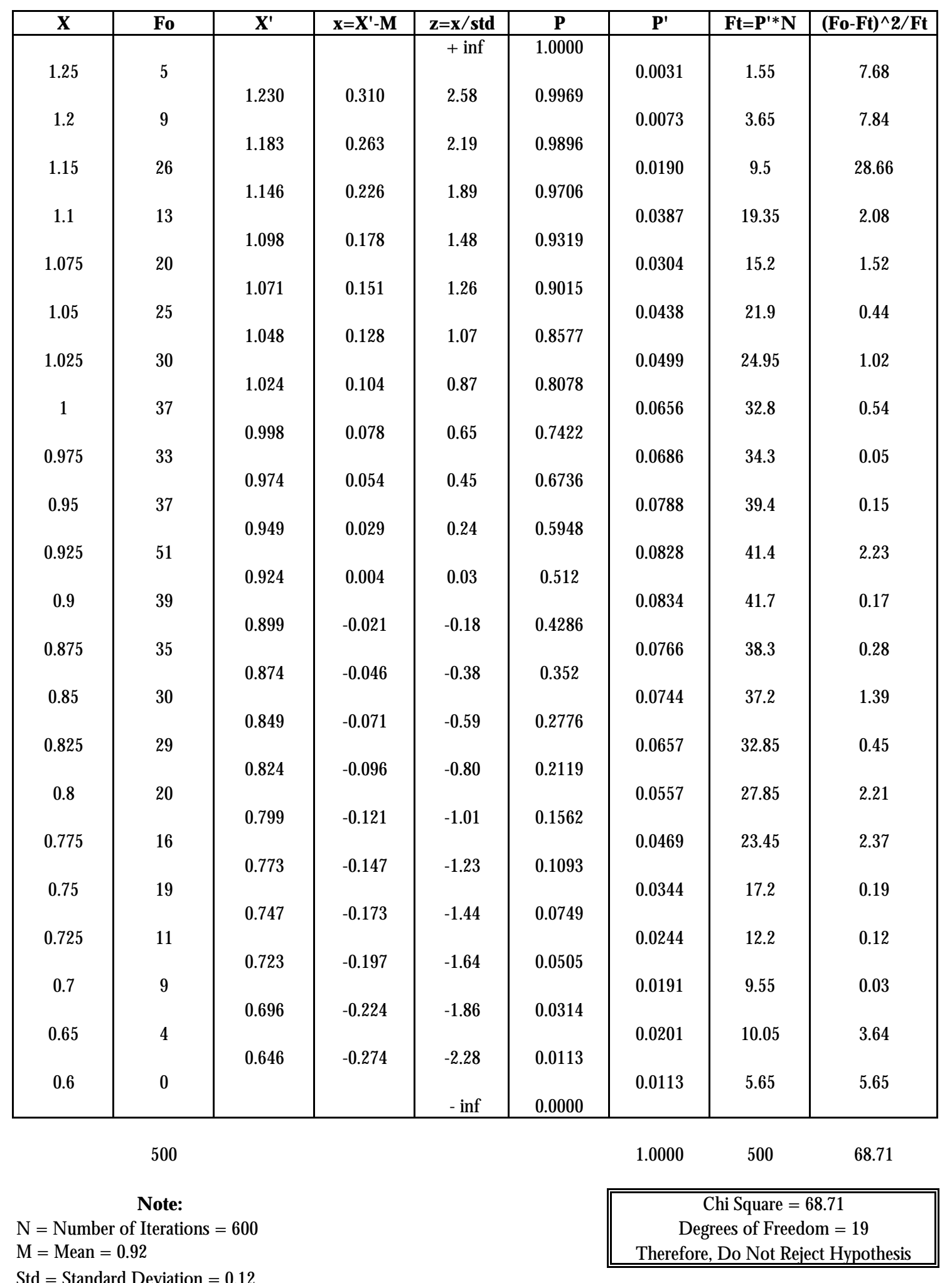

D egrees of Freedom $=23-3=19$ 
Table A-4: Chi Square Test for Evaluating Fit of N ormal Curve Infinite Slope without Seepage, $\beta=26.6^{\circ}$ (3)

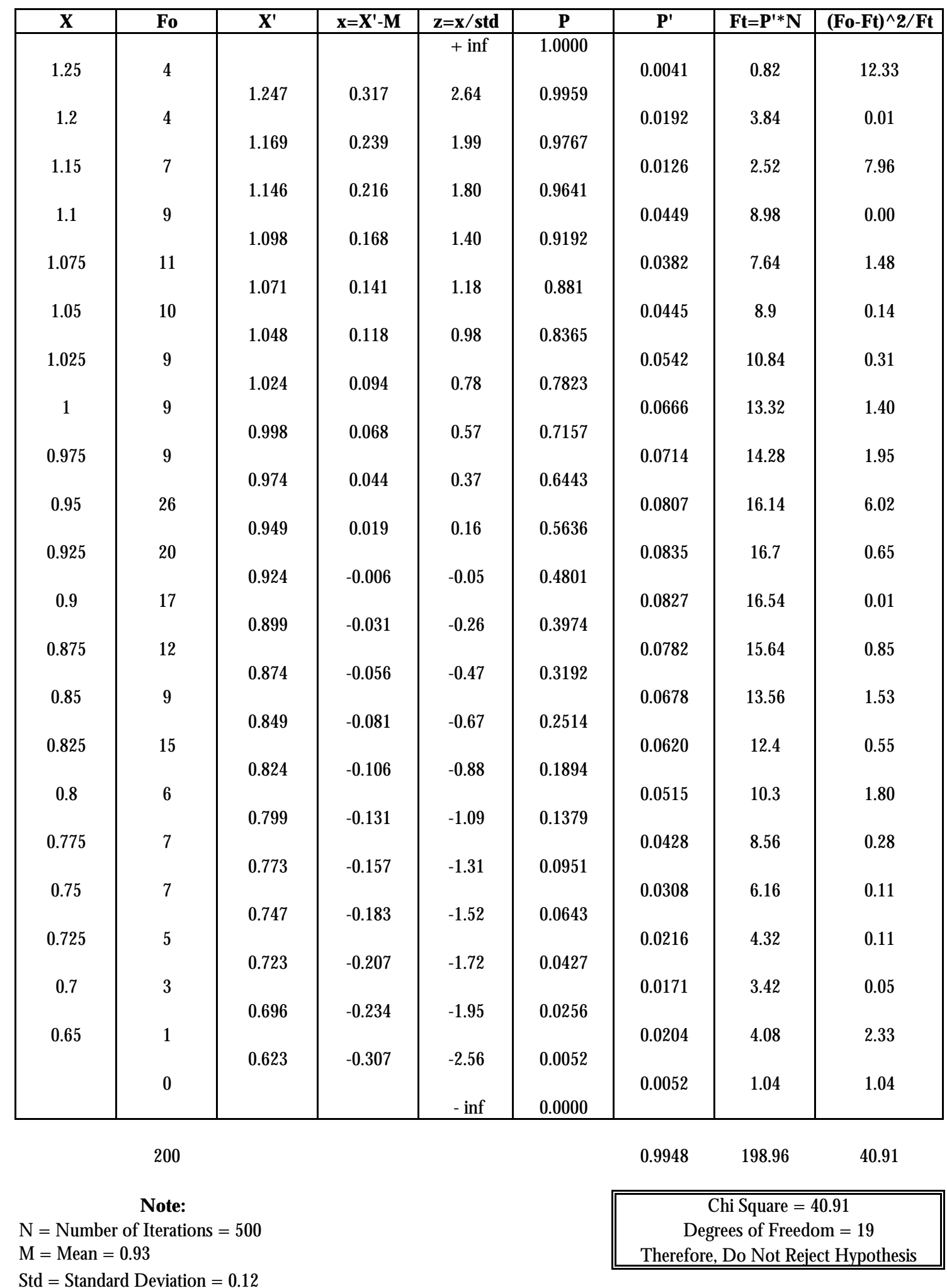

D egrees of Freedom $=21-3=18$ 
Simulation 1 and Simulation 2 for 21.8, Factor of Safety

$\begin{array}{cccccc}\text { mean x1 } & \text { mean x2 } & \text { std x1 } & \text { std x2 } & \text { n1 } & \text { n2 } \\ 1.1 & 1.103 & 0.14 & 0.139 & 500 & 400\end{array}$

m x1-m x2

$-0.003$

std 1/n1 std 2/n2

$\begin{array}{lll}0.00028 & 0.000348 & 0.000628\end{array}$

Simulation 2 and Simulation 3 for 21.8, Factor of Safety

$\begin{array}{ccccc}\text { mean x2 } & \text { mean x3 } & \text { std x2 } & \text { std x3 } & \\ 1.103 & 1.103 & 0.139 & 0.14 & \\ & & & & \\ \mathbf{m} \mathbf{x} 2-\mathbf{m} \mathbf{x} 3 & & \mathbf{s t d} \mathbf{2} / \mathbf{n} \mathbf{2} & \mathbf{s t d} \mathbf{3} / \mathbf{n} 3 & \\ 0 & & 0.000348 & 0.0002 & 0.000548\end{array}$

Simulation 1 and Simulation 3 for 21.8, Factor of Safety

$\begin{array}{cccccc}\text { mean x1 } & \text { mean x3 } & \text { std x1 } & \text { std x3 } & \text { n1 } & \text { n3 } \\ 1.1 & 1.103 & 0.14 & 0.14 & 500 & 700\end{array}$

m x1-m x3

std $1 / n 1 \quad$ std $3 / \mathbf{n} 3$

n2 n3

$400 \quad 700$

$-0.003$

$\begin{array}{lll}0.00028 & 0.0002 & 0.00048\end{array}$

$$
\begin{array}{rr}
\text { Right } \\
+ \text { or }-\quad 0.049098
\end{array}
$$$$
\begin{array}{|lll|}
\hline-0.052098 & -0.003 & 0.046098 \\
\hline
\end{array}
$$$$
\text { Do Not Reject Hypothesis }
$$

$$
\begin{array}{cc} 
& \text { Right } \\
+ \text { or - } & 0.045861
\end{array}
$$

\begin{tabular}{|lll|}
\hline-0.045861 & 0 & 0.045861 \\
\hline
\end{tabular}

Do Not Reject Hypothesis

$$
\begin{array}{cc} 
& \text { Right } \\
\text { + or }- & 0.042941
\end{array}
$$

\begin{tabular}{|lll|}
\hline-0.045941 & -0.003 & 0.039941 \\
\hline
\end{tabular}

Do Not Reject Hypothesis 
Table A-6: Chi Square Test for Evaluating Fit of Normal Curve

Infinite Slope without Seepage, $\beta=218^{\circ}$ (1)

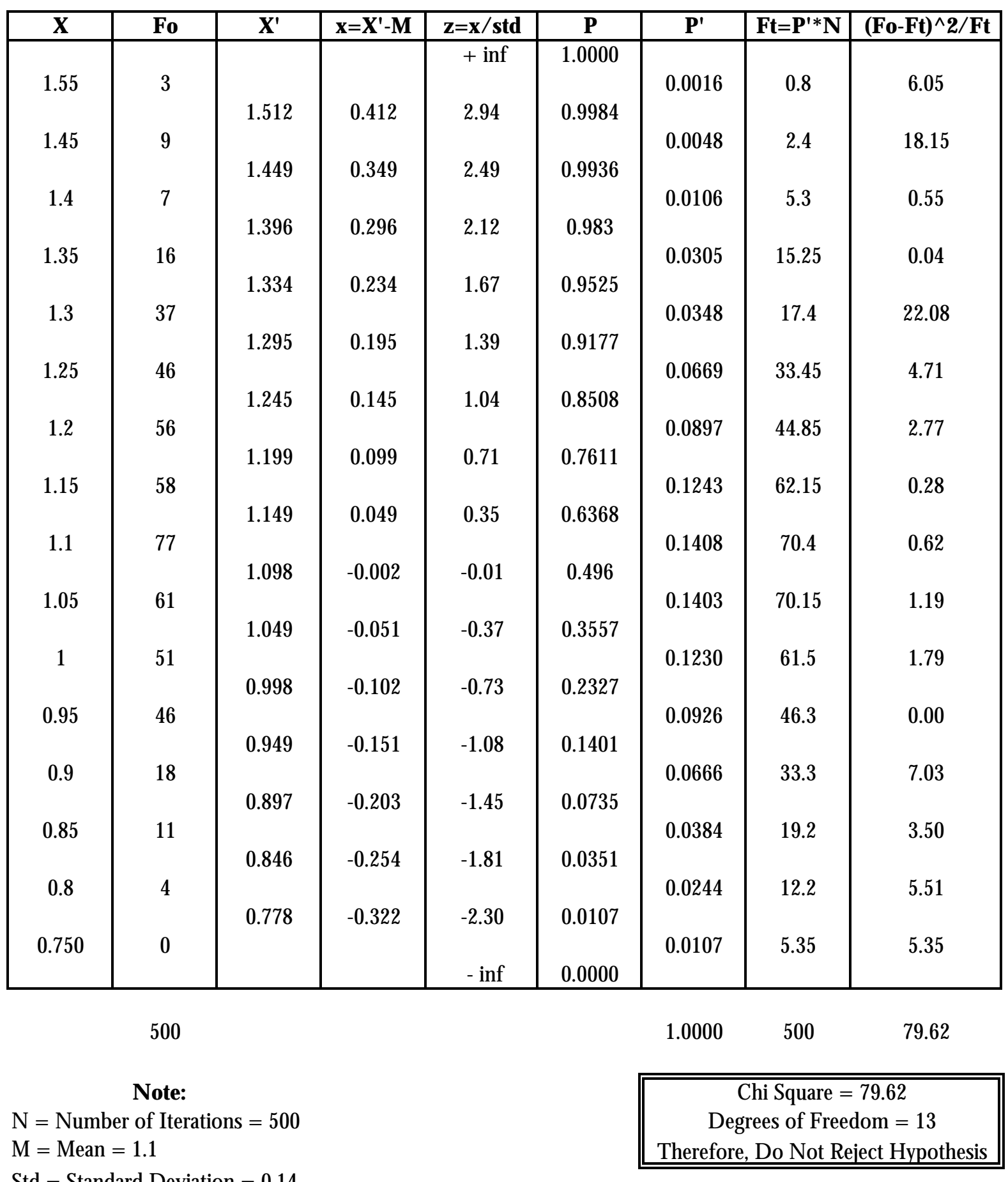

Std $=$ Standard D eviation $=0.14$

D egrees of Freedom $=16-3=13$ 
Table A-7: Chi Square Test for Evaluating Fit of Normal Curve Infinite Slope without Seepage, $\beta=21.80$ (2)

\begin{tabular}{|c|c|c|c|c|c|c|c|c|}
\hline $\mathbf{X}$ & Fo & $\mathbf{X}^{\prime}$ & $\mathbf{X}=\mathbf{X}^{\prime}-\mathbf{M}$ & $\mathrm{z}=\mathrm{x} / \mathrm{std}$ & $\mathbf{P}$ & $\mathbf{P}^{\prime}$ & $\mathbf{F t}=\mathbf{P}^{\prime *} \mathbf{N}$ & $\overline{(F o-F t)^{\wedge} 2 / F t}$ \\
\hline \multirow{3}{*}{1.45} & \multirow{3}{*}{4} & & & $+\inf$ & 1.0000 & \multirow[b]{2}{*}{0.0099} & \multirow{3}{*}{3.96} & \multirow[b]{2}{*}{0.00} \\
\hline & & & & & & & & \\
\hline & & 1.426 & 0.326 & 2.33 & 0.9901 & \multirow{2}{*}{0.0071} & & \multirow{2}{*}{1.64} \\
\hline 1.4 & 5 & & & & & & 2.84 & \\
\hline \multirow[t]{2}{*}{1.35} & \multirow[t]{2}{*}{19} & & 0.200 & 2.14 & 8.000 & 0.0214 & 8.56 & 12.73 \\
\hline & & 1.348 & 0.248 & 1.77 & 0.9616 & \multirow{2}{*}{0.0409} & \multirow[b]{2}{*}{16.36} & \multirow[b]{2}{*}{13.10} \\
\hline 1.3 & 31 & & & & & & & \\
\hline \multirow[t]{2}{*}{1.25} & \multirow[t]{2}{*}{46} & 1.297 & 0.197 & 1.41 & 0.9207 & \multirow[t]{2}{*}{0.0630} & \multirow[t]{2}{*}{25.2} & \multirow[t]{2}{*}{17.17} \\
\hline & & 1.249 & 0.149 & 1.07 & 0.8577 & & & \\
\hline \multirow{2}{*}{1.2} & 47 & & & & & 0.0966 & 38.64 & 1.81 \\
\hline & 46 & 1.199 & 0.099 & 0.71 & 0.7611 & 0.1243 & 49.72 & 0.28 \\
\hline 1.15 & & 1.149 & 0.049 & 0.35 & 0.6368 & & & \\
\hline 1.1 & 39 & & & & & 0.1408 & 56.32 & 5.33 \\
\hline 1.05 & 62 & 1.098 & -0.002 & -0.01 & 0.496 & 0.1403 & 56.12 & 0.62 \\
\hline & & 1.049 & -0.051 & -0.37 & 0.3557 & & & \\
\hline 1 & 37 & & & & & 0.1230 & 49.2 & 3.03 \\
\hline & & 0.998 & -0.102 & -0.73 & 0.2327 & & & \\
\hline 0.95 & 29 & & & & & 0.0926 & 37.04 & 1.75 \\
\hline & & 0.949 & -0.151 & -1.08 & 0.1401 & & & \\
\hline 0.9 & 15 & & & & & 0.0666 & 26.64 & 5.09 \\
\hline & & 0.897 & -0.203 & -1.45 & 0.0735 & & & \\
\hline 0.85 & 11 & 0.846 & -0.254 & -1.81 & 0.0351 & 0.0384 & 15.36 & 1.24 \\
\hline 0.8 & 9 & & & & & 0.0244 & 9.76 & 0.06 \\
\hline & & 0.778 & -0.322 & -2.30 & 0.0107 & & & \\
\hline 0.750 & 0 & & & - inf & 0.0000 & 0.0107 & 4.28 & 4.28 \\
\hline & 400 & & & & & 1.0000 & 400 & 68.11 \\
\hline $\begin{array}{l}\mathrm{N}=\mathrm{Nur} \\
\mathrm{M}=\mathrm{Mer}\end{array}$ & $\begin{array}{l}\text { Note: } \\
\text { of Iter } \\
\text { l.1 }\end{array}$ & $=400$ & & & & $\begin{array}{r}\mathrm{D} \\
\text { Therefor }\end{array}$ & $\begin{array}{l}\text { hi Square }= \\
\text { rees of Free } \\
\text { Do Not R }\end{array}$ & $\begin{array}{l}68.11 \\
\text { om = } 12 \\
\text { ect Hypothesis }\end{array}$ \\
\hline
\end{tabular}

Std $=$ Standard D eviation $=0.14$

Degrees of Freedom $=15-3=12$ 
Table A-7: Chi Square Test for Evaluating Fit of Normal Curve Infinite Slope without Seepage, $\beta=21.80$ (3)

\begin{tabular}{|c|c|c|c|c|c|c|c|c|}
\hline $\mathbf{X}$ & Fo & $\mathbf{X}^{\prime}$ & $\mathrm{x}=\mathrm{X}^{\prime}-\mathrm{M}$ & $\mathrm{z}=\mathrm{x} / \mathrm{std}$ & $\mathbf{P}$ & $\mathbf{P}^{\prime}$ & $\mathbf{F t}=\mathbf{P}^{\prime *} \mathbf{N}$ & $\overline{(F o-F t)^{\wedge} 2 / F t}$ \\
\hline \multirow[b]{2}{*}{1.50} & \multirow[b]{2}{*}{2} & & & $+\inf$ & 1.0000 & \multirow[b]{2}{*}{0.0031} & \multirow[b]{2}{*}{2.17} & \multirow[b]{2}{*}{0.01} \\
\hline & & & & & & & & \\
\hline \multirow[t]{2}{*}{1.45} & \multirow[t]{2}{*}{7} & 1.483 & 0.383 & 2.74 & 0.9969 & \multirow{2}{*}{0.0069} & \multirow[t]{2}{*}{4.83} & 0.97 \\
\hline & & 1.444 & 0.344 & 2.46 & 0.9931 & & & \multirow[b]{2}{*}{9.02} \\
\hline \multirow[t]{2}{*}{1.4} & \multirow[t]{2}{*}{17} & & & & & \multirow[t]{2}{*}{0.0119} & \multirow[t]{2}{*}{8.33} & \\
\hline & & 1.391 & 0.291 & 2.08 & 0.9812 & & & \multirow[b]{2}{*}{5.00} \\
\hline 1.35 & 22 & & & & & 0.0196 & 13.72 & \\
\hline \multirow[t]{2}{*}{1.3} & \multirow[t]{2}{*}{42} & 1.348 & 0.248 & 1.77 & 0.9616 & \multirow{2}{*}{0.0409} & \multirow[t]{2}{*}{28.63} & \multirow{2}{*}{6.24} \\
\hline & & 1.297 & 0.197 & 1.41 & 0.9207 & & & \\
\hline 1.25 & 61 & & & & & \multirow{2}{*}{0.0630} & \multirow[t]{2}{*}{44.1} & 6.48 \\
\hline 1.2 & 93 & 1.249 & 0.149 & 1.07 & 0.8577 & & & 9.53 \\
\hline & & 1.199 & 0.099 & 0.71 & 0.7611 & & & \\
\hline 1.15 & 90 & & & & & 0.1243 & 87.01 & 0.10 \\
\hline 1.1 & 95 & 1.149 & 0.049 & 0.35 & 0.6368 & 0.1408 & 98.56 & 0.13 \\
\hline & & 1.098 & -0.002 & -0.01 & 0.496 & & & \\
\hline 1.05 & 106 & & & & & 0.1403 & 98.21 & 0.62 \\
\hline & & 1.049 & -0.051 & -0.37 & 0.3557 & & & \\
\hline 1 & 68 & & & & & 0.1230 & 86.1 & 3.80 \\
\hline & & 0.998 & -0.102 & -0.73 & 0.2327 & & & \\
\hline 0.95 & 45 & & & & & 0.0926 & 64.82 & 6.06 \\
\hline & & 0.949 & -0.151 & -1.08 & 0.1401 & & & \\
\hline 0.9 & 31 & 0.897 & -0.203 & -1.45 & 0.0735 & 0.0666 & 46.62 & 5.23 \\
\hline 0.85 & 12 & & & & & 0.0384 & 26.88 & 8.24 \\
\hline & & 0.846 & -0.254 & -1.81 & 0.0351 & & & \\
\hline 0.8 & 11 & & & & & 0.0244 & 17.08 & 2.16 \\
\hline & & 0.778 & -0.322 & -2.30 & 0.0107 & & & \\
\hline 0.750 & 0 & & & - inf & 0.0000 & 0.0107 & 7.49 & 7.49 \\
\hline & 700 & & & & & 1.0000 & 700 & 71.09 \\
\hline $\begin{array}{l}\mathrm{N}=\mathrm{Nur} \\
\mathrm{M}=\mathrm{Me}\end{array}$ & $\begin{array}{l}\text { Note: } \\
\text { of Ite } \\
1.1\end{array}$ & $=700$ & & & & $\begin{array}{r}\text { D } \\
\text { Therefo }\end{array}$ & $\begin{array}{l}\text { Shi Square } \\
\text { rees of Free } \\
\text { Do Not R }\end{array}$ & $\begin{array}{l}71.09 \\
\text { lom = } 13 \\
\text { ect Hypothesis }\end{array}$ \\
\hline
\end{tabular}

Std $=$ Standard D eviation $=0.14$

D egrees of Freedom $=16-3=13$ 
Simulation 1 and Simulation 2 for 18.5, Factor of Safety

$\begin{array}{cccccc}\text { mean x1 } & \text { mean x2 } & \text { std x1 } & \text { std x2 } & \text { n1 } & \text { n2 } \\ 1.3 & 1.3 & 0.16 & 0.16 & 200 & 700\end{array}$

m x1-m x2

0

std 1/n1 std 2/n2

$\begin{array}{lll}0.0008 & 0.000229 & 0.001029\end{array}$

Simulation 2 and Simulation 3 for 18.5, Factor of Safety std $\times 2 \quad$ std $\times 3$

$0.16 \quad 0.18$

m x2-m x3

$-0.01$

std $\mathbf{2} / \mathbf{n} \mathbf{2}$ std $\mathbf{3 / n} 3$

$\begin{array}{lll}0.000229 & 0.00045 & 0.000679\end{array}$

Simulation 1 and Simulation 3 for 18.5, Factor of Safety

$\begin{array}{cc}\text { mean } \mathbf{x 1} & \text { mean } \mathbf{x} \\ 1.3 & 1.31\end{array}$

m x1-m x3

$-0.01$

$\begin{array}{cc}\text { std x1 } & \text { std x3 } \\ 0.16 & 0.18\end{array}$

std 1/n1 std 3/n3

$\begin{array}{lll}0.0008 & 0.00045 & 0.00125\end{array}$ n2 n3

$700 \quad 400$

$$
\begin{array}{cc} 
& \text { Right } \\
+ \text { or - } & 0.051057
\end{array}
$$

\begin{tabular}{lll}
-0.061057 & -0.01 & 0.041057 \\
\hline
\end{tabular}

Do Not Reject Hypothesis

n1 n3

$200 \quad 400$

\section{Right \\ + or - 0.069296}

$\begin{array}{lll}-0.079296 & -0.01 & 0.059296\end{array}$ 
Table A-10: Chi Square Test for Evaluating Fit of N ormal Curve

Infinite Slope without Seepage, $\beta=18.5^{\circ}$ (1)

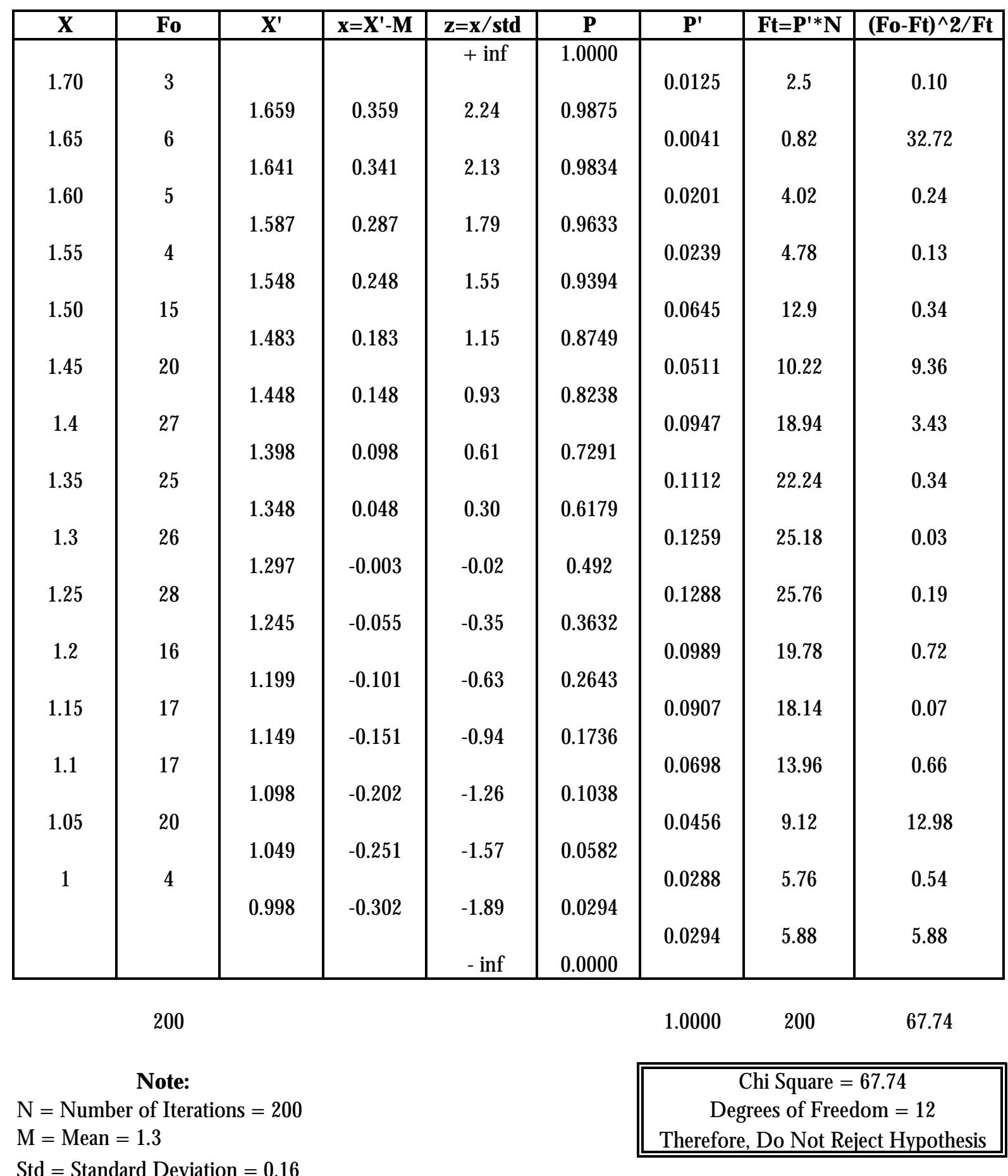

D egrees of Freedom $=15-3=12$ 
Table A-11: Chi Square Test for Evaluating Fit of Normal Curve

Infinite Slope without Seepage, $\beta=18.5^{\circ}$ (2)

\begin{tabular}{|c|c|c|c|c|c|c|c|c|}
\hline $\mathbf{X}$ & Fo & $\mathrm{X}^{\prime}$ & $x=X^{\prime}-M$ & $\mathrm{z}=\mathrm{x} / \mathrm{std}$ & $\mathbf{P}$ & $\mathbf{P}^{\prime}$ & $\mathbf{F t}=\mathbf{P}^{\prime} * \mathbf{N}$ & $(\mathrm{Fo}-\mathrm{Ft})^{\wedge} 2 / \mathrm{Ft}$ \\
\hline \multirow[b]{2}{*}{1.70} & \multirow[b]{2}{*}{8} & & & $+\inf$ & 1.0000 & \multirow[b]{2}{*}{0.0125} & \multirow[b]{2}{*}{8.75} & \multirow[b]{2}{*}{0.06} \\
\hline & & & & & & & & \\
\hline \multirow[t]{2}{*}{1.65} & \multirow[t]{2}{*}{5} & 1.659 & 0.359 & 2.24 & 0.9875 & \multirow[t]{2}{*}{0.0025} & \multirow[t]{2}{*}{1.75} & 6.04 \\
\hline & & 1.648 & 0.348 & 2.17 & 0.9850 & & & \multirow[b]{2}{*}{0.37} \\
\hline 1.60 & 13 & & & & & 0.0157 & 10.99 & \\
\hline \multirow{2}{*}{1.55} & \multirow[t]{2}{*}{43} & 1.599 & 0.299 & 1.87 & 0.9693 & \multirow{2}{*}{0.0299} & 20.93 & 23.27 \\
\hline & & 1.548 & 0.248 & 1.55 & 0.9394 & & & \\
\hline 1.50 & 46 & & & & & 0.0450 & 31.5 & 6.67 \\
\hline \multirow[t]{2}{*}{1.45} & \multirow[t]{2}{*}{61} & 1.499 & 0.199 & 1.25 & 0.8944 & 0.0706 & 49.42 & 2.71 \\
\hline & & 1.448 & 0.148 & 0.93 & 0.8238 & & & \\
\hline 1.4 & 84 & & & & & 0.0947 & 66.29 & 4.73 \\
\hline & & 1.398 & 0.098 & 0.61 & 0.7291 & & & \\
\hline 1.35 & 77 & & & & & 0.1112 & 77.84 & 0.01 \\
\hline 1.3 & 82 & 1.348 & 0.048 & 0.30 & 0.6179 & 0.1259 & 88.13 & 0.43 \\
\hline & & 1.297 & -0.003 & -0.02 & 0.492 & & & \\
\hline 1.25 & 72 & & & & & 0.1288 & 90.16 & 3.66 \\
\hline 1.2 & 82 & 1.245 & -0.055 & -0.35 & 0.3632 & 0.0989 & 69.23 & 2.36 \\
\hline & & 1.199 & -0.101 & -0.63 & 0.2643 & & & \\
\hline 1.15 & 44 & & & & & 0.0907 & 63.49 & 5.98 \\
\hline & & 1.149 & -0.151 & -0.94 & 0.1736 & & & \\
\hline 1.1 & 40 & 1000 & & & & 0.0698 & 48.86 & 1.61 \\
\hline 1.05 & 22 & 1.098 & -0.202 & -1.26 & 0.1038 & 0.0456 & 31.92 & 3.08 \\
\hline 1 & 13 & $\begin{array}{l}1.049 \\
0.998\end{array}$ & $\begin{array}{l}-0.251 \\
-0.302\end{array}$ & $\begin{array}{l}-1.57 \\
-1.89\end{array}$ & $\begin{array}{l}0.0582 \\
0.0294\end{array}$ & 0.0288 & 20.16 & 2.54 \\
\hline 0.95 & 8 & & & & & 0.0155 & 10.85 & 0.75 \\
\hline & & 0.949 & -0.351 & -2.20 & 0.0139 & & & \\
\hline & & & & $-\inf$ & 0.0000 & 0.0139 & 9.73 & 9.73 \\
\hline & 700 & & & & & 1.0000 & 700 & 74.00 \\
\hline $\begin{array}{l}\mathrm{N}=\mathrm{Nun} \\
\mathrm{M}=\mathrm{Mea}\end{array}$ & $\begin{array}{l}\text { Note: } \\
\text { of Ite } \\
1.3\end{array}$ & $=700$ & & & & $\begin{array}{r}\text { D } \\
\text { Therefo } \\
\end{array}$ & $\begin{array}{l}\text { hi Square }= \\
\text { rees of Free } \\
\text { D o Not R }\end{array}$ & $\begin{array}{l}74.00 \\
\text { om = } 13 \\
\text { ect Hypothesis }\end{array}$ \\
\hline
\end{tabular}

D egrees of Freedom $=16-3=13$ 
Table A-12: Chi Square Test for Evaluating Fit of N ormal Curve Infinite Slope without Seepage, $\beta=18.5^{0}$ (3)

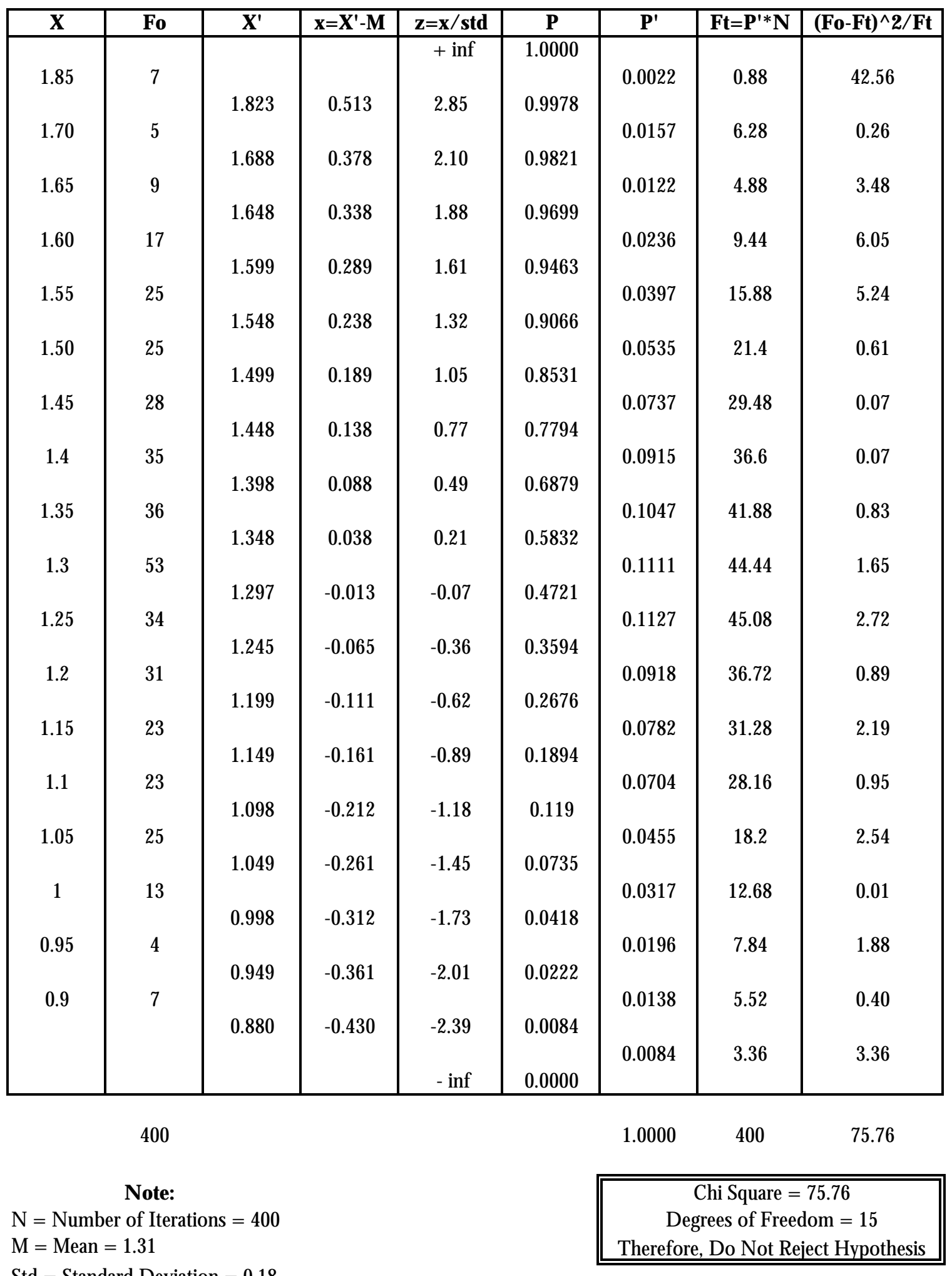

Std $=$ Standard D eviation $=0.18$

D egrees of Freedom $=18-3=15$ 


\section{Appendix B:}

(Wong, 1985) 
Table B-1: Hypothesis Testing for Planar Failure Analysis, Critical Height, Correlated

Simulation 1 and Simulation 2 for Planar Failure Analysis, Correlated

$\begin{array}{cccccc}\text { mean x1 } & \text { mean x2 } & \text { std x1 } & \text { std x2 } & \text { n1 } & \text { n2 } \\ 30.51 & 29.85 & 10.62 & 9.83 & 1200 & 600 \\ & & & & & \\ \text { m x1-m x2 } & & \text { std 1/n1 } & \text { std 2/n2 } & & \\ 0.66 & 0.00885 & 0.016383 & 0.025233 & \end{array}$

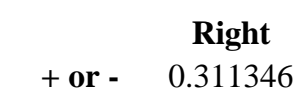

\begin{tabular}{|lll|}
\hline 0.348654 & 0.66 & 0.971346 \\
\hline
\end{tabular}

Do Not Reject Hypothesis

Simulation 2 and Simulation 3 for Planar Failure Analysis, Correlated

$\begin{array}{cccccc}\text { mean x2 } & \text { mean x3 } & \text { std x2 } & \text { std x3 } & \mathbf{n 2} & \mathbf{n 3} \\ 29.85 & 30.22 & 9.83 & 10.21 & 600 & 800\end{array}$

$\begin{array}{cccc}\mathbf{m} \times \mathbf{2}-\mathbf{m} \mathbf{x 3} & \mathbf{s t d} \mathbf{2} / \mathbf{n} \mathbf{2} & \mathbf{s t d} \mathbf{3} / \mathbf{n} \mathbf{3} & \\ -0.37 & 0.016383 & 0.012763 & 0.029146\end{array}$

Simulation 1 and Simulation 3 for Planar Failure Analysis, Correlated

$\begin{array}{cccccc}\text { mean x1 } & \text { mean x3 } & \text { std x1 } & \text { std x3 } & \text { n1 } & \mathbf{n 3} \\ 30.51 & 30.22 & 10.62 & 10.21 & 1200 & 800\end{array}$

m x1-m x3

0.29 std 1/n1 std 3/n3

$\begin{array}{lll}0.00885 & 0.012763 \quad 0.021613\end{array}$ n3

800

$$
\begin{array}{cc}
\text { Right } \\
+ \text { or }-\quad & 0.334614
\end{array}
$$

\begin{tabular}{|lll|}
\hline-0.704614 & -0.37 & -0.035386 \\
\hline
\end{tabular}

Do Not Reject Hypothesis

n3

800

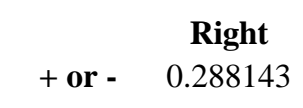

\begin{tabular}{|lll|}
\hline 0.001857 & 0.29 & 0.578143 \\
\hline
\end{tabular}

Do Not Reject Hypothesis 
Table B-2: Chi Square Test for Evaluating Fit of Normal Curve Planar Failure Analysis Correlated Input Parameters: Critical Height (1)

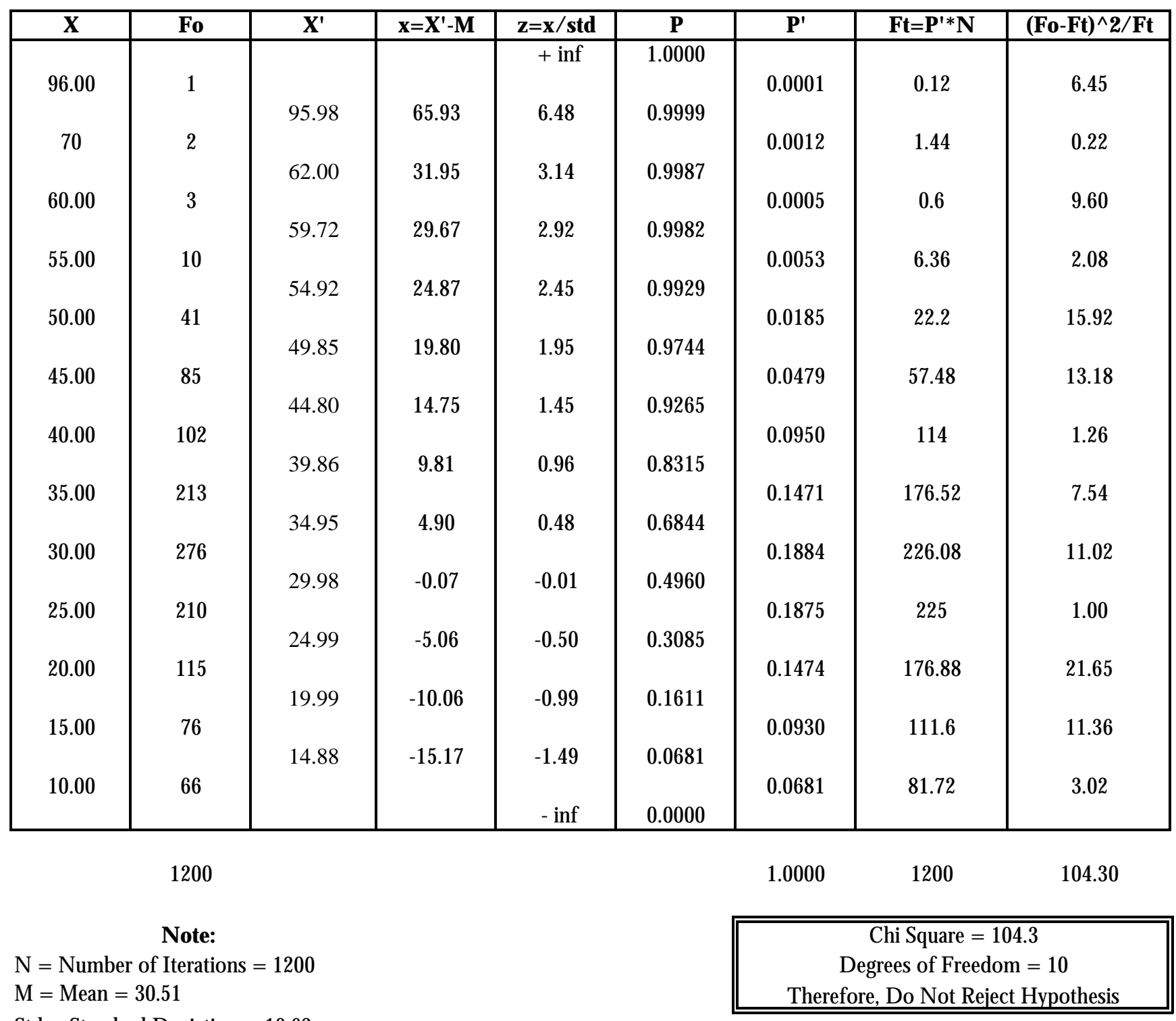

Std $=$ Standard D eviation $=10.62$

D egrees of Freedom $=13-3=10$ 
Table B-3: Chi Square Test for Evaluating Fit of N ormal Curve Planar Failure Analysis Correlated Input Parameters: Critical Height (2)

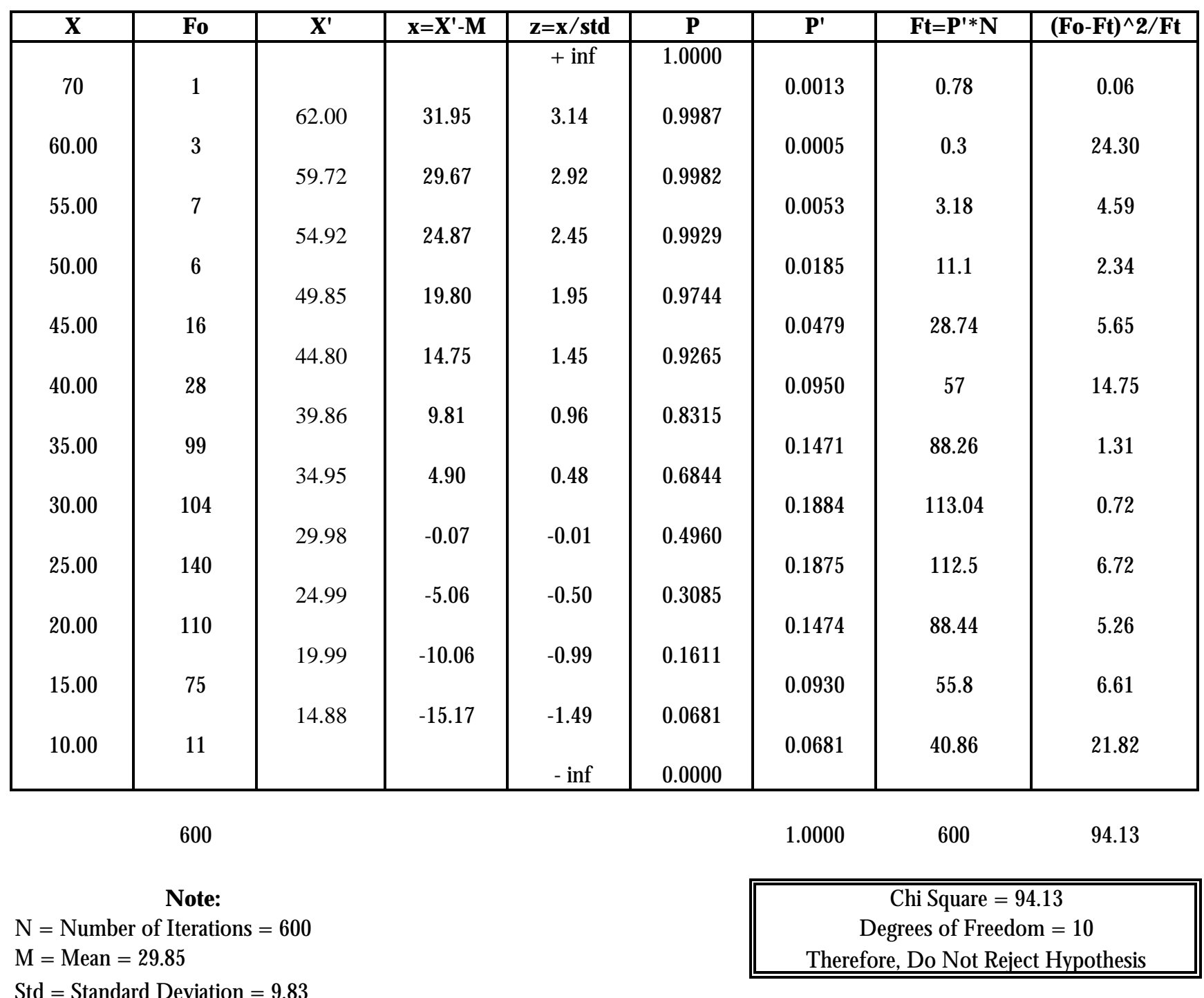

D egrees of Freedom $=13-3=10$ 
Table B-4: Chi Square Test for Evaluating Fit of N ormal Curve Planar Failure Analysis Correlated Input Parameters: Critical Height (3)

\begin{tabular}{|c|c|c|c|c|c|c|c|c|}
\hline $\mathbf{X}$ & Fo & $\mathbf{X}^{\prime}$ & $x=X^{\prime}-M$ & $\mathrm{z}=\mathrm{x} / \mathrm{std}$ & $\mathbf{P}$ & $\mathbf{P}^{\prime}$ & $\mathbf{F t}=\mathbf{P}^{\prime} * \mathbf{N}$ & $(\mathrm{Fo}-\mathrm{Ft})^{\wedge} 2 / \mathrm{Ft}$ \\
\hline 70 & 3 & & & $+\inf$ & 1.0000 & 0.0013 & 1.04 & 3.69 \\
\hline & & 62.00 & 31.95 & 3.14 & 0.9987 & & & \\
\hline 60.00 & 4 & 59.72 & 29.67 & 2.92 & 0.9982 & 0.0005 & 0.4 & 32.40 \\
\hline 55.00 & 7 & & & & & 0.0053 & 4.24 & 1.80 \\
\hline 50.00 & 32 & 54.92 & 24.87 & 2.45 & 0.9929 & 0.0185 & 14.8 & 19.99 \\
\hline 45.00 & 35 & 49.85 & 19.80 & 1.95 & 0.9744 & 0.0479 & 38.32 & 0.29 \\
\hline 40.00 & 96 & 44.80 & 14.75 & 1.45 & 0.9265 & 0.0950 & & 5.26 \\
\hline 35.00 & 99 & 39.86 & 9.81 & 0.96 & 0.8315 & 0.1471 & 117.68 & 2.97 \\
\hline 30.00 & 138 & 34.95 & 4.90 & 0.48 & 0.6844 & 0.1884 & 150.72 & 1.07 \\
\hline 25.00 & 133 & 29.98 & -0.07 & -0.01 & 0.4960 & 0.1875 & 150 & 1.93 \\
\hline 20.00 & 136 & 24.99 & & & 0.3085 & 0.1474 & 117.92 & 2.77 \\
\hline 15.00 & 93 & 19.99 & -10.06 & & & 0.0930 & 74.4 & 4.65 \\
\hline 10.00 & 24 & 14.88 & -15.17 & $\begin{array}{l}-1.49 \\
-\inf \end{array}$ & $\begin{array}{l}0.0681 \\
0.0000\end{array}$ & 0.0681 & 54.48 & 17.05 \\
\hline \multicolumn{3}{|c|}{800} & & & & 1.0000 & 800 & 93.87 \\
\hline \multicolumn{3}{|c|}{$\begin{array}{l}\text { Note: } \\
\text { Iterations = } 800 \\
.78\end{array}$} & & & & \multicolumn{3}{|c|}{$\begin{array}{l}\text { Chi Square }=93.87 \\
\text { egrees of Freedom }=10 \\
\text { re, Do Not Reject Hypothesis }\end{array}$} \\
\hline
\end{tabular}

Std $=$ Standard D eviation $=10.06$

D egrees of Freedom $=13-3=10$ 
Table B-5: Hypothesis Testing for Planar Failure Analysis, Critical Height,Uncomelated

Simulation 1 and Simulation 2 for Planar Failure Analysis, Uncorrelated

\begin{tabular}{|c|c|c|c|c|c|}
\hline mean $x 1$ & mean $\mathbf{2}$ & std $x 1$ & std $x 2$ & & n1 \\
\hline 29.22 & 29.1 & 1.95 & 1.99 & & 600 \\
\hline$m \times 1-m \times 2$ & & std $1 / n 1$ & std $2 / \mathrm{n} 2$ & & \\
\hline 0.12 & & 0.00325 & 0.00398 & 0.00723 & \\
\hline
\end{tabular}

Simulation 2 and Simulation 3 for Planar Failure Analysis, Uncorrelated

$\begin{array}{cc}\text { mean } \mathbf{x} & \text { mean } \mathbf{x} 3 \\ 29.1 & 29.12\end{array}$

m x2-m x3

$-0.02$

Simulation 1 and Simulation 3 for Planar Failure Analysis, Uncorrelated

$\begin{array}{cccc}\mathbf{s t d} \mathbf{x} 2 & \text { std } \mathbf{x} & \mathbf{n} 2 & \mathbf{n 3} \\ 1.99 & 1.86 & 500 & 600\end{array}$

std $2 / \mathrm{n} 2 \quad$ std $\mathbf{3 / n} 3$

$0.00398 \quad 0.0031 \quad 0.00708$

$\begin{array}{cccccc}\text { mean x1 } & \text { mean x3 } & \text { std x1 } & \text { std x3 } & \mathbf{n 1} & \mathbf{n 3} \\ 29.22 & 29.12 & 1.95 & 186 & 600 & 600\end{array}$

m x1-m x3

0.1

std 1/n1 std 3/n3

$\begin{array}{lll}0.00325 & 0.31 & 0.31325\end{array}$ n2

500

\begin{tabular}{|c|c|c|}
\hline \multicolumn{3}{|c|}{ Right } \\
\hline + or - & 0.166658 & \\
\hline-0.046658 & 0.12 & 0.286658 \\
\hline
\end{tabular}

n3

600

\begin{tabular}{|c|c|c|}
\hline \multicolumn{3}{|c|}{ Right } \\
\hline+ or - & 0.16492 & \\
\hline-0.18492 & -0.02 & 0.14492 \\
\hline
\end{tabular}

n3

600

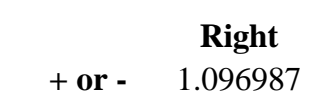

\begin{tabular}{lll}
\hline-0.996987 & 0.1 & 1.196987 \\
\hline
\end{tabular}

Do Not Reject Hypothesis 
Table B-6: Chi Square Test for Evaluating Fit of N ormal Curve

Planar Failure Analysis Uncomelated Input Parameters: Critical H eight (1)

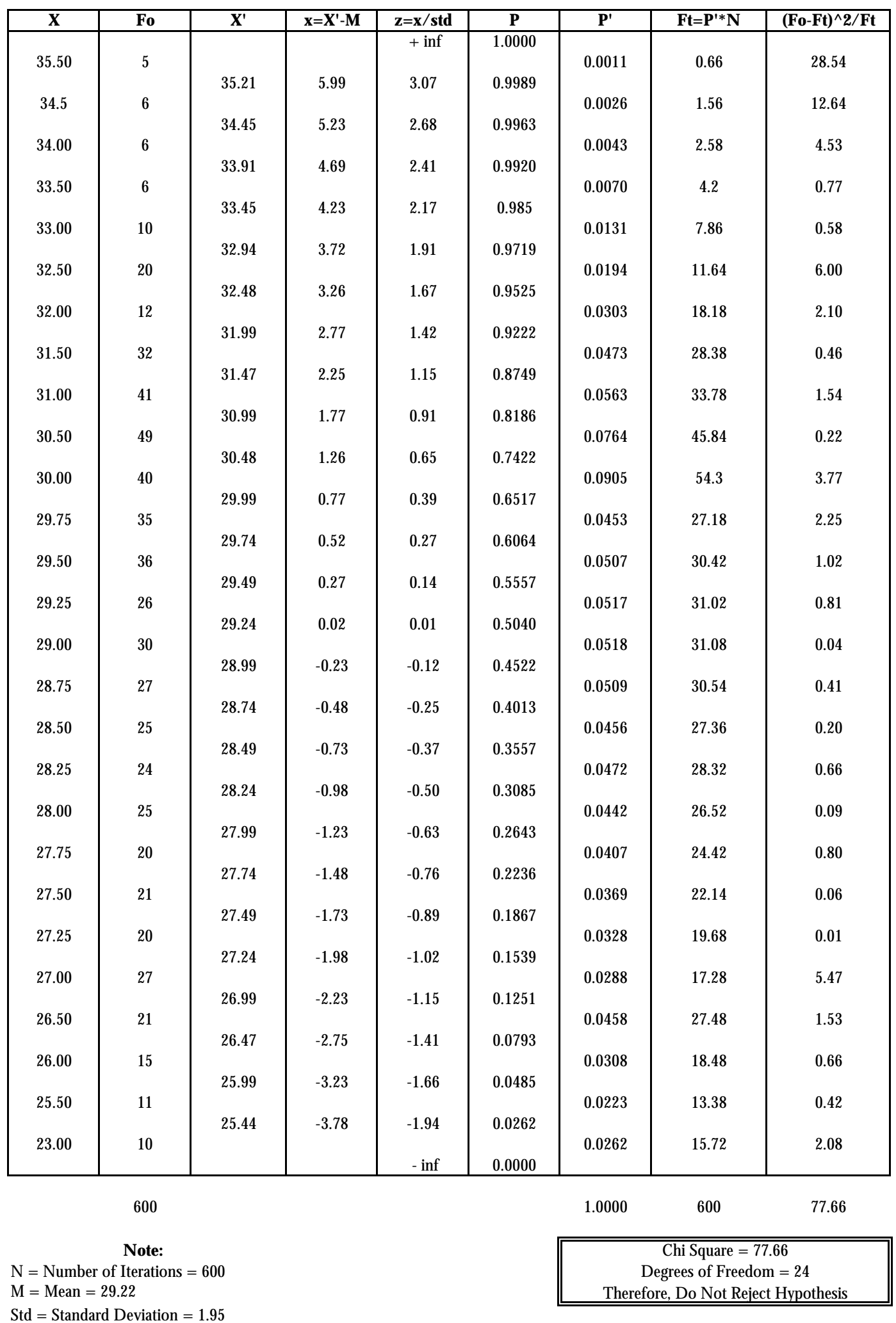

Std $=$ Standard Deviation $=1.95$

D egrees of Freedom $=27-3=24$ 
Table B-7: Chi Square Test for Evaluating Fit of Normal Curve

Planar Failure Analysis, Uncomelated Input Parameters: Critical Height (2)

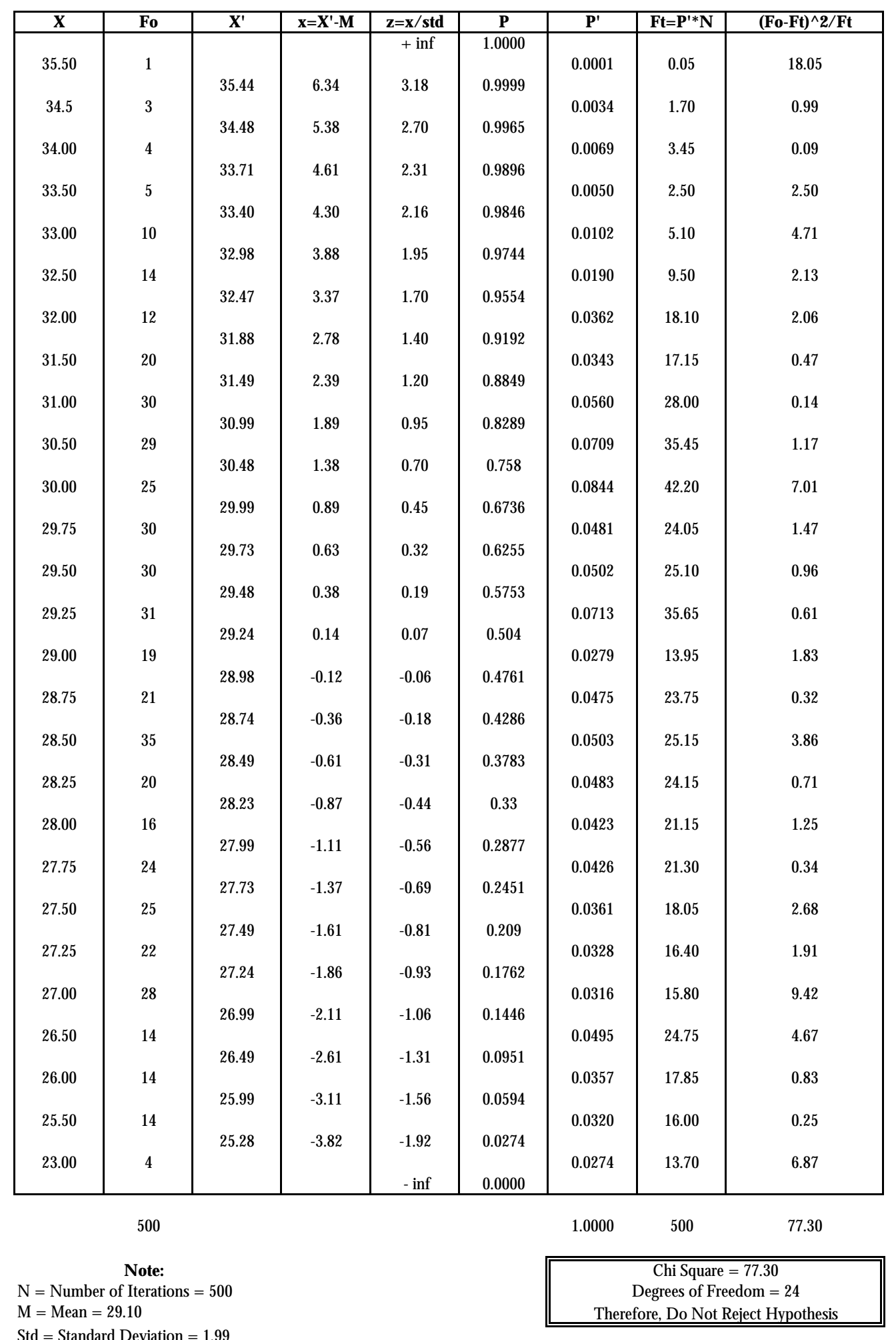

Standard Deviatic

D egrees of Freedom $=27-3=24$ 
Table B-8: Chi Square Test for Evaluating Fit of Normal Curve

Planar Failure Analysis, Uncomelated Input Parameters: Critical H eight (3)

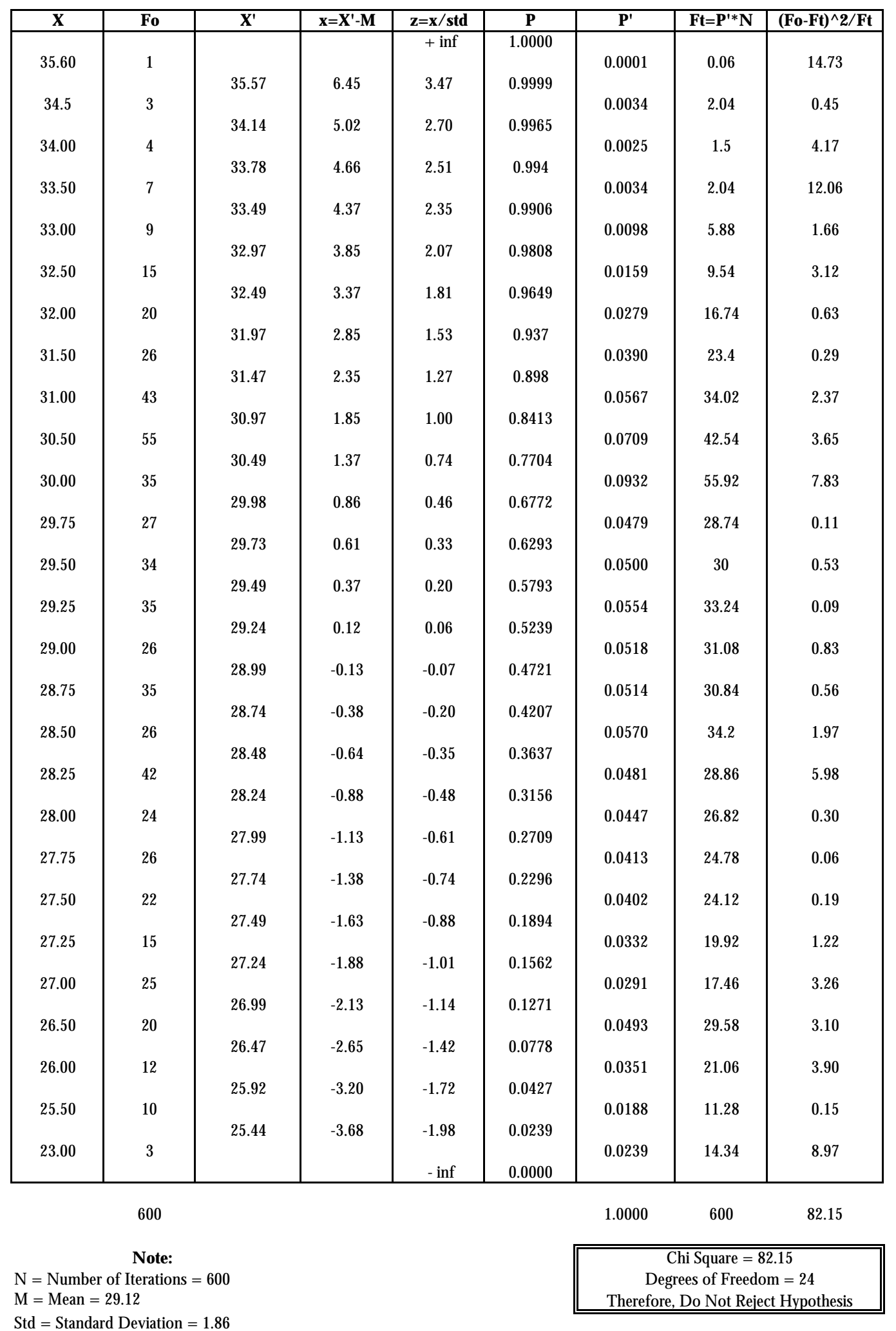

Degrees of Freedom $=27-3=24$ 
Table B-9: Hypothesis Testing for Circular Failure Analysis, Factor of Safety

Simulation 1 and Simulation 2 for Circular Failure Analysis, Uncorrelated Factor of Safety

$\begin{array}{cccccc}\text { mean x1 } & \text { mean x2 } & \text { std x1 } & \text { std x2 } & \text { n1 } & \text { n2 } \\ 0.93 & 0.93 & 0.02 & 0.02 & 600 & 400\end{array}$

m x1-m x2

0 std 1/n1 std $2 / \mathrm{n} 2$

3.33E-05 $0.00005 \quad 8.33 \mathrm{E}-05$ $\mathbf{n 2}$

00

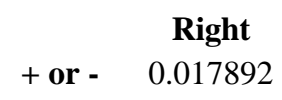

\begin{tabular}{lll}
-0.017892 & 0 & 0.017892 \\
\hline
\end{tabular}

Do Not Reject Hypothesis

Simulation 2 and Simulation 3 for Circular Failure Analysis, Uncorrelated Factor of Safety

$\begin{array}{cccccc}\text { mean x2 } & \text { mean x3 } & \text { std x2 } & \text { std x3 } & \text { n2 } & \text { n3 } \\ 0.93 & 0.93 & 0.02 & 0.02 & 400 & 200\end{array}$

m x2-m x3

0

\begin{abstract}
std $2 / \mathrm{n} 2 \quad$ std $3 / \mathrm{n} 3$
\end{abstract}
$0.00005 \quad 0.0001 \quad 0.00015$ n3

00 
Table B-10: Chi Square Test for Evaluating Fit of N ormal Curve Circular Slope Failure, Response Surface Analysis: Factor of Safety (1)

\begin{tabular}{|c|c|c|c|c|c|c|c|c|}
\hline $\mathbf{X}$ & Fo & $\mathbf{X}^{\prime}$ & $x=X^{\prime}-M$ & $\mathrm{z}=\mathrm{x} / \mathrm{std}$ & $\mathbf{P}$ & $\mathbf{P}^{\prime}$ & $\mathbf{F t}=\mathbf{P}^{\prime * N}$ & $(\mathrm{Fo}-\mathrm{Ft})^{\wedge} 2 / \mathrm{Ft}$ \\
\hline & & & & $+\inf$ & 1.0000 & & & \\
\hline 0.987 & 5 & & & & & 0.0027 & 1.62 & 7.05 \\
\hline & & 0.986 & 0.056 & 2.78 & 0.9973 & & & \\
\hline 0.98 & 4 & & & & & 0.0116 & 6.96 & 1.26 \\
\hline & & 0.974 & 0.044 & 2.19 & 0.9857 & & & \\
\hline 0.97 & 12 & & & & & 0.0101 & 6.06 & 5.82 \\
\hline & & 0.969 & 0.039 & 1.97 & 0.9756 & & & \\
\hline 0.965 & 25 & & & & & 0.0261 & 15.66 & 5.57 \\
\hline 0.96 & 20 & 0.963 & 0.033 & 1.64 & 0.9495 & 0.0230 & 13.8 & 2.79 \\
\hline & & 0.959 & 0.029 & 1.45 & 0.9265 & & & \\
\hline 0.955 & 30 & & & & & 0.0377 & 22.62 & 2.41 \\
\hline & & 0.954 & 0.024 & 1.22 & 0.8888 & & & \\
\hline 0.95 & 35 & & & & & 0.0548 & 32.88 & 0.14 \\
\hline & & 0.949 & 0.019 & 0.97 & 0.834 & & & \\
\hline 0.945 & 55 & & & & & 0.0698 & 41.88 & 4.11 \\
\hline & & 0.944 & 0.014 & 0.72 & 0.7642 & & & \\
\hline 0.94 & 56 & & & & & 0.0834 & 50.04 & 0.71 \\
\hline 0.935 & 69 & 0.939 & 0.009 & 0.47 & 0.6808 & 0.0937 & 56.22 & 2.91 \\
\hline & & 0.934 & 0.004 & 0.22 & 0.5871 & & & \\
\hline 0.93 & 58 & & & & & 0.0991 & 59.46 & 0.04 \\
\hline 0.925 & 47 & 0.929 & -0.001 & -0.03 & 0.488 & 0.0594 & 35.64 & 3.62 \\
\hline & & 0.924 & -0.006 & -0.28 & 0.4286 & & & \\
\hline 0.92 & 52 & & & & & 0.1305 & 78.3 & 8.83 \\
\hline 0.915 & 64 & 0.919 & -0.011 & -0.53 & 0.2981 & 0.0804 & 48.24 & 5.15 \\
\hline & & 0.914 & -0.016 & -0.78 & 0.2177 & & & \\
\hline 0.91 & 68 & & & & & 0.1629 & 97.74 & 9.05 \\
\hline 0.880 & 0 & 0.898 & -0.032 & $\begin{array}{l}-1.60 \\
- \text { inf }\end{array}$ & $\begin{array}{l}0.0548 \\
0.0000\end{array}$ & 0.0548 & 32.88 & 32.88 \\
\hline
\end{tabular}

600

$1.0000 \quad 600 \quad 92.33$

Note:

$\mathrm{N}=$ Number of Iterations $=600$

$\mathrm{M}=$ Mean $=0.93$

Std $=$ Standard D eviation $=0.02$

Degrees of Freedom $=16-3=13$
Chi Square $=92.33$

D egrees of Freedom $=13$

Therefore, Do Not Reject Hypothesis 
Table B-11: Chi Square Test for Evaluating Fit of Normal Curve Cincular Slope Failure, Response Surface Analysis: Factor of Safety (2)

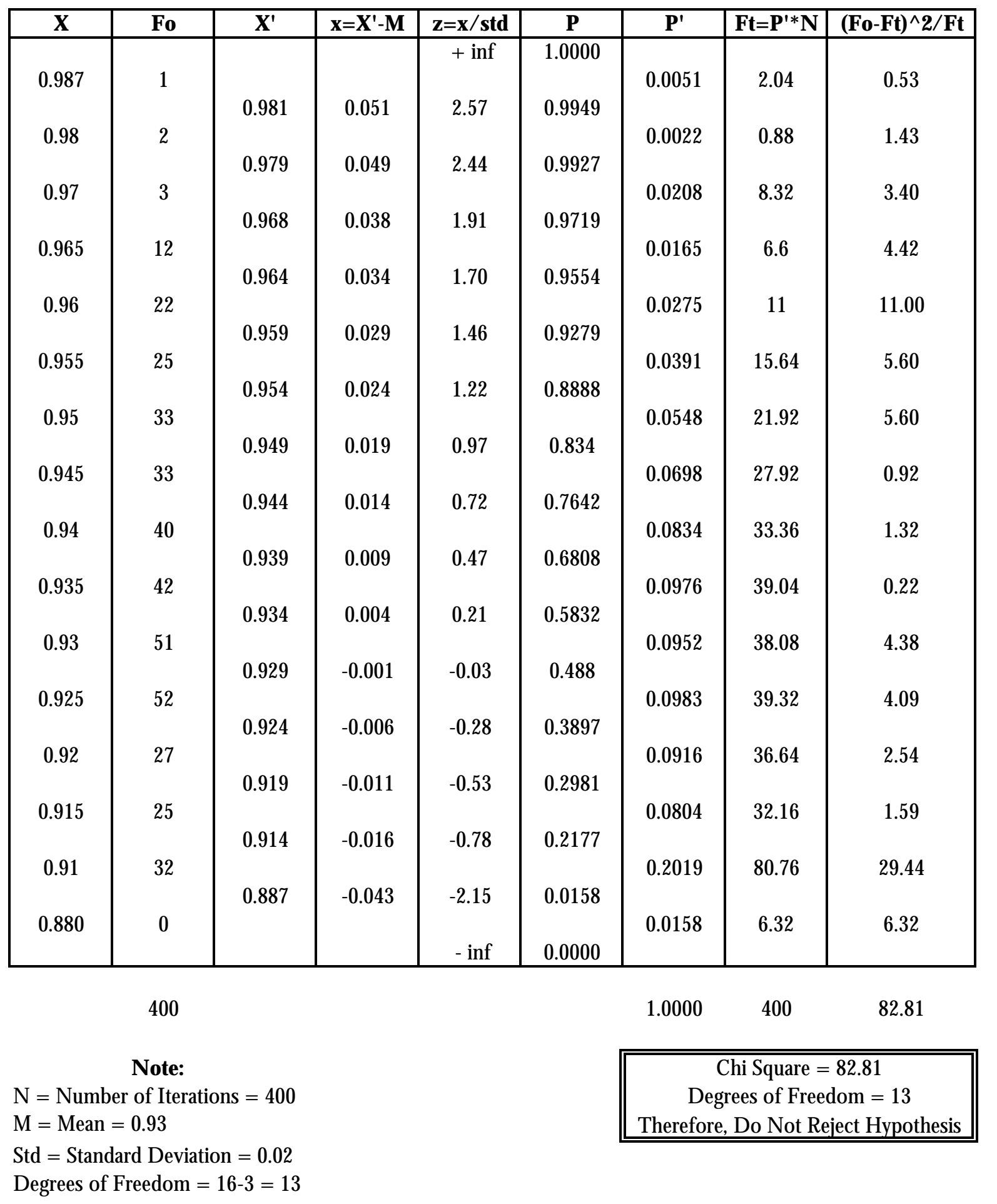


Table B-12: Chi Square Test for Evaluating Fit of N ormal Curve Cincular Slope Failure, Response Surface Analysis: Factor of Safety (3)

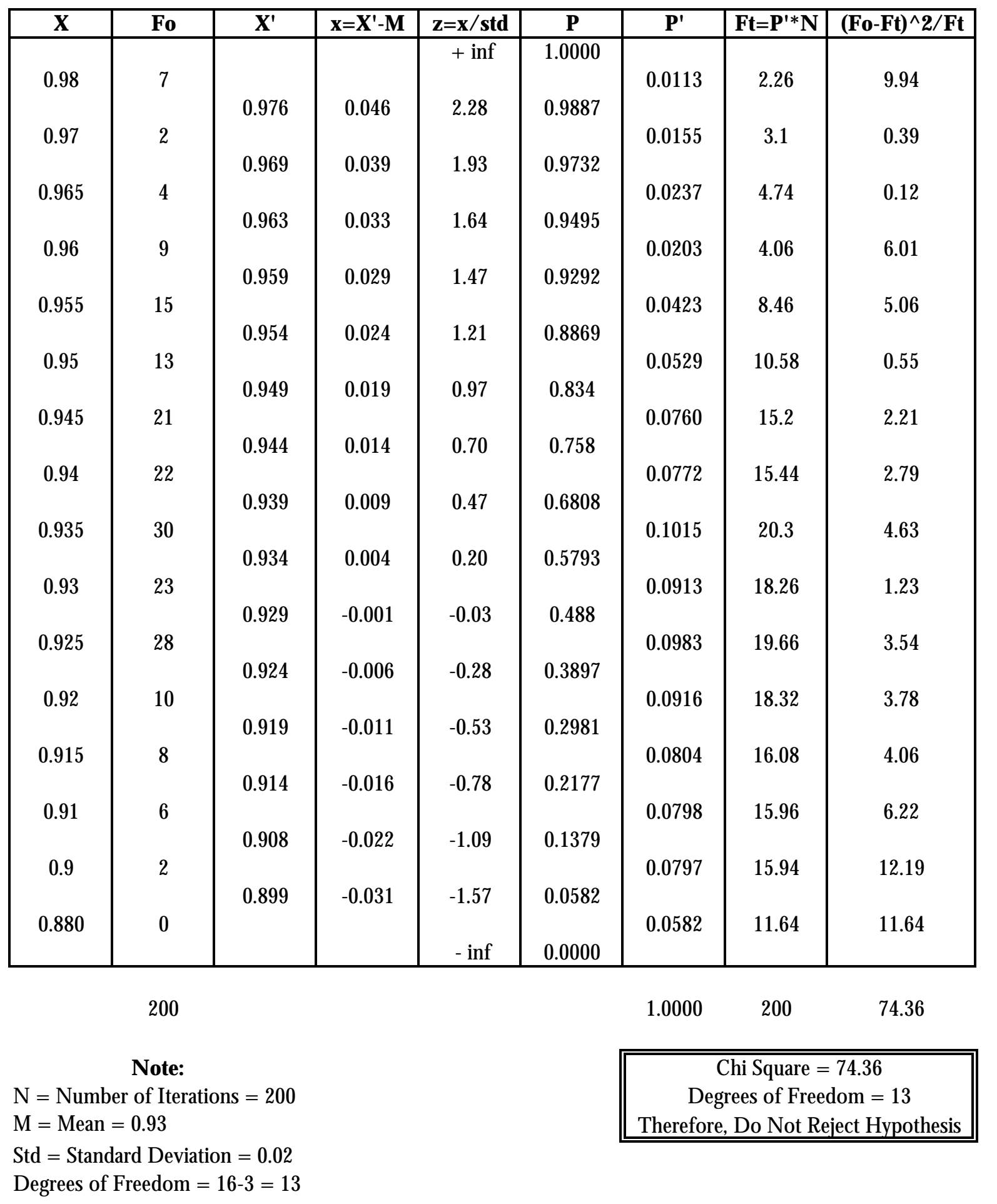




\section{Vita}

Jennifer Lynn Peterson was born in Flemington, New Jersey on March 12, 1976. She was raised in Holland Township, New Jersey and attended D elaware Valley Regional High School, graduating in 1994. In August 1994, Jennifer began furthering her education at West Virginia University majoring in Civil Engineering. She completed her Bachelor's D egree in May of 1998. In pursuit of a Masters degree in Civil Engineering, she returned to WVU in August 1998 to focus her graduate studies in the disciplines of G eotechnical and Materials Engineering. In addition, she fulfilled the first step to becoming a Professional Engineer by passed the Fundamental of Engineering exam in the Spring of 1999. Jennifer is currently a candidate for a Masters of Science degree in Civil Engineering at West Virginia University, and plans to graduate in D ecember 1999. 